Illinois State University

ISU ReD: Research and eData

Theses and Dissertations

$12-9-2013$

\title{
An Examination of the Role of Fundraising in Divisions of Student Affairs at Seven Four-Year Public Universities in the Midwest
}

Danielle Nicole Miller-Schuster

Illinois State University, dnmille@ilstu.edu

Follow this and additional works at: https://ir.library.illinoisstate.edu/etd

Part of the Higher Education Administration Commons

\section{Recommended Citation}

Miller-Schuster, Danielle Nicole, "An Examination of the Role of Fundraising in Divisions of Student Affairs at Seven Four-Year Public Universities in the Midwest" (2013). Theses and Dissertations. 81.

https://ir.library.illinoisstate.edu/etd/81

This Dissertation is brought to you for free and open access by ISU ReD: Research and eData. It has been accepted for inclusion in Theses and Dissertations by an authorized administrator of ISU ReD: Research and eData. For more information, please contact ISUReD@ilstu.edu. 


\title{
AN EXAMINATION OF THE ROLE OF FUNDRAISING IN DIVISIONS OF STUDENT AFFAIRS AT SEVEN FOUR-YEAR PUBLIC UNIVERSITIES IN THE MIDWEST
}

\author{
Danielle N. Miller-Schuster
}

\section{Pages}

May 2014

With higher accountability standards, divisions of student affairs must find alternative ways to balance the rising costs of college with the survival and growth of the programs and services expected. This study examined one such alternative, fundraising in student affairs, to further develop the profession's understanding of engaging in or growing development efforts. As more divisions become involved, it becomes important to learn from colleagues in the profession who are engaging in development activities. The purpose of this study was to examine the extent to which divisions of student affairs were involved in fundraising activities at seven 4-year public universities across four Midwestern states. A pair of vice presidents for student affairs and advancement was interviewed using a semi-structured interview format at each of the seven institutions. In addition to the voices of the participants, documents and artifacts were collected and analyzed individually and collectively.

Using an interpretivist paradigm, the results of this study provided insight into what types of development initiatives divisions of student affairs were participating in, a deeper understanding of who was involved in fundraising efforts, how and in what ways 
the two divisions (institutional advancement and student affairs) were collaborating, and the effects of involvement by staff on traditional responsibilities and organizational structures. The study's findings also offer those who work in divisions of student affairs a broader understanding of fundraising practices and how to leverage participation in such practices if desired. This foundation provides practitioners with strategies on how to work together to create a more systematic and coordinated effort for accomplishing the institution’s fundraising goals. 


\title{
AN EXAMINATION OF THE ROLE OF FUNDRAISING IN DIVISIONS \\ OF STUDENT AFFAIRS AT SEVEN FOUR-YEAR \\ PUBLIC UNIVERSITIES IN THE MIDWEST
}

DANIELLE N. MILLER-SCHUSTER

\author{
A Dissertation Submitted in Partial \\ Fulfillment of the Requirements \\ for the Degree of \\ DOCTOR OF PHILOSOPHY \\ Department of Educational Administration and Foundations \\ ILLINOIS STATE UNIVERSITY
}


(C) 2014 Danielle N. Miller-Schuster 


\section{AN EXAMINATION OF THE ROLE OF FUNDRAISING IN DIVISIONS OF STUDENT AFFAIRS AT SEVEN FOUR-YEAR PUBLIC UNIVERSITIES IN THE MIDWEST}

DANIELLE N. MILLER-SCHUSTER

COMMITTEE MEMBERS:

Wendy G. Troxel, Chair

Phyllis A. McCluskey-Titus

Brent G. Paterson

John W. Presley 


\section{ACKNOWLEDGMENTS}

I am grateful to the faculty in Educational Administration and Foundations for selecting me into the higher education doctoral program. As a student who was prepared to learn, I appreciated the opportunity to grow from those who were called so appropriately to teach. I was also very fortunate to have a committee who challenged and supported me from the very day they accepted to serve. Any success I have accomplished was the result of a dedicated team of individuals who cared deeply about me and my progress. Thank you Dr. John Presley, Dr. Phyllis McCluskey-Titus, and Dr. Brent Paterson for teaching, encouraging, and supporting me. In particular, I wish to thank my chair, Dr. Wendy Troxel, who was my teacher first and foremost, my colleague, my advocate, and my friend. Your genuine belief in my ability to do what was asked of me gave me confidence in myself. I was blessed to have you by my side throughout this entire journey. I would not have wanted it any other way!

I also wish to acknowledge Vice President for Student Affairs Larry Dietz and Vice President Emeritus for Student Affairs Steve Adams. The strength and consistency of your support made it possible for me to achieve this personal and professional goal. I am grateful to you both beyond measure.

To the 14 vice presidents who accepted my call and warmly invited me to their campuses, I thank you for sharing your time, your expertise, and for serving as a tremendous resource. I enjoyed profoundly the opportunity to learn from you. Your 
willingness to participate deepens our understanding of the topic, informs practice, and aids practitioners as they begin to enter into, grow, or expand their development efforts. Your participation exemplifies what it means to give back to the profession. Thank you. Accomplishing this educational goal was the direct result of the people around me. It all began with a foundation of strong support from family and friends. I am indeed the lucky one. The showering of support from loved ones, friends, and colleagues provided me with my greatest source of strength and inspiration. This accomplishment would not have been possible without each of you.

To my husband, Andy, words cannot begin to express how blessed I am to have you as my partner. From start to finish, you showed me unconditional love and support week after week and year after year. Believing in myself came easier because of your unwavering belief in me and my ability to take this on while working full-time. I am grateful to you and for you. Thank you for being so generous with your love. I could not be more proud to share this dissertation with you!

"When I stand before God at the end of my life, I would hope that I would not have a single bit of talent left, and could say, 'I used everything you gave me'."

Erma Bombeck

This dissertation is dedicated to Katy, Issac, Jarron, Simon, and Sydney. May you always believe in yourself and surround yourself with people who challenge you to accomplish your dreams and support you every step of the way. If you work hard, anything is possible. My prayer for you is to use everything He gave you. My heart is full because of each of you. I love you.

D. M. S. 


\section{CONTENTS}

Page

ACKNOWLEDGMENTS

CONTENTS

iii

TABLES

vii

CHAPTER

I. INTRODUCTION 1

Statement of the Problem 1

Overview 2

Role Expansion in Student Affairs 2

A Brief Look at the Evolution of Student Affairs 3

A Contemporary View of the Profession 5

$\begin{array}{ll}\text { Current and Future Expectations } & 6\end{array}$

Becoming adaptive $\quad 7$

Increasing collaboration $\quad 9$

$\begin{array}{ll}\text { Purpose of the Study } & 10\end{array}$

Research Questions $\quad 11$

Significance of the Study $\quad 11$

Scope of the Study 13

Important Terms

$\begin{array}{ll}\text { Summary } & 17\end{array}$

$\begin{array}{ll}\text { Organization of the Study } & 18\end{array}$

II. REVIEW OF RELATED LITERATURE 19

$\begin{array}{ll}\text { Introduction } & 19\end{array}$

$\begin{array}{ll}\text { Institutional Advancement Overview } & 20\end{array}$

A Rationale for Student Affairs Involvement in
Development Efforts

Defining Student Engagement and Its Significance 24 
Theory of involvement

The Role of Institutional Policies and Practices

The Relationship Among Student Engagement, Institutional Policies, Donor Motivations for Giving, and Student Affairs Fundraising

\section{METHODOLOGY AND PROCEDURES}

Statement of the Problem

Purpose

Research Questions

Research Procedures

Positionality

Participants

Qualitative Techniques

Data Analysis

Ethical Issues

Truthworthiness and Authenticity

Introduction 
Building a culture early $\quad 82$

Family connections $\quad 83$

“The ___experience” 84

Affinity group affiliation and alumni giving 85

$\begin{array}{ll}\text { Research Question } 2 & 87\end{array}$

The role as vice president $\quad 88$

Fundraising priorities $\quad 90$

Supervision of fundraising staff $\quad 91$

Cultivation of donors $\quad 92$

Culture of philanthropy 93

The role of the division $\quad 93$

Research Question $3 \quad 98$

Expanding responsibility $\quad 98$

Relationship-building in new directions $\quad 100$

Education and training 105

Measuring success in development 108

$\begin{array}{ll}\text { Summary } & 109\end{array}$

V. DISCUSSION, IMPLICATIONS, AND RECOMMENDATIONS 111

Introduction $\quad 111$

Overview of the Study $\quad 111$

\begin{tabular}{ll} 
Participants & 112 \\
\hline
\end{tabular}

Research Design and Methodology 112

Summary of Findings $\quad 114$

Research Question $1 \quad 114$

Research Question $2 \quad 116$

Research Question $3 \quad 119$

$\begin{array}{ll}\text { Implications for Practice } & 123\end{array}$

Build Organizational Capacity for Adaptive Work 124

Brand the Division of Student Affairs 125 
Draw a Solid Connection Between Co-curricular Involvement and Fundraising Goals

Increase Staff Competency in Development

Strengthen Partnerships With Institutional

Advancement Through Cultural Integration

Cultivate a Culture of Philanthropy Within the

Division at All Levels of the Organization

Develop an Infrastructure for Development Before Raising Money

Move From Cooperation to Intentional Collaboration

Effectively Communicate With Constituencies 


\section{TABLES}

Table Page

1. Summary of Participants Profiled 80

2. Summary of Responses Regarding the Role Senior Student Affairs Officers Play in University Development Efforts

3. How Would You Describe the Role of the Division of Student Affairs in Development Efforts at the University?

4. Characteristics for an Ideal Relationship Between Student Affairs and Institutional Advancement 


\section{CHAPTER I}

\section{INTRODUCTION TO THE STUDY}

\section{Statement of the Problem}

Many American public colleges and universities operate within financial constraints that require educational leaders to aggressively seek private funding to obtain essential resources. Decreasing state appropriations have led many public institutions to describe their relationship as state-assisted rather than state-supported (Hossler, 2004; Rovig, 2008). This reduction in state funding has urged public institutions to create a new paradigm that in some cases will balance, and in other cases increase, the traditional sources of funding to higher education. Speck (2010) posits that the promise of a highquality public education for everyone has changed. To compensate for the loss in state appropriations, institutions must raise tuition and fees, making access and affordability out of reach for many students and their families. For every decade since 1930, tuition has increased more than the consumer price index for public and private institutions (Baum \& Ma, 2011; Woodward, Love, \& Komives, 2000a). Many factors contribute to higher tuition costs, such as faculty and staff earnings, increased cost of health care benefits, deferred facility maintenance, rising utility costs, technology advancements, and student expectations of modern amenities (Rovig, 2008). As expected, colleges and universities look to educational fundraising as an important vehicle for seeking external resources

(Crowe, 2011; Gold, Golden, \& Quatroche, 1993; Kroll, 1991; Matasar, 1998; Rovig, 
2008; Schuh, 2003; Shay, 1999; Woodward et al., 2000).

When budget reductions occur, virtually every level of the organization is compromised and divisions of student affairs are equally vulnerable. Although a fairly new practice in divisions of student affairs, fundraising is surfacing as a viable source of external funding for student programs and services (Kroll, 1991; Miller, 2010; Rovig, 2008; Schoenecke, 2005; Schuh, 2003; Terrell \& Gold, 1993). With increased involvement in fundraising by divisions of student affairs, little research has been conducted on the topic regarding student affairs participation and role (Arminio, Clinton, \& Harpster, 2010; Gold et al., 1993; Gordon, Strode, \& Brady, 1993; Kroll, 1991; Miller, 2010; Rovig, 2008; Schoenecke, 2005; Terrell \& Gold, 1993). Therefore, it becomes critical to examine the involvement of divisions of student affairs as partners in meeting the fundraising goals of the institution.

\section{Overview}

\section{Role Expansion in Student Affairs}

In a report titled “Greater Expectations," the Association of American Colleges and Universities (2002) put forth a challenge to institutions of higher education. This challenge called for "improvements in the quality of student learning by providing a practical liberal education that prepares students for life, work, and civic participation in an increasingly complex world” (Keeling, 2006, p. 1). To meet this challenge, emphasis is placed on providing a "practical” liberal education. A practical education requires more than a student's acquisition of knowledge and insists on his or her participation in experiential learning within and beyond the classroom. Keeling (2004) describes this type of learning as transformative, and defines it as the integration of learning across 
campus, producing intentional learners. As a result, graduate outcomes include the ability to "adapt to new environments, integrate knowledge from different sources and continue learning through their lives” (Association of American Colleges and Universities, 2002, p. xi).

\section{A Brief Look at the Evolution of Student Affairs}

To produce graduates capable of such outcomes, students must be presented with opportunities to create habits of both learning and application. These habits are created not only through the traditional curriculum, but also through the co-curriculum. It is not difficult to trace the roots of student life or the co-curriculum to the founding of Harvard College in 1636 (Cohen \& Kisker, 2010; Geiger, 2005; Thelin, 2004). Brubacher and Rudy $(1976,1997)$ remind readers that colonial colleges included residential facilities designed to bring faculty and students together in common life. Moreover, they assert that "more and more college presidents were coming to the conclusion that 'good housing contributes to academic success, and the securing of proper housing is as important as providing proper classroom instruction'” (Brubacher \& Rudy, 1997, p. 336). The moral development of students during this era was as important as academic growth; therefore, student life and behavior were strictly controlled and developed through campus residential living (Cohen \& Kisker, 2010; Nuss, 1996; Thelin, 2004). The role of in loco parentis during the colonial period was the responsibility of faculty members, tutors, presidents, and college trustees (Brubacher \& Rudy, 1976; Cohen \& Kisker, 2010; Nuss, 1996). Cohen and Kisker (2010) describe the design of colonial college life as a system for "controlling the often exuberant youth and for inculcating within them discipline, morals, and character” (p. 27). As the purpose of higher education evolved throughout 
the decades that followed, so did student life on college campuses.

The nexus of change occurred when colleges began to relax their oppressive discipline in the 1820s (Geiger, 2005). According to Geiger (2005), student life transformed into a "self-contained world of activities and social ceremony that engendered deep loyalties instead of intense hostility” (p. 49). This was an important distinction because the purpose of higher education was evolving into a liberal education that could provide students with not only disciplinary knowledge, but also with social and economic mobility (Geiger, 2005; Thelin, 2004).

Many factors influenced the growth of colleges and universities from 1870 to 1944, such as the formation of community colleges; the emergence of professional schools, black colleges, and women's institutions; the passing of the second Morrill Act; and an increased emphasis on scientific research. Coined the "University Transformation Era” by Cohen and Kisker (2010), the number of colleges quintupled and enrollments soared, including a large increase in the diversity of students. As a result, many reasons were cited for the need to create student personnel positions, such as (a) housing expansions, (b) monitoring student conduct, (c) growing demands on college presidents, (d) changing faculty roles and expectations, (e) increasing focus on health and wellness of students, and (f) a changing demography of students enrolling (Nuss, 1996). As a consequence, the profession of student affairs or student personnel administration emerged during this significant period in history. Distinct functions included deans of men and women, housing, health care, judicial, and vocational guidance. Furthermore, Brubacher and Rudy (1997) claimed that the student personnel movement gained national recognition and professional stature in the years following 1918. As higher education 
expanded again after WWII, the student affairs profession also expanded at colleges and universities to help organize and grow the programs and services needed for students with diverse and emerging needs (Cohen \& Kisker, 2010; Nuss, 1996).

\section{A Contemporary View of the Profession}

Each college and university is unique in its mission, values, composition, tradition, and location. These distinctive characteristics determine the nature and organizational structure of divisions of student affairs at each institution (NASPA, 1987). However, principles of good practice are common across divisions, which include: (a) engaging students in active learning; (b) helping students develop coherent values and ethical standards; (c) setting and communicating high expectations for student learning; (d) using systematic inquiry to improve student and institutional performance; (e) using resources effectively to achieve institutional mission and goals; (f) forging educational partnerships that advance student learning; and (g) building supportive and inclusive communities (NASPA, 1987). The foundation for these guiding principles is grounded in the American Council on Education's 1937 publication entitled The Student Personnel Point of View. This publication was updated only twice, once in 1949 and again in 1987, and the philosophy continues to guide the profession. The philosophy reiterates the importance of student affairs work being grounded in the mission of the institution (Ellis, 2010). In addition to this philosophy, members of the profession embraced a Student Learning Imperative in 1994 as a result of increased inquiry among internal and external stakeholders about the goals of undergraduate education (ACPA, 1994). The imperative contends that student affairs practitioners are "educators who share responsibility with faculty, academic administrators, other staff, and students themselves for creating 
conditions under which students are likely to expend time and energy in educationallypurposeful activities” with the goal of educating the whole person (ACPA, 1994, p. 3).

\section{Current and Future Expectations}

For divisions of student affairs to share responsibility for creating conditions which educate the whole person, it is critical that "learning” be defined at colleges and universities in order to fully integrate academic and developmental outcomes for students. Fried (2006) asserts that the construction of meaning no longer occurs only in the academic context. She urges a shift away from a positivist paradigm of learning to a need for constructivism, whereby this paradigm "acknowledges that individual perspective and life experience shape each person’s interpretation of life” (Fried, 2006, p. 14). It is within these life experiences that student affairs practitioners share in the responsibility for the educational goals of the institution. In Learning Reconsidered: A Campus-Wide Focus on the Student Experience, Keeling (2004) states that the construction of knowledge, meaning, and self in society is a result of three contexts-

academic, social, and institutional—in which a student makes meaning while enrolled in institutions of higher learning. In addition to the traditional curriculum, student affairs programs, activities, and services provide unique opportunities and experiences that engage students in an effort to achieve the shared outcomes of student learning. One illustration providing context for the contributions of divisions of student affairs is the student outcomes outlined in Learning Reconsidered. As noted in the document, the outcomes and their dimensions are drawn from research on student development, personal development, and learning (Baxter Magolda, 1999; Baxter Magolda \& King, 2004; Council for the Advancement of Standards, 2002; Hamrick, Evans, \& Schuh, 
2002; Kuh, 1993; Kuh, Douglas, Lund, \& Ramin-Gvurnek, 1994; McEwen, 2003;

National Panel, AAC\&U, 2002; Pascarella \& Terenzini, 1991; Schroeder, 2003; Schuh \& Whitt, 1999; Terenzini, Pascarella, \& Blimling, 1996; Whitt, 1999). These outcomes include: “cognitive complexity, knowledge acquisition, integration and application, humanitarianism, civic engagement, interpersonal and intrapersonal competence, practical competence, persistence, and academic achievement” (Keeling, 2004, pp. 21- 22).

Becoming adaptive. If divisions of student affairs share the responsibility for shared outcomes, their roles and contributions are no longer on the periphery of students' learning, and practitioners become accountable for institutional goals and outcomes. As a result, division leadership should consider how to build organizational capacity for adaptive work. Adaptive systems differ sharply from those of traditional mechanical systems by means of introducing a systems way of thinking so that staff members and units are actively involved in collaborating, coalition-building, and boundary spanning with other staff members and departments campus-wide (Heifetz, 1998). This is important because the diversity and scope of departments in student affairs have historically been considered a stand-alone division within existing collegiate organizations. Redefining what units within student affairs do to contribute to student learning outcomes is essential. Understanding organizational culture provides an increased opportunity to align resources and develop collaborative approaches for accomplishing the tasks and goals of the institution.

A central component of an organization's ability to adapt to change in light of competition and conflict includes a leadership model that practices distributed leadership. According to Harris (2009), individuals occupying formal leadership positions are 
"increasingly recognizing the limitations of existing structural arrangements to secure organizational growth and transformation” (p. 3). Divisions of student affairs must continue to redesign their structures and modify behaviors to reapportion who has authority in order to properly leverage shared decision making. This redesign and modification requires transforming what individuals in the organization know about what will work in the division in relation to the "culture, norms, beliefs, ways of communicating, models of decision making, and who has what kind of power within the larger organization” (Kuk, Banning, \& Amey, 2010, p. 146).

Divisions of student affairs cannot operate independently from the academic mission of the institution. They must adapt their missions, priorities, structures, and practices to better align with the core academic mission of the institution. The evolution and expansion of student affairs as a profession since WWII shows the strength and value of the role they play on college campuses. In order to remain sustainable, they must create adaptable organizations ready and willing to embrace change. This willingness to adapt will increase the likelihood of being viewed and treated as partners in the learning and development of students. Furthermore, few students choose to compartmentalize their learning while in college. They view their involvement as one seamless learning experience. This perspective provides opportunities for institutions to consider more broadly what aspect or aspects of a student's experience he or she finds most meaningful and what he or she attributes future success to. Therefore, it seems appropriate to expand fundraising efforts to include an appeal for programs, services, and activities that also prepare students for life, work, and civic participation in an increasingly complex world. 
Competition for resources, along with increasing expectations from stakeholders, force divisions like student affairs to participate in fundraising in order to maintain and enhance operations (Arminio et al., 2010; Matasar, 1998; Miller, 2010; Shay, 1993). Therefore, it is important to understand how organizations like divisions of student affairs can position themselves for sustainable change. In an effort not to compete with academic units for state appropriations and tuition-based funding, divisions of student affairs have sought alternative funding through fee increases, fundraising, corporate support, and grants. However, continued reductions in state appropriations and higher tuition rates continue to challenge the successful continuation of these efforts, because the competition for private dollars within academic units will increase (Kuk et al., 2010). As a result, divisions of student affairs will need to adapt to remain viable and maintain relevancy. This will require not only a paradigm shift to increase funding, but a shift in how divisions of student affairs operate organizationally to create a more strategic alignment with the academic mission of the institution in order to fundraise (ACPA \& NASPA, 2004; JessupAnger, 2009; Kuk et al., 2010).

Increasing collaboration. According to Gordon et al. (1993), colleges and universities are organizationally situated to emphasize individually differentiated units. However, the literature reveals that diminishing resources are leading to increased collaboration across campus to share expenses and reduce costs (Gordon et al., 1993; Rissmeyer, 2010; Speck, 2010; Woodward et al., 2000). One successful strategy for cutting budgets includes the collaborative partnerships created by divisions of student affairs with divisions of academic affairs and institutional advancement (Romano, Hanish, Phillips, \& Waggoner, 2010). When alignment is apparent, it is not uncommon 
for student affairs to gain support from advancement offices and academic affairs for their own fundraising efforts (Arminio et al., 2010; Jackson, 2000). However, alignment is not always obvious or agreed upon.

The increased involvement in educational fundraising by divisions of student affairs has commanded greater contact with institutional advancement staff and departments. As a result, Fygetakis and Dalton (1993) assert that issues regarding how the two divisions communicate, collaborate, and compete become forcefully visible. This relationship is relatively new, since non-academic units are often overlooked in fundraising efforts because they do not have a natural pool of alumni from whom to solicit money (Schoenecke, 2005). With the limited amount of research conducted on the participation of divisions of student affairs in fundraising, even less has been conducted investigating the impact involvement has on the traditional responsibilities or organizational structures of divisions.

\section{Purpose of the Study}

The purpose of this study was to examine the extent to which divisions of student affairs were involved in fundraising activities at seven 4-year public universities across four Midwestern states. This study expanded upon the work of an earlier dissertation on role expansion in student affairs in selected liberal arts colleges in the Midwest (Kroll, 1991). This study examined the role of the senior student affairs officer in fundraising initiatives, as well as the role of division departments and staff in development efforts. 


\section{Research Questions}

This study examined the role of divisions of student affairs in fundraising at selected 4-year public institutions in the Midwest and was guided by the following research questions:

1. What role, if any, do senior advancement officers and senior student affairs officers believe divisions of student affairs can/should play in fundraising?

2. To what extent is the division of student affairs involved in fundraising activities at the institution (senior student affairs officers and division staff)? How has participation in development efforts evolved?

3. How do senior student affairs and advancement officers describe the impact of student affairs fundraising on traditional responsibilities and/or organizational structures?

4. What are the implications on the future of fundraising for divisions of student affairs?

\section{Significance of the Study}

Educational fundraising has been and continues to be a mechanism for colleges and universities, private and public, to raise additional funding to offset the costs of a deteriorating economy and decreased state support to higher education. In order to balance the decrease in funding, tuition is rising, student fees are increasing, and auxiliary units are being levied at higher levels in order to support institutional needs. This swell in costs coincides with the demand for higher internal and external accountability and expectations by students, parents, legislators, donors, and accreditation agencies. The need to expand institutional fundraising paradigms to increase private funding to public institutions is essential. One approach is to include non-academic units like divisions of student affairs in fundraising efforts. It is evident that the programs, services, and activities provided through divisions of student affairs have a significant impact on 
student involvement, engagement, and persistence (Astin, 1985, 1999; Chickering \& Reisser, 1993; Kuh, 1993, 1995; Pascarella \& Terenzini 1991, 2005; Tinto, 1988, 1993). Increasing dollars to support and encourage high impact practices is important because these programs and services make a difference in the quality of a student's life and learning while in college (Kuh, 1993, 1995; Kuh, Kinzie, Buckley, Bridges, \& Hayek, 2006). As divisions of student affairs across the country are given increased responsibility for expanding programs and services, senior student affairs officers are finding it necessary to involve themselves in the development efforts of the institution.

Using an interpretivist paradigm, the results of this study provided insight into what types of development initiatives divisions of student affairs participate. It aids senior student affairs officers and senior advancement officers in determining how their counterparts at other institutions collaborate to obtain much needed dollars across the institution. Likewise, adding fundraising to a division's responsibilities requires shifts in infrastructure, appropriate staffing, resources, professional development, and time. Therefore, results from this study provided new understanding into how involvement in fundraising was impacting the traditional responsibilities and organizational structures at these institutions. As colleges and universities become increasingly complex, the study's findings also offer those who work in divisions of student affairs a broader understanding of fundraising practices and how to leverage participation in such practices if desired. This foundation provides practitioners with strategies on how to work together to create a more systematic and coordinated effort for accomplishing the institution's fundraising goals. Jackson (2000) posits that this is significant because student affairs divisions have a unique opportunity to help their institution finance projects that may not have been 
funded by external sources a decade ago. Furthermore, Hendrix-Kral (1995) describes this unique opportunity as an advantage because of the role staff members in student affairs play throughout a student's tenure on campus. Finally, the results of this research offer divisional leadership with potential challenges and/or barriers unique to fundraising in divisions of student affairs.

\section{Scope of the Study}

The findings of this study were delimited by the purposive sample selected. The research focused on institutions that were similar in type, size, region, and mission. The sample included states that were included in the Midwest regional membership of the National Association of Student Personnel Administrators (NASPA) and the Council for the Advancement and Support of Education (CASE). Each region included seven states/provinces. The states shared between the two included Illinois, Indiana, Michigan, Minnesota, Ohio, and Wisconsin. Since the state of Iowa and the Canadian province of Ontario were not shared between them, they were not included in this study. NASPA and CASE were selected because they were the largest professional associations for student personnel administrators and advancement officers in higher education.

Large 4-year primarily residential campuses were selected in each of the six states using Carnegie classifications. Institutions meeting the following criteria were included:

- Fall enrollment data showed full-time equivalent enrollment of at least 10,000 degree-seeking students at bachelor's degree level,

- Twenty-five to $49 \%$ of degree-seeking undergraduates lived on campus in institutionally-owned, -controlled, or -affiliated housing, and

- At least $50 \%$ of undergraduates attended full time. 
To reduce bias, only one of the 22 institutions that met these criteria was not included because it was my professional institution. The sample was narrowed again using criteria about the composition of the division of student affairs at each institution. Divisions of student affairs with responsibility for enrollment management and/or athletics were eliminated from the sample because these departments may have had a longer history fundraising for scholarships and support programs than divisions without responsibility for these departments. As a result, an additional 12 institutions were excluded, narrowing the sample to 9 institutions across four states. Of the 9 institutions invited to participate, a pair of vice presidents (student affairs and institutional advancement) agreed to participate from a total of 7 institutions.

The scope of this study was narrowly focused; therefore, a number of limitations exist. One of the goals of this study was to gain a greater understanding of the role of the senior student affairs officer and the division of student affairs in fundraising efforts at 4year public institutions. An effort was made to interview senior student affairs officers and senior advancement officers in similar environments with parallel goals. However, each college and university was unique in its mission, values, composition, tradition, and location. These distinctive characteristics determine the nature and organizational structure of the divisions of student affairs and institutional advancement (NASPA, 1987). For that reason, one senior student affairs officer's or one senior advancement officer's experience or relationship may not be reflective of other senior officers simply because of the unique organizational structure of the institution or division. Every effort was also made to include institutions with centralized rather than decentralized models of development. Nevertheless, the structure of these models varies from institution to institution. 
Surveys and interviews rely on self-reported data. Many factors can limit the study's findings and the validity of the research. The first is inaccurate information. A respondent's inability to provide accurate information to a question or statement could result in a participant not having enough experience with what the question is asking to provide an accurate judgment. Participants may also provide inaccurate information if they do not fully understand what the question is asking of them or if unfamiliar terminology is used. Participants may also intentionally report inaccurate information about their experiences. Another important limitation to consider is the framing of the question as it relates to time. According to Vogt (2007), it is important to ask individuals about relatively recent activities, which aids memory recall more accurately.

\section{Important Terms}

For the purposes of this study, the terms used are defined as follows:

Advancement: a strategic, integrated method of managing relationships to increase understanding and support among an educational institution's key constituents, including alumni and friends, government policy makers, the media, members of the community and philanthropic entities of all types (CASE, n.d.).

Centralized Development Unit: an organizational structure in which all development officers and programs are organized under the central development office (Evans, 1993).

Co-curricular Activities: activities that complement the academic program of study and enhance the overall experience of students through the development of, exposure to, and participation in social, cultural, recreational, and governance programs (Hendrix-Kral, 1995). 
Decentralized Development Unit: an organizational structure in which development efforts are divided by schools, colleges, or other units within the institution, with the development officers reporting to deans or other program directors (Evans, 1993).

Development: a term used interchangeably with fundraising or fundraisers. Fundraising activities are usually conducted by the development office (Kroll, 1991).

Director of Development: an individual who is responsible for fundraising within a defined area (Patton, 1993).

Division of Student Affairs: the administrative unit that includes departments pertaining to student services at an institution of higher education such as student retention, student development, and student welfare (Moxley \& Duke, 1986).

Educational Fundraising: the solicitation of gifts from private sources consisting of four activities: annual giving, capital giving, deferred giving, and major gift cultivation (Terrell \& Gold, 1993).

Institutional Advancement: the administrative unit of a college or university charged with the responsibility of raising external funds traditionally associated with fundraising, alumni affairs, and public relations (Hendrix-Kral, 1995; Kroll, 1991).

Major Gift: a gift larger than an annual gift often paid in installments over a period of years and usually designated for a capital or endowment purpose. The dollar level at which a gift is considered major depends on the needs and fundraising history of the institution (Schoenecke, 2005; Worth, 1993)

Senior Advancement Officer (SAO): the senior administrative officer who oversees matters pertaining to internal and external communications, government and public relations, educational fundraising, and alumni relations (Terrell \& Gold, 1993). 
Senior Student Affairs Officer (SSAO): the senior administrative officer leading the operations of student services and development in an institution (Barr, Desler, \& Associates, 2000).

Student Affairs: a profession where professionals work in a variety of different positions on college and university campuses. Functional areas can include: student activities, residence life, academic advising, financial aid, admissions, campus recreation, career services, volunteer services, and student orientation. Professionals also work at a variety of institutions_-community colleges, public universities, private universities, and institutions of all sizes (NASPA, n.d.).

Student Affairs Practitioner: a professional staff member who works in a department within a division of student affairs. This term is used interchangeably with Student Personnel Administrator.

Student Personnel Administrator: a professional staff member who works in a department within a division of student affairs. This term is used interchangeably with Student Affairs Practitioner.

\section{Summary}

As illustrated, educational fundraising has been and continues to be an approach for increasing private funding to offset the costs of a deteriorating economy and decreased state support to higher education. As costs increase to attend college, so does the demand for higher internal and external accountability and expectations. It is no surprise that divisions of student affairs are choosing to become involved in the development efforts of the institution. However, the demand for involvement often comes from within the division and not at the request of institutional advancement or the leadership of the 
university. Therefore, if success in educational fundraising is to take flight in divisions of student affairs, research must continue to show evidence that what they do strengthens the image of the institution and contributes to meeting the learning outcomes and fundraising goals of the university.

\section{Organization of the Study}

This study is divided into five chapters. The following chapter will provide a context for understanding both the purpose and significance of this study through its review of related literature. Chapter III will focus on the study’s methodology and research procedures. The fourth chapter will present the findings, analysis, and discussion of the results. Finally, Chapter V will offer conclusions, implications, limitations, and recommendations. 


\section{CHAPTER II}

\section{REVIEW OF RELATED LITERATURE}

\section{Introduction}

As more emphasis is placed on the important role of fundraising in higher education, it is necessary to examine the literature on the involvement of student affairs as a development partner in meeting the fundraising goals of the institution. Therefore, the purpose of this review is to analyze what the literature reveals about the role of divisions of student affairs in educational fundraising. Although there has been an increase in participation by divisions of student affairs, a limited amount of research has been conducted on the topic regarding their involvement prior to the $21^{\text {st }}$ century (Gold et al., 1993; Gordon et al., 1993; Fygetakis \& Dalton, 1993; Kroll, 1991; NASPA, 1997; Shay, 1993; Terrell \& Gold, 1993). However, in the past decade, quite a few new studies and practitioner-related literature have shed light on development support characteristics, role expansion for student affairs officers, current strategies and practices, differing perceptions regarding involvement, and financial implications (Crowe, 2011; Hillman, 2002; Hodson, 2010; Jackson, 2000; Miller, 2010; Morgan \& Policello, 2010; Penney \& Rose, 2001; Rissmeyer, 2010; Romano et al., 2010; Rovig, 2008; Schoenecke, 2005; Schuh, 2003; Sonn, 2008).

This review will highlight the literature by first providing a brief overview of institutional advancement and then describing what the literature uncovers across three 
themes: (a) a rationale for involvement, (b) process for inclusion and collaboration, and (c) role expansion. In order to provide a rationale for student affairs involvement in development efforts, the first theme defines student engagement and its significance on persistence and alumni success. Upon understanding more clearly student engagement, the role of institutional policies and practices will be discussed, followed by why a relationship exists among student engagement, institutional policies, and educational fundraising. Additionally, this theme explores what motivates donors to invest in their alma maters. The second theme reveals the process for inclusion as discussed in the literature and will highlight the role collaboration plays between divisions of student affairs and other divisions on campus, paying special attention to the division's relationship with institutional advancement. The third theme showcases the studies and practitioner-related literature on role expansion to include fundraising in student affairs. The review of the literature will conclude by situating the current study within the context of what has been written and why its significance will add value to not only the profession of student affairs but the university as a whole.

\section{Institutional Advancement Overview}

Private giving to institutions of higher education has had a long history dating back to the beginning of the colonial colleges in America. Over the course of nearly 400 years, fundraising has become a critical component of financial support for innovation and excellence in education. According to Hall (1992), "no single force is more responsible for the emergence of the modern university in America than the giving of individuals and foundations” (p. 403). The role of institutional advancement is anchored by the definition of philanthropy. Walton and Gasman (2010) define philanthropy as a "voluntary giving 
of time and money for public purposes including the financial gifts of individuals, groups, and foundations, as well as the service of trustees and volunteerism of students and faculty” (p. xxii).

The earliest example of philanthropy in higher education was the renaming of New College to Harvard College after its first benefactor John Harvard, who bequeathed his library of 400 books. Colleges during the colonial period relied heavily on voluntary contributions. The concept of localism became commonplace for institutions during this era and gifts of money and time for the public good helped solidify ties between colleges and universities and their local setting (Walton \& Gasman, 2010, p. 3). Deemed statechurch colleges by Rudolph (1962), the earliest American colleges were funded by both local and government resources. Although no formal fundraising programs existed, Croteau and Smith (2012) state that the first nine colony colleges relied on "philanthropy as an important capital resource” in addition to taxes, military exemptions, lotteries, student fees, and tuition (p. 8).

Between the late 1700s and late 1800s, higher education expanded and private donations accelerated rapidly. According to Cohen and Kisker (2010), donors were solicited through "personal contacts made by the president or a member of the board of trustees” (p. 171). However, a shift occurred during this era when fundraising became more systematic and organized on college campuses. It was also during this time that colleges and universities began to create formal alumni systems and associations. The first alumni system was created by the Reverend Timothy Mater Cooley at Yale University in 1792 when he compiled biographical summaries of members of the graduating class (CASE, n.d.). In 1821, Williams College organized an alumni 
association. Brown University established an alumni fund in 1823, and Yale sponsored the first class reunion in 1824 (CASE, n.d.). As enrollments grew, so did the number of alumni and the level of interest to invest in higher education by graduates and businesses.

In the early $20^{\text {th }}$ century, fundraising efforts were led by paid consultants who used presidents, vice presidents, faculty, and trustees to make personal visits to solicit donations. However, the scope of higher education continued to expand, and college and university structures shifted again. As a result, the responsibility for cultivation, solicitation, and stewardship of donors moved to a more formalized structure for advancement work within the university. Staff members were hired to assume development roles previously held by consultants and university leadership. As early as the 1920s, Harvard University established the first fundraising office, and Northwestern University is credited with first using the term "development” in its current form (Croteau \& Smith, 2012). Other colleges and universities began to follow suit.

As the role of development continued to advance rapidly, two associations were formed and continue to guide the profession of institutional advancement: (a) Council for the Advancement of Education (CASE), which was a merger between the American Alumni Council and the American College Public Relations Association, and (b) the Association of Fundraising Professionals (AFP). CASE serves as an international membership association committed to advancing and supporting educational institutions by providing "knowledge, standards, advocacy, and training designed to strengthen the combined efforts of alumni relations, communications, fundraising, marketing, and allied professionals” (CASE, n.d.). AFP advances ethical and effective fundraising worldwide. The association's reach goes beyond higher education and includes fundraising 
professionals from a variety of industries. Like CASE, they work to "advance philanthropy through advocacy, research, education, and certification programs” (AFP, n.d.). AFP, in collaboration with CASE and the Association for Healthcare Philanthropy (AHP), developed the Donor Bill of Rights to ensure that philanthropy merits the respect and trust of the general public (AFP, n.d.). In addition to these associations, another international association's mission is dedicated to setting standards in philanthropy through a valid and reliable certification process. The Certified Fund Raising Executive (CFRE) credential is highly regarded by advancement professionals and holds fundraising professionals to the highest standards of professional competence and ethical practice in serving the philanthropic sector (CFRE, n.d.).

The formation of institutional advancement has changed dramatically since the renaming of New College to Harvard College. The modernization of advancement in many ways is a result of the growth of higher education. Recently, economic decline has led to decreased state funding to institutions of higher education and increasing tuition costs to students and their families, yet enrollment in degree-granting institutions continues to rise. According to the National Center for Education Statistics (2011), enrollment increased by 11\% between 1990 and 2000 and increased by $37 \%$ between 2000 and 2010. If giving by individuals and foundations was in large part responsible for the emergence of the modern university in America, then the role of institutional advancement will play an even larger part in continuing America’s efforts to develop innovation and excellence in education. 


\section{A Rationale for Student Affairs Involvement in Development Efforts}

As it relates to a rationale for involvement, the review of literature brought two themes to the surface. The first theme defines student engagement and describes its significance to student success and persistence. Upon understanding more clearly student engagement, the role of institutional policies and practices will be discussed. Finally, this section will examine the relationship that exists among student engagement, institutional policies, and educational fundraising. To deepen the conversation, research results will be shared which explore what motivates donors to invest in their alma maters and their relationship to student engagement and institutional policy making.

\section{Defining Student Engagement and Its Significance}

Student engagement has a long-standing relationship with the desired outcomes of college that go far beyond student persistence. As early as 1921, Dewey called attention to the need for students to become effective, productive citizens through education and experience (Rovig, 2008). Divisions of student affairs play an essential role on college campuses by providing effective educational practices that engage students in active and experiential learning. Keeling (2004) defines learning as a “complex, holistic, multicentric activity that occurs throughout and across the college experience” (p. 5). Learning occurs in structured ways and in ways that are unstructured but effective. For example, a visit to the Student Health Clinic or Student Counseling Center goes beyond transactional service providing students with opportunities to engage in active learning to achieve interpersonal, intrapersonal, practical competence, and cognitive complexity. In short, students learn from what they do in college (Pike \& Kuh, 2005). 
The positive effects of providing educationally purposeful activities are well supported by research (Astin, 1985, 1999; Chickering \& Reisser, 1993; Kuh, 1993, 1995; Pascarella \& Terenzini 1991, 2005; Tinto, 1988, 1993). In order to maximize learning opportunities, two critical factors are cited to enhance student engagement. According to Kuh, Kinzie, Buckley, Bridges, and Hayek (2006), the first factor includes the amount of time and effort students put into their studies and other educationally purposive activities. The second critical factor is the way in which the institution deploys its resources and organizes its curriculum, other learning opportunities, and support services to induce students to participate in activities that lead to the desired outcomes of persistence, satisfaction, learning, and graduation (Kuh et al., 2006). This claim is reinforced by the research of Pascarella and Terenzini (1991), who concluded that “one of the most inescapable and unequivocal conclusions we can make is that the impact of college is largely determined by the individual's quality of effort and level of involvement in both academic and non-academic activities’’ (p. 610). In the first of three theories discussed in this review, research conducted by Astin $(1975,1985,1999)$ states that the degree of fit between the student and institution is an important aspect of persistence.

Theory of involvement. Astin's theory of involvement pertains to the behaviors students engage in while attending college which influence student outcomes (Astin, 1975). The basic purpose of Astin’s Inputs-Environment-Outcomes (I-E-O) model is to assess the impact of various environmental experiences to better understand how negative encounters can lead students to withdraw, while positive encounters cause students to invest in the college experience (Pascarella \& Terenzini, 2005). According to this model, the inputs, environment, and outcomes are described as a student's background 
characteristics, such as demographics, previous experiences, and the range of opportunities available at the institution, which include programs, activities, services, peers, faculty, staff, and community, and the characteristics, knowledge, attitudes, beliefs, and values of the student as a result of their experience at the institution (Astin, 1975, 1985, 1999). In order to fully understand the role of involvement, Astin (1985) provides five assumptions of which institutions, specifically faculty and staff, should take note:

1. Involvement refers to the student's investment of physical and psychological energy in various objects of the college experience;

2. Involvement occurs along a continuum with the student investing different degrees of involvement at different times;

3. Involvement can be measured quantitatively and qualitatively;

4. Student learning and personal development is directly related to the quantity and quality of the student involvement; and

5. The effectiveness of an educational policy or practice is directly related to the ability of that policy or practice to increase student involvement.

This theory of involvement urges institutional leadership at all levels to provide and encourage opportunities for student engagement. Moreover, Astin (1975) stresses "if ways can be found to involve students more in the life and environment of the institution, their chances of staying in college are improved” (p. 148).

Theory of departure. A second theory from which to gain perspective is Tinto's Model of Student Departure, which substantiates Astin’s theory of involvement and further asserts that institutional integration is a key component of why students persist or depart college (Tinto, 1993). He argues that academic and social integration are essential 
to ensure academic success (Tinto, 1993). The definition of integration includes the relationships students build through participation in the life of campus, such as events, organizations, civic engagement, leadership, and activities offered by the college or university. Tinto $(1988,1993)$ emphasizes that this involvement should occur both inside and outside the classroom. Purposeful academic and social integration provides students the opportunity to shed entering characteristics (e.g., family background, grades, socioeconomic status, etc.) and form new goals and commitments for academic and social achievement (Tinto, 1993; Kuh et al., 2006).

Theory of engagement. Finally, Kuh (1993, 1995, 1996, 2008, 2009) provides another theoretical lens from which to better understand student engagement, through which he posits "student engagement represents the time and effort students devote to activities that are empirically linked to desired outcomes of college and what institutions do to induce students to participate in these activities” (Kuh, 2009, p. 683). Focusing on how to engage students has the ability to improve the chances a student will succeed and persist. More specifically, Kuh, Kinzie, Schuh, and Witt (2005) submit examples to connect students with the institution, such as meaningful interactions between students and faculty, supportive environments, clearly identified and reasonable expectations, and mutual and shared learning. In research conducted, Kuh et al. (2005) set out to discover what institutions do to promote student success through student learning and engagement. They discovered six features that foster student engagement and persistence, which include: (a) a living mission and lived educational philosophy, (b) an unshakeable focus on student learning, (c) environments adapted for educational enrichment, (d) clearly marked pathways to student success, (d) an improvement-oriented ethos, and (f) shared 
responsibility for educational quality and student success (Kuh et al., 2005).

In a follow-up study, Kezar (2007) found that a campus or institutional ethos "draws students into their learning experience by moving beyond activities that engage the mind and body to make connections with the student’s spirit and heart” (p. 14). In order to foster this ethos, faculty and staff must work to ensure that there is congruency between the spirit of the culture and institutional policies and practices.

\section{The Role of Institutional Policies and Practices}

These three theories provide a foundation for understanding the effects of student engagement and the motivation for colleges and universities to continually evaluate their engagement strategies. Lynn (2008) asserts that educational leaders should plan activities and services that encourage involvement, engage students, and facilitate student success. Her claim is well supported by Pascarella and Terenzini (1991), who indicate that a substantial amount of evidence points to instructional and programmatic intervention increasing a student's active engagement in learning academic work and enhancing knowledge acquisition. In earlier research conducted by Pascarella and Terenzini (1985), these core concepts assessed student change using the direct and indirect effects of an institution's structural characteristics and its environment as a method for evaluating engagement strategies. The types of intervention described by Pascarella and Terenzini (1985, 1991) and Lynn (2008) should be seamless. Kuh (1996) insists that experiences should connect all of the courses, programs, and services offered to students under one overarching umbrella to appear whole and continuous.

Creating seamless environments requires the development of student-centered campus environments that support learning and encourage involvement. This is essential 
because the institutional environment has been cited as a strong factor in precipitating or prolonging a student's integration into the campus community and ultimately persistence (Astin, 1975, 1985, 1999; Tinto, 1993). This is further supported by Strange and Banning (2000) who affirm that “a measure of any educational institution’s environmental capacity to encourage and sustain learning is the degree to which it provides the conditions for students’ inclusion, safety, involvement and full membership in a community” (p. 200).

The effects of academic and social integration influence more than a student's decision to persist or depart. The effects assist university decision makers on deciding the importance of allocating resources to high impact practices that make a difference in the quality of student life and learning. The use of student engagement data is propelled by questions about whether colleges and universities are (a) using resources effectively to foster student learning, (b) to enhance success of students from diverse backgrounds, and (c) the requirement (by accrediting agencies) to show evidence in the assessment of student outcomes and aspects of the campus environment associated with these outcomes (Ewell, 2008; Kuh et al., 2006). As an important variable today, internal and external constituencies consider the results of engagement measures like the National Survey of Student Engagement (NSSE) to make policy or policy revisions, create programs, construct space, allocate resources, and plan for the future.

Studies consistently show that the "greatest impact on learning and personal development during college seems to be a function of institutional policies and practices that induce higher levels of engagement across various kinds of in-class and out-of-class educationally purposeful activities” (Kuh, 2009, p. 689). Since learning occurs across campus, it is important for administrators, faculty, staff, and students to have a clear 
understanding of what student engagement is and what it represents on campus to determine how to share responsibility. Kuh (2009) draws attention to the need for colleges and universities to shift away from the philosophy of putting the responsibility on students to adjust to the institution to succeed. In fact, Astin (1985) more than a decade before argued that the "effectiveness of any educational policy or practice is directly related to the capacity of that policy or practice to increase student involvement” (p. 36). As students enrolling in college become more diverse, so do their needs and expectations. Kuh (2007b) urges policy makers and institutional leaders to change teaching and learning approaches and cultivate campus cultures that both welcome and affirm students.

\section{The Relationship Among Student Engagement, Institutional Policies, Donor Motivations for Giving, and Student Affairs Fundraising}

When few student affairs leaders were engaged in educational fundraising, Garvin (1980), using a utility maximizing model, predicted reasons why they would likely want to participate. These reasons included increased prestige, improving the quality and number of students, and to handle costs and revenues. Although these reasons continue to be important decades later, colleges and universities are reminded that they must respond to the changing demands of the $21^{\text {st }}$ century. The Association of American Colleges and Universities created an initiative called the Liberal Education and America's Promise (LEAP) in 2005. This initiative advocates for a liberal education for college graduates, who will need "higher levels of learning and knowledge as well as strong intellectual and practical skills to navigate this more demanding environment successfully and responsibly” (AAC\&U, 2005). 
The role played by divisions of student affairs as a contributor to these demands is more essential than ever. According to Schuh and Gansemer-Topf (2010), "the role and contribution of the services, programs, and experiences developed by student affairs practitioners have moved from the periphery to the center of students' learning at college” (p. 5). Increased competition for resources, along with increasing expectations from stakeholders, forces divisions like student affairs to participate in fundraising in order to maintain and enhance operations (Arminio et al., 2010; Miller, 2010; Shay, 1993). This becomes critical if divisions of student affairs are expected to share in the responsibility of meeting the institution's educational goals.

The role of divisions of student affairs in fundraising efforts goes beyond the solicitation of monetary gifts. As illustrated earlier in this chapter, the engagement strategies used by divisions of student affairs are instrumental in ongoing development endeavors. Gordon et al. (1993) strongly encourage the inclusion of student affairs in development efforts because of the division's involvement in enrollment management, retention, and student development. Many others draw attention to the notion that staff members in divisions of student affairs are natural partners to other divisions such as academic affairs and institutional advancement (Jackson, 2000; Miller, 2010; Morgan \& Policello, 2010; Rissmeyer, 2010; Shay 1993). As indicated, “student affairs professionals are educators who share responsibility with faculty, academic administrators, other staff, and students themselves for creating the conditions under which students are likely to expend time and energy in educationally-purposeful activities” (ACPA, 1996, p. 2). Because of their expertise and knowledge, staff members in departments that comprise divisions of student affairs can be powerful allies to the development officers who are 
cultivating donors (Miller, 2010). For example, staff members in student affairs form bonds with current students and continue to nurture those relationships well beyond graduation through personal contact, mentorship, and invitations to campus for speaking engagements, panel discussions, and reunions.

Rissmeyer (2010) corroborates Miller’s claim and asserts that leveraging these strong connections with young alumni is a valuable proponent for cultivation. These valuable allies can also assist with documenting involvement and engagement information for current students and alumni. Additionally, the value placed on student affairs programs and services by alumni is often high and there is likely an increased interest to give back to activities and organizations that made a difference in their lives (Morgan \& Policello, 2010; Rissmeyer, 2010). Furthermore, program outcomes in student affairs are easy to identify and communicate to donors, providing them with tangible ways to see their gifts in action (e.g., leadership, service, and diversity programs). Another strength of division staff is their ability to engage current students in development efforts such as involvement in donor events and visits, and in acknowledging gratitude for gifts (Arminio et al., 2010; Miller, 2010; Morgan \& Policello, 2010; Shay, 1993).

Donor motivation. Understanding the motivations of donors is another important characteristic when considering who should be engaged in development initiatives. Alumni are the largest category of donors to colleges and universities (Council for Aid to Education, 2007). When considering philanthropic practice, Greenfield (1994) posits that making gifts is a voluntary act each and every time. Furthermore, this practice is "carried out by sharing valid needs with selected audiences who are invited to lend their support” (Greenfield, 1994, p. 8). Successful solicitation occurs when the institution can match 
its needs with donor interest. Brittingham and Pezzullo (1990) argue that "determining who is emotionally connected to the institution and why is one of the strongest predictors of alumni giving” (p. 35).

There are many factors that may trigger these emotions as an alumnus reflects on his or her experience as a student or his or her current involvement or connection to the institution. For example, Harrison, Mitchell, and Peterson (1995) conducted research using data for 3 years from 18 universities and colleges (public, private, large, small, research, and teaching-oriented). They believed that altruism was not the dominant factor for alumni giving and that graduates need to be motivated to give back to their alma mater. The results of the study showed that the greatest influence on alumni giving was expenditures on alumni relations. Additionally, they found two explanatory variables regarding student life: (a) the percent of students who participated in fraternities and sororities positively affected giving, and (b) the percent of students who were part-time negatively affected giving (Harrison, Mitchell, \& Peterson, 1995). The positive effect of organization involvement was an important discovery in the nineties when this study was conducted.

In 2000, Patouillet published a study which analyzed alumni association members’ attitude toward their alma mater, toward donating to the university, and their perception of the rewards of giving at a public AAU institution. The results of this study put forward that both donors and non-donors identified the highest ranking aspects of student life as important factors for their willingness to give back, which included the quality of the educational experience, overall university experience, and the quality of the faculty. However, both donors and non-donors identified service provided by staff and quality of 
student life as the two areas with the lowest levels of satisfaction. Therefore, enhancing the quality of student life on college campuses should be considered a priority when building strategies to increase alumni participation in giving. As a recommendation for practice, Patouillet (2000) urges universities to place more emphasis on “developing a greater sense of institutional loyalty among the students while they are attending the university” (p. 88).

With Patouillet's (2000) research as a springboard, the purpose of dissertation research conducted by Pumerantz (2004) determined the status of alumni giving at public comprehensive institutions in the state of California. He examined the indicators of performance from alumni fundraising and examined institutional factors associated with achieving greater alumni giving at public comprehensive institutions. The study used a student-centered philosophy, referred to as an Alumni-in-Training approach to student life. The results indicated the need to ensure a positive experience for students and the importance of getting them connected to alumni as early in the relationship as possible. Furthermore, understanding and identifying the affinity types among alumni was critical to attracting private investment. Pumerantz (2004) states, "the better performing institutions recognized that they needed to identify the connections that alumni had with their alma mater and to match their solicitation efforts accordingly” (p. 107). He further advocates that using an Alumni-in-Training philosophical approach improved the institutional culture as it related to student life. Through a series of 36 interviews with key administrators, the study’s findings confirmed that the institutions having active and ongoing efforts to engage students while on campus did so intentionally and in some cases with the clear understanding that positive student experiences could lead to greater 
giving as students became alumni.

Another important finding was the comments made by administrators about the "value of a visible and caring leader who spends a significant amount of time with students and continually demonstrates to them that they are valued” (Pumerantz, 2004, p. 111). From a collaboration perspective, this study also uncovered that student affairs and alumni affairs work together more often than alumni affairs and academic affairs. Those interviewed commented that student affairs and alumni affairs had a longstanding relationship.

In a qualitative study on how reciprocity influences alumni giving, Baldwin (2008) found that reciprocity did emerge from interviews as a primary motivation for giving, and this feeling for reciprocity emerged while alumni were students. Furthermore, she asserts "Participants talked a great deal about their philosophy of giving back. Most related their sense of gratitude for their entire UA experience. They felt the lessons learned while students prepared them for life” (Baldwin, 2008, p. 69). When asked to reflect on the benefits received as a student, respondents discussed the beauty of the campus, their positive engagement with campus life, and the good times they had while students. One aspect of these benefits included meeting friends and partners.

Moreover, becoming involved in Greek-letter organizations was useful to participants in making connections with other students, more specifically, "Greek affiliation provided an immediate sense of belonging and sense of family" (Baldwin, 2008, p. 76). The results also found that non-Greeks who were active in co-curricular activities also experienced the benefit of meeting friends and making close bonds with other students (e.g., student government association, intramural sports, and band). From 
the 18 donor interviews conducted, Baldwin (2008) concluded that respondents believed:

Involvement in campus activities was an important way to learn about life as the classroom was to learn academics. They believed the University played a critical role in their intellectual and social development. For them, knowledge exists in both areas, and higher education has a responsibility to expose students to both academic and social. (p. 77)

The results of this study illuminated a growing body of evidence for including cocurricular needs alongside curricular ones when approaching donors. As illustration, Baldwin (2008) learned from participants that their education provided them with "life skills and a sense of purpose that enabled them to advance in life and their careers” (p. 90). The respondents commented on their love for the total undergraduate experience. As students, they were made to feel special and believed that their experience was unique to them.

Baldwin (2008) shared a number of recommendations for practice, many of which provide confirmation for divisions of student affairs (and others) to be a partner in development efforts:

1. University administrators should determine what promotes reciprocity among their students and work to develop feelings of reciprocity among students during their collegiate years.

2. Colleges and universities must not only develop a student intellectually, but they must also develop students morally and prepare them to be productive, responsible members of society.

3. Pedagogy should be committed to the education of the whole student.

4. Staff should be trained to understand their role in the student experience.

5. Campus care programs should be strengthened.

6. Institutions in which students are involved in governance can lead to more meaningful educational experiences. 
7. Creating a small college feel within the larger college or university is crucial.

8. Residential colleges and universities need to ensure intimacy is not displaced by growth.

As demonstrated, divisions of student affairs can play a valuable role in both the solicitation of donations and in roles which assist university advancement with the identification, cultivation, and participation of current students and alumni. With a sound rationale for involvement in development efforts, the literature also discusses the process for divisions of student affairs to be invited to participate.

\section{Process for Inclusion and Collaboration}

With limited research on the impact of student affairs involvement in educational fundraising, perceptions about whether they should be involved vary. One factor that influences inclusion is the president's philosophy of executive involvement in fundraising. Research conducted by Shay (1993) found that involving the senior student affairs officer when the senior academic officer is not involved can make it more difficult to obtain approval from the president, whereas, the role of the senior financial officer has little influence on whether or not a senior student affairs officer is involved. Therefore, the senior student affairs officer should make it a priority to understand the president's philosophy of executive involvement in fundraising before consulting the senior advancement officer.

Acknowledging Shay’s finding, Hodson (2010) also asserts that presidents are ultimately responsible for the success of the fundraising program, for they are in the best position to create the vision, establish priorities, and make the case for support. Whether or not the division of student affairs is part of that vision relies on the senior student 
affairs officer's ability to articulate the student affairs perspective and its support of institutional goal setting and planning (Gold et al., 1993; Gordon et al., 1993; Miller, 2010; Terrell \& Gold, 1993). Therefore, the senior student affairs officer should become, if not already, an integral part of strategic planning. Support for this recommendation can be found in the analysis of data gathered from interviews and related documents in a purposeful sample of five comprehensive public institutions in two Mid-Atlantic States. Arminio et al. (2010) found that if senior student affairs officers aim to have division priorities included at the institutional level, they must link student affairs fundraising goals to the university's strategic plan. Results indicated that this was consistently cited by both presidents and senior development officers (Arminio et al., 2010). The fundraising goals in divisions of student affairs should provide support for how the division's involvement will increase, not compete for, private dollars to the institution.

The more involved a division is in the strategic planning of the institution, the easier it will be to articulate how the goals of student affairs fundraising align with student and institutional needs. Although a purposive sample was used to conduct the study, there were limitations to the generalizability of the results, given the size and location of the sample. However, each of the institutions selected had established and respected fundraising programs as determined by funds raised during the institution's most recent campaign. Many factors can influence whether student affairs will be invited to participate in educational fundraising. It is important to briefly draw attention to the time required to create a fundraising program in a division of student affairs and weigh the cost effectiveness of the program. Shay (1993) cautions senior student affairs officers to consider these in preparation for making a case to the president or the senior 
advancement officer.

If all divisions at the university are involved in the strategic planning process, goals and objectives will become shared, which means collaboration will naturally emerge between units. These partnerships provide the critical next step for student affairs to engage successfully with the campus to meet fundraising goals.

According to Gordon et al. (1993), colleges and universities are organizationally situated to emphasize individually differentiated units. However, the literature reveals that diminishing resources are leading to increased collaboration across campus to share expenses and reduce costs (Gordon et al., 1993; Rissmeyer, 2010; Speck, 2010; Woodward et al., 2000). One successful strategy for cutting budgets, documented in a qualitative study conducted by Romano et al. (2010) included the collaborative partnerships created by student affairs with academic affairs and institutional advancement. When alignment is apparent, it is not uncommon for student affairs to gain support from central development offices and academic affairs for their own fundraising efforts (Arminio et al., 2010; Jackson, 2000).

In another study, Eller (2010) sought to identify and describe the collaborative practices that vice presidents play in university fundraising at a selected California State University. This single-site case study approach found that "collaboration among institutional leaders fosters a productive environment in higher education” (Eller, 2010, p. viii). Through interviews and observations, Eller (2010) found that "fundraising efforts on an individual basis by each of the four vice presidents could be made more effective if all collaborated as a fundraising team” (p. 70). Involvement by vice presidents could include donor engagement, friend raising efforts to foster relationships, and donor 
appreciation. A recommendation from this study suggests involvement in fundraising needs a consistent, unified message in order to reduce "silos” across divisions which could allow for a collaborative environment that is conducive to effective donor engagement. Although the findings of this study are encouraging, they cannot be generalizable to other state universities in California or beyond.

A strategy for collaboration supported by the research of Gordon et al. (2010) uses an organizational communication theory as a framework. This framework examines the conditions and means for establishing a dialogue with institutional advancement, especially when such linkages do not already exist. Organizational structures in colleges and universities can lead to a disparate set of values and goals; however, working together through consistent communication and collaboration maximizes the benefits to both the division of student affairs, university advancement, and the institution. Communication and collaboration between divisions establishes new horizontal links rather than a vertical disenfranchised system (Gordon et al., 2010). As a key component of educational fundraising, horizontal communication affords both student affairs and institutional advancement an opportunity to share relevant information, establish trust, and coordinate activities with the potential to increase private funding for the institution as a whole (Gordon et al., 2010; Morgan \& Policello, 2010; Schuh, 2009). It is the responsibility of the senior student affairs officer to lay the foundation of collaboration with the senior advancement officer and to provide a rationale for the desire and need to increase interaction between divisions (Gordon et al., 2010; Morgan \& Policello, 2010; Shay, 1993). 
Another related study conducted by Sonn (2010) examined the nature of collaboration at the department level, more specifically between student affairs and development units at private research universities with successful student affairs fundraising efforts. This multi-site case study design collected and analyzed data from three institutions. His findings reinforced the view that student affairs fundraising “supported not just student services, facilities, and activities, but also addressed institutional mission and fundraising objectives” (Sonn, 2010, p. 274). The participants interviewed recognized student affairs fundraising as an effective way to engage donors (Sonn, 2010). As in the practitioner-related literature, this study's findings confirmed the following: (a) student involvement and outside-of-the-classroom activities produced emotional reactions in prospective donors that led to engagement, (b) student affairs fundraising was a value-added activity to the university’s overall development and alumni engagement effort, (c) student affairs fundraising projects engaged donors and produced a return on investment, and (d) student affairs fundraising projects tapped into donors' areas of interest. As noted by Sonn (2010), contextual factors like campus and organizational cultures played too significant a role to be generalizable to other organizations. However, it does provide a template for other studies like this one when examining collaboration with development officers and other institutional partners to raise money for student affairs programs, services, and facilities. Additionally, the sample only included private research institutions, further limiting the use of the findings.

In order to maintain and enhance operations, divisions of student affairs are positioning themselves for sustainable change by expanding their role to include a more deliberate approach to fundraising and development efforts. 


\section{Role Expansion to Include Fundraising in Student Affairs}

Against the backdrop of decreasing state support for public higher education, institutional leaders are considering new and innovative approaches to budget management and planning. In a 2010 study, public higher education institutions were used as case studies to increase our understanding of strategies used by leaders in student affairs to reduce expenses as a result of budget cuts (Romano et al., 2010). Twelve public colleges and universities that endured at least 3\% to $4 \%$ annual reductions for 3 or more years were identified and selected to participate. Phone interviews with senior student affairs officers were conducted in 2005 and again in 2009. Results indicated that although many strategies remained the same, a heavier reliance on extensive communication, assessment, and fundraising surfaced as themes in 2009. Furthermore, fundraising consistently emerged as an income-generating strategy. The responses revealed that all senior student affairs officers who participated in the study were in at least one stage or another of fundraising activity including: considering it, beginning new efforts, or strengthening their development programs (Romano et al., 2010). A reader might consider the small sample size as a limitation of the study; however, the researchers selected four institutions in three enrollment categories by design. Another limitation could be construed as any change that occurred in the vice president position between 2005 and 2009, yet the authors did not discuss this as a constraint.

It is not surprising that fundraising consistently emerges as an income-generating strategy for public colleges and universities. The literature reveals that the number of student affairs divisions involved in fundraising activities continues to climb. Kimmel reported in 1986 that divisions of student affairs had not yet embraced the concept of 
fundraising. However, within the first few years of the following decade, an increasing number of senior student affairs officers reported they were starting fundraising efforts within their divisions to support and enhance student services and programs (Gordon et al., 2010; Jackson, 2000; Kroll, 1991; Rovig, 2008).

A good illustration of this growth is the number of directors of development assigned to student affairs fundraising. In a national study conducted by Fygetakis and Dalton (1993), results indicated that $12.5 \%$ of respondents (senior student affairs officers) employed their own development officers. By 1997, the National Association of Student Personnel Administrators’ (NASPA) survey results concluded that 30\% of respondents (senior student affairs officers) had a full-time development officer assigned to student affairs (Penney \& Rose, 2001; Rovig, 2008). Furthermore, in both studies, respondents indicated that they had a cooperative relationship with institutional advancement in terms of fundraising activities with or without a director of development (Fygetakis \& Dalton, 1993; Penney \& Rose, 2001).

In addition to the rising number of directors of development hired by divisions of student affairs, another study examined specifically the role senior student affairs officers played in fundraising activities. The purpose of the interpretive paradigm used was to gain a greater understanding of the kinds of fundraising activities with which student affairs officers were involved, attitudes about their changing roles, and implications such changes and involvement have for the future of student personnel work (Kroll, 1991). The sample included 12 colleges and universities in the Great Lakes College Association and 13 institutions in the Associated Colleges of the Midwest. This research focused on institutions that were similar in type, size, and mission. As to be expected, the results 
may only be generalizable to institutions of similar type. However, it provides divisions of student affairs another lens from which to view fundraising in the profession.

Pertinent results showed that a majority of senior student affairs officers expressed a desire to contribute to the institution, in addition to their division, through fundraising efforts. A majority of the senior student affairs officers were doing so at the request or invitation of the president. Respondents also indicated that their skill set and institutional perspective was easily transferrable to development work. Another meaningful result was the recommendation that a stronger emphasis on finance and fundraising should be paid to graduate education for student affairs professionals. Although both presidents and development officers reported that student affairs involvement in development activities was important, both groups reported that fundraising activities did not enhance the stature of student affairs divisions on their campuses. According to senior student affairs officers, a drawback to participation included the amount of time and energy required, taking them away from other core responsibilities, a concern also noted by Shay in 1993. The results of this study are important given the researcher's goal to provide a multi-faceted explanation which can be used to explore the implications of expanding student affairs divisions to include fundraising duties and activities. However, the sample used can be considered a limitation of the study, as well as the age of the results. Interestingly, only one institution of the 12 interviewed was not currently involved or in finishing a campaign which may or may not have affected the results. Furthermore, Kroll (1991) states that at 10 of the 12 institutions studied, "student affairs concerns were included in capital campaign projects” which may have influenced the level of involvement by student affairs officers and division staff (p. 70). 
Nearly 10 years later, Hillman (2002) examined the current status of fundraising activities and training within student affairs divisions in Texas colleges and universities. According to the researcher, the study sought to "determine the predominance of chief student affairs officers trained in development and the types of training that they received” (Hillman, 2002, p. 3). Another area of focus was cooperation between student affairs divisions and development offices and whether there was a correlation between a cooperative relationship and the number of successful fundraising goals (Hillman, 2002). Two findings marginally related included: (a) although there is communication between the divisions of student affairs and development, the relationship might still be too tentative to have an understanding of the other office's philosophy and mission at the institution (p. 86), and (b) a feeling of cooperation exists between the development offices and student affairs offices, but the actual working relationship appears ill defined (p. 82). According to Hillman (2002), future growth will depend on "more cohesiveness and mutual goals shared by development and student affairs” (p. 93).

To determine if development practices for raising money were different for divisions of student affairs and academic colleges, Schoenecke (2005) utilized qualitative research to identify the practices and principles employed by divisions of student affairs. Three institutions recognized as leaders in student affairs fundraising by the National Association of College Student Personnel Administrators were selected. Each institution had a full-time development officer employed to raise money specifically for the division of student affairs. The study examined what factors were associated with best practices in fundraising, what institutional development practices influenced fundraising in student affairs, what kinds of projects were supported by student affairs fundraising, and what 
types of programs and strategies could be implemented to increase opportunities for fundraising (Schoenecke, 2005).

The results of this study found that what worked at one institution did not necessarily work at another institution. However, results indicated that each of the institutions used similar methods of communication and each director of development was an experienced fundraiser and used voluntary advisory boards for support and guidance (Schoenecke, 2005). Another prevalent theme to take notice of was the study's finding that the "culture within the student affairs division impacted the development efforts" (Schoenecke, 2005, p. 162). As for future research, Schoenecke (2005) recommended additional objective research compiling the most creative strategies and practices in divisions of student affairs. Since his study only included three large research institutions, myriad opportunities exist to conduct similar studies at institutions of different types and sizes.

With little known about the characteristics that affect a student affairs division's ability to raise funds, Rovig (2008) examined this relationship using a survey instrument. The characteristics used to define development support included the placement of the development officer, level of involvement in fundraising of the senior student affairs officer, level of support from the president of the institution, type of institution, and size of the institution's endowment. Senior student affairs officers of accredited, degreegranting institutions included in the 2008 Higher Education Directory were invited to participate. The researcher garnered a low $10 \%$ response rate, which should be considered as a limitation of the study. 
Relevant results included support for divisions of student affairs to work collaboratively with the development office to: (a) ensure inclusion in institutional fundraising campaigns and (b) employ at least a part-time development officer dedicated to fundraising (reporting either to student affairs or institutional advancement). Furthermore, the results support the need for senior student affairs officers to actively involve other student affairs staff in development efforts for the division. Rovig (2008) contends that creating a culture of awareness of fundraising is critical for success. Implications for future research are recommended to build upon this study including not only characteristics that affect funds raised, but a model that may accurately predict which characteristics are most influential.

Building upon the literature available to student affairs leaders and practitioners, Crowe (2011) developed a survey using an adaptation of previous instruments (Fygetakis, 1992; Hillman, 2002) to focus on development and fundraising practices within divisions of student affairs. This study surveyed 261 senior student affairs officers at 4-year, public institutions with enrollment greater than 5,000 students. With a $42.5 \%$ response rate, the findings of this study uncovered the "current state of student affairs practitioners' understanding and utilization of successful, systematic development and fundraising practices, including the role department heads play in these efforts” (p. 41).

Results indicated a continued emphasis on a growing interest and role in fundraising by divisions of student affairs. However, the researcher notes that even with increased participation and growing interest, the findings indicated a "lack of understanding on campuses of the role and potential student affairs administrators have in the success of an institution's overall development and fundraising efforts” (Crowe, 
2011, p. 95). Surprisingly, Crowe (2011) reports that "little has been done to dig deeper to identify those departments within student affairs divisions that have the most direct contact with students who, in turn, have the potential to become the most loyal of alumni” (p. 96). Therefore, a strong recommendation for planning and coordination should engage current students, department heads, and alumni at a higher level in the process. The results of this study provided much-needed strategies for improvement:

1. Clearer intra-institutional communication about the purposes and functions of student affairs divisions;

2. Inclusion of other administrators and personnel in development and fundraising efforts;

3. Support of continued training and educational preparation for this work;

4. The need for greater coordination of fundraising strategies; and

5. Greater attention to the needs of small institutions.

An advantage of this study was the size of the sample; with 111 institutions responding, the results provided a snapshot of activities and fundraising practices from 2002-2007 at 4-year, public institutions with enrollment greater than 5,000 students. An opportunity to expand the quantitative study would be to conduct a similar study using qualitative methods to deepen the profession's understanding of strategies used. My study took advantage of this opportunity and conducted a qualitative study with 4-year, public institutions with enrollment greater than 10,000 students in the Midwest.

\section{Summary}

This review provided a foundation for understanding the scope of what has been written about student affairs involvement in educational fundraising organized around three themes: rationale for involvement, process for inclusion and collaboration, and role 
expansion. With each empirical study conducted, the results make available another perspective from which to understand the phenomenon better; however, the literature available continues to be incomplete.

The purpose of this study was to extend specifically the dissertation work of Kroll (1991) and Crowe (2012) as it sought to examine: (a) perceptions about the role of student affairs in development efforts, (b) the extent to which divisions of student affairs are involved in fundraising activities and how participation has evolved, (c) how involvement has impacted traditional responsibilities and/or the organizational structure of divisions, and (d) implications on the future of fundraising in student affairs. Differences do exist between previous studies and this one. A key difference from the research conducted by Kroll (1991) was this study's focus on large 4-year public universities in the Midwest rather than private institutions located in the Midwest. This study did, however, use qualitative measures similar to Kroll (1991) and examined the phenomenon from the perspective of senior student affairs officers and senior advancement officers. The most comprehensive quantitative research on the topic to date is the study conducted by Crowe (2012). Through the use of a survey, senior student affairs officers were asked to comment on: (a) preparation for development and fundraising, (b) student affairs priorities and monies raised, (c) development and fundraising practices, and (d) relationships with institutional advancement staff. The chance to extend this line of inquiry using qualitative methods provided the opportunity to construct new meaning based on additional probing.

With limited research on the impact of student affairs involvement in educational fundraising, the need to study the effect of participation on meeting the desired financial 
goals of the division and the institution continues to be important. As institutions become increasingly more complex, the results also provide those who work in student affairs a broader understanding of fundraising practices and the effects of involvement on the traditional responsibilities and organizational structure of divisions of students affairs. This foundation will provide staff in both student affairs and advancement with recommended strategies on how to prepare for and work together to create a more systematic and coordinated effort for achieving the institution's fundraising goals. Finally, the results of this research provide divisional leadership with an understanding of the potential barriers that exist. 


\section{CHAPTER III}

\section{METHODOLOGY AND PROCEDURES}

This chapter describes the methodological procedures that were used to conduct this study, starting with reiterating the problem affecting student affairs organizations and the significance of continued research in the area of educational fundraising. The purpose of the study, the research questions and procedures follow. Special emphasis was paid to how participants were selected and what techniques were used to collect and analyze the data. Finally, ethical issues are discussed including the measures taken by the researcher to ensure the authenticity and trustworthiness of the data and results.

\section{Statement of the Problem}

There has been an increase in the number of student affairs divisions engaging in fundraising initiatives and development efforts (Crowe, 2011; Fygetakis \& Dalton, 1993; Gold et al., 1993; Gordon et al., 1993; Hillman, 2002; Hodson, 2010; Jackson, 2000; Kroll, 1991; Miller, 2010; Morgan \& Policello, 2010; NASPA, 1997; Penney \& Rose, 2001; Rissmeyer, 2010; Romano et al., 2010; Rovig, 2008; Schoenecke, 2005; Schuh, 2003; Shay, 1993; Sonn, 2008; Terrell \& Gold, 1993). Involvement requires that staff in student affairs, primarily the senior student affairs officer, clearly articulate the impact of student affairs programs and services to students on the quality of the lived experience on campus and their contributions to persistence. Even though student affairs divisions have not historically been included in traditional fundraising efforts at colleges and 
universities, they have been intimately involved in the quality of the student experience since the beginning of higher education. The evolution of student affairs as a profession has led to increased responsibilities in a variety of areas. Furthermore, the level of service with which practitioners are expected to deliver programs, activities, and services is higher than anything the profession has experienced previously.

With higher accountability standards, divisions of student affairs must find alternative ways to balance the rising costs of college with the survival and growth of the programs and services expected. This study examined one such alternative, fundraising in student affairs, to further develop the profession's understanding of engaging in or growing development efforts. The problem of practice was that adding fundraising as a responsibility expanded the role of the division of student affairs and their relationship with institutional advancement. The results of this study provide information on how a group of institutions were preparing for, sustaining, or growing their development programs in student affairs and the effects of participation on both the division of student affairs and advancement, as well as the university.

\section{Purpose}

This study examined the role of fundraising in divisions of student affairs at seven 4-year public universities in the Midwest.

\section{Research Questions}

The study was guided by the following questions:

1. What role, if any, do senior advancement officers and senior student affairs officers believe divisions of student affairs can/should play in fundraising?

2. To what extent is the division of student affairs involved in fundraising activities at the institution (senior student affairs officers and division staff)? How has participation in development efforts evolved? 
3. How do senior student affairs and advancement officers describe the impact of student affairs fundraising on traditional responsibilities and/or organizational structures?

4. What are the implications on the future of fundraising for divisions of student affairs?

\section{Research Procedures}

To gain a meaningful understanding of how divisions of student affairs could position themselves for sustainable change through fundraising at 4-year public institutions in the Midwest, a qualitative study was conducted from the perspective of senior student affairs officers and senior advancement officers. The study utilized an interpretivist approach that describes knowledge as emergent, socially constructed, and interactive (Guido, Chavez, \& Lincoln, 2010). This study joined three other qualitative studies examining this topic (Kroll, 1991; Schoenecke, 2005; Sonn, 2008). As illustrated in the review of the literature, the other empirical studies were conducted using a positivist or post-positivist paradigm (Crowe, 2011; Fygetakis \& Dalton, 1993; Gold et al., 1993; Gordon et al., 1993; Hillman, 2002; Hodson, 2010; Jackson, 2000; NASPA, 1997; Penney \& Rose, 2001; Rissmeyer, 2010; Romano et al., 2010; Rovig, 2008; Schoenecke, 2005; Schuh, 2003; Shay, 1993; Terrell \& Gold, 1993). Since there are multiple interpretations of reality, this study employed a semi-structured interview format to provide a forum for participants to express in their own words their thoughts, opinions, and experiences in a comfortable and confidential environment chosen by the participant. A list of carefully considered questions aimed at answering the study's research questions were used as a guide, with flexibility for follow-up questions and new questions to be asked based on participant responses (see Appendix D). The interviews were scheduled 
for 90 minutes and, with permission of participants, audio-recorded. Transcripts of the recordings were compiled and coded. All transcripts were analyzed for similarities and differences according to the themes that emerged.

This interpretivist approach included not only the voices of the participants, but it also situated the researcher's voice as significant to the process. Cohen and Crabtree (2006) assert that this type of subjectivist epistemology assumes that we cannot separate ourselves from what we know. The two are inexplicably linked.

\section{Positionality}

The interest in this topic came from a professional opportunity I had in a new position in 2008. With changes in leadership, the director of development in student affairs had been reassigned 2 years earlier by institutional advancement to meet the needs of higher priorities within the division. As a result, the foundation created by four former directors would begin to dissolve if attention was not paid to building on what had been established. It is my opinion that two issues were at play. First, the creation of the first director position came out of a need to increase funding to programs such as leadership for students in preparation for a capital fundraising campaign. This area of need was appealing to both donors and corporations alike. Unfortunately, an infrastructure had not been created when the first director was hired, making it difficult to raise significant dollars in the beginning.

When resources became scarce and priorities shifted, the need to reorganize became apparent, which illuminated the second issue. When comparing the role of the director of development for student affairs to his or her counterparts in academic colleges, it was obvious that the dollars raised and the pool of prospects were significantly smaller, 
providing just cause to eliminate the position. In the years that followed, state appropriations continued to decrease and expectations of students and their parents continued to increase. The need to build a proper infrastructure was necessary to provide rationale for the need to rehire a director for student affairs fundraising in the future.

A position was created in 2008 with partial responsibility for building an infrastructure, and I was appointed into that role. As a student affairs practitioner for the majority of my career at this institution, I was acutely aware of the needs and goals of the division. However, the division of student affairs would need to better understand the needs and priorities of the division of institutional advancement and how student affairs could support the goals of fundraising for the institution. I was embraced by the division of institutional advancement and invited to participate in unit meetings and discussions. In addition to active involvement in institutional advancement, my participation at conferences for student affairs development officers and the limited empirical data available motivated me to conduct this study.

The role non-academic units, like divisions of student affairs, play in fundraising are unique compared to their academic counterparts. They are confronted with different challenges, including the relationship they share with institutional advancement, institutional history and culture, and student and alumni prospecting. With the expectation that divisions like student affairs would need to do more with less, it became increasingly important to learn more from senior student affairs and advancement officers in order to make recommendations that would prove useful to both professions. 


\section{Participants}

The focus of this study was on institutions that were similar in type, size, region, and mission. The states selected for this study included those assigned to the Midwest regional membership of the National Association of Student Personnel Administrators (NASPA) and the Council for the Advancement and Support of Education (CASE). The states in these regions included Illinois, Indiana, Michigan, Minnesota, Ohio, and Wisconsin. Since the state of Iowa and the Canadian province of Ontario were not included in both regional memberships, they were not included. NASPA and CASE were selected because they were the largest professional associations for student personnel administrators (student affairs) and advancement officers in higher education. The institutions chosen were selected because they had not been selected for any previous qualitative studies on this topic.

Using Carnegie Classifications, large 4-year primarily residential campuses were selected in each of the six states. This classification included fall enrollment data showing full-time equivalent enrollment of at least 10,000 degree-seeking students at bachelor's degree granting institutions. In addition, 25\%-49\% of degree-seeking undergraduates lived on campus in institutionally-owned, -controlled, or -affiliated housing and at least 50\% attended full time. To reduce bias, only one of the 22 institutions that met these criteria was not included because it was my professional institution.

The sample of 21 institutions was narrowed again using criteria about the composition (arrangement of departments) of the division of student affairs at each institution in order to select divisions of student affairs that were similar in type, size, and mission. Divisions of student affairs with responsibility for enrollment management 
and/or athletics were eliminated from the sample because fundraising efforts are uniquely different when departments like financial aid and athletics are included because they have often had a long history fundraising for scholarships and support programs. From the list of 21 institutions, a website review was conducted to determine which divisions of student affairs included enrollment management, athletics, or both. An additional 12 institutions were excluded because student affairs at these universities included enrollment management and/or athletics narrowing the sample to nine institutions across four states.

The participants for this study included the senior student affairs officer and the senior advancement officer at each of the institutions who chose to participate. Participants were recruited using two recruitment letters. The first letter was sent by a senior student affairs officer not included in the study’s sample to inform his or her counterparts about the significance of the study and its results (see Appendix A). The second recruitment letter, in the form of an e-mail, was sent from me (see Appendix B). For those who responded, informed consent was obtained in writing prior to the start of the interview and verbally during the interview (see Appendix C). Of the nine sets of vice presidents invited to participate, seven pairs (SSAO and SAO) confirmed participation and were, in turn, interviewed.

\section{Qualitative Techniques}

The interviews provided for a conversation between me and the participant in a relaxed and confidential location of the participant's choosing. deMarrais (2004) posits that this conversation can be defined as an interview when it focuses on questions related to a research study. By construction, the interview questions were created in a semistructured format providing the opportunity for more flexibility to respond with follow- up 
questions (see Appendix D). Assuming that individual respondents "define the world in unique ways,” Merriam (2009) states that “semi-structured interviews have an advantage over a structured format because they adhere less rigidly to predetermined questions” (p. 90). This structure is a common naturalistic approach when rooted in a interpretivist paradigm because it provides an opportunity to make sense of the human experience through the participant's responses in order to both understand and derive shared meaning.

Patton (1990, 2002) developed a question typology as a guide to developing interview questions, which includes: (a) experience and behavior, (b) opinion and values, (c) feeling, (d) knowledge, (e) sensory, and (f) background /demographic questions. These six types of questions were used as the framework for developing the interview guide for this study. A deliberative effort was also made to avoid multiple questions within a question, closed questions, leading questions, dichotomous questions, vague and complex questions, and technical language (Maykut \& Morehouse, 1994; Merriam, 2009; Patton 1990, 2002). As a result, bias and assumptions were minimized by providing a neutral and non-threatening environment for the participants to answer questions. Probes were used when warranted throughout the interviews. According to Merriam (2009), probes can come "in the form of asking for more details, for clarification, or for examples” (p. 101). Likewise, Patton (1990) defines a probe as an interview tool to go deeper into interview responses and can include detail-oriented probes, elaboration probes, and clarification probes. This tool strengthened the use of a semi-structured interview format for this study. 
In addition to interviews, documents and artifacts were collected throughout the study. According to Wolff (2004), “documents represent an independent level of data” (p. 288). More specifically, documents were used as evidence or indications of factual content or decision-making processes (Wolff, 2004). For example, documents collected for this study included organizational charts, strategic planning documents, divisional materials (print and electronic), and fundraising publications (print and electronic). Each of the documents collected for this study provided demonstration, corroboration, or disagreement with how participants responded. Documents can also be researchergenerated (Merriam, 2002). Therefore, the use of field notes and memoranda were collected alongside the documents and artifacts available in the research setting.

\section{Data Analysis}

The data analysis for this study was iterative and included two interviews from seven institutions. Each interview was analyzed before the next interview was conducted, allowing for the revision of questions and the organization and categorization of data. This type of analysis is reinforced by Caudle (2004), because it provided the ability to "move between, explore, and enhance the design, design analysis, and findings as the study proceeds” (p. 417).

Each respondent was interviewed individually. Seven interviews were conducted in person, six face-to-face with video technology, and one by phone at the request of the participant. The interviews were audio-recorded with participant permission. Patton (1990, 2002) and Merriam (1998) recommend audio-taping the interviews to get an accurate record of the participant's responses and experiences. A transcript of the audio file was created by GMR Transcription, Inc. within 5 days of each interview. Each 
transcript was coded using three types of coding to systematically organize the data around the phenomenon in question—open, axial, and selective. According to Charmaz and Belgrave (2012), coding “is the pivotal first step that moves the researcher from description to conceptualizing that description” (p. 355). Open coding refers to naming and categorizing the phenomenon by breaking down the data into discrete parts (Strauss \& Corbin, 1998). Data were broadly labeled and then categorized as concepts based on their discrete characteristics. Similarly, Charmaz and Belgrave (2012) assert that initial or open coding involves "constructing short labels that describe, dissect, and distill data while preserving their essential properties” (p. 356).

Once categorized, axial coding was used to confirm that concepts and categories were accurately represented, and the data were then compared to determine if relationships existed between them (Strauss \& Corbin, 1998). As a result, sub-categories emerged. This level of coding involved both inductive and deductive reasoning. Strauss and Corbin (1998) describe this in terms of properties that include dimensions for further analysis across a continuum. An interpretivist paradigm encourages that the researcher "be reflexive about the constructions—including preconceptions and assumptions—-that inform the inquiry” (Charmaz \& Belgrave, 2012, p. 355).

In addition to looking for similarities between categories, identifying negative cases was also useful. Negative cases were important to analyze because they addressed objectivity and validity concerns (Strauss \& Corbin, 1998). Furthermore, negative case analysis looks at whether a reasonable number of cases fit the appropriate categories (Bitsch, 2005; Lincoln \& Guba, 1985). In order to refine categories, rules of inclusion 
were written. The purpose of writing rules for inclusion is "to distill the meaning carried ... and write a rule that will serve as the basis for including (or excluding) subsequent data” (Maykut \& Morehouse, 1994, p. 139). Ultimately, the goal was to convey the meaning that was contained in the data under each category. Finally, selective coding involved the integration of the categories to create a core category as the context for understanding the results (Strauss \& Corbin, 1998).

The analysis stage also took into account field notes and memoranda (memos) as part of open, axial, and selective coding. The notes and memos were used to create an inventory of all the information collected in order to make sense of the data when coding. According to Merriam (2009), making sense of it all involves “consolidating, reducing, and interpreting what people have said and what the researcher has seen and read” (p. 176). Charmaz and Belgrave (2012) add to the importance of memo writing by asserting that analyzing data and codes in memos early in the research process will alleviate being overwhelmed by "stacks of undigested data ... and provide the foundation for building whole sections of papers and chapters” (pp. 357-358).

Finally, documents and artifacts were collected throughout the study. Each document or artifact was analyzed using the following framework: (a) title of document, (b) date of document retrieval, (c) context of the document, (d) date (or approximate) of creation, (e) author of the document (analysis included if bias was present on the part of the author), (f) authenticity of document, (g) representativeness of the document (has there been selectivity in what was recorded?), (h) intended audience, (i) content of the document, (j) relationship to other information/data collected, and (k) significance of the document to this study. Using this framework provided for a systematic method for 
analyzing each document and artifact individually and collectively. This type of technique made available the opportunity to triangulate the data between interview transcripts, documents, and field notes/memoranda. As indicated by Bowen (2009), "examining information collected through different methods, the researcher can corroborate findings across data sets and thus reduce the impact of potential biases that can exist in a single study” (p. 28).

\section{Ethical Issues}

Resources were consulted providing a range of methods used in qualitative research to better inform the methodology and process for conducting this study (Caudle, 2004; Charmaz \& Belgrave, 2012; Creswell, 2008; Denzin \& Lincoln, 1994; Ewell, 2008; Flick, 2004a, 2004b; Lincoln \& Guba, 2004; Maykut \& Morehouse, 1994; Merriam, 2009; Richards \& Morse, 2007; Strauss \& Corbin, 1998; Vogt, 2006; Wolff, 2004). I disclosed to all of the participants that I work in the field of student affairs and development, but specifically revealed that I am not responsible for major gift fundraising for student affairs at my institution.

Each participant was provided the purpose of the study and research questions in writing and orally at the beginning of each interview. Likewise, an informed consent form was provided and explained prior to the start of each interview, including specific references about the right to privacy and protection from harm (see Appendix C). Additionally, the right to refuse to answer any of the questions posed was explained to each participant, and that pseudonyms would be used to safeguard his or her identity and the identity of his or her institution. I also explained how the data would be stored and accessed as outlined in the Institutional Review Board protocol. The questions posed to 
the participant were asked to draw out the participant's opinions and experiences as they related to the phenomenon being studied rather than eliciting speculation or forecasting. Finally, participants were also informed in the recruitment letter (see Appendix B), informed consent (see Appendix C), and in-person or by phone that I was working with an experienced principal investigator (dissertation committee chair) who would have access to the data, analysis, and results. Prior to starting the audio recorder, the participants were asked if they had questions and if they were comfortable moving forward. All 14 participants were comfortable continuing with the interview.

As indicated, many steps were taken to minimize ethical concerns, including researcher training and preparation, applicable disclosures of role and subsequent biases of the researcher, specific purposes of the study, safeguards in place for privacy, confidentiality, and harm, and the purposeful framing of interview questions.

\section{Trustworthiness and Authenticity}

Since the nature of reality asserts there is no single truth, Lincoln and Guba (1994) argue that qualitative inquiry includes multiple realities that are socially constructed. Descriptions of the phenomenon were the nexus for comparison to other contexts for this study. This was necessary because "all human behavior is time and context bound" (Lincoln \& Guba, 1994, p. 652). Furthermore, Holliday (2002) asserts that thick descriptions go deeper to analyze the cultural meaning of an action. Likewise, Denzin (1994) notes that a thick description "gives the context of an experience, states the intentions and meanings that organized the experience, and reveals the experience as a process (p. 505). Since this is the case, close attention was paid to the credibility, transferability, dependability, and confirmability of the results. These four were 
considered the criteria for trustworthiness and authenticity and were used as the framework for the collection and analysis of data (Lincoln \& Guba, 1994).

For ensuring credibility, Lincoln and Guba (1994) offer prolonged engagement, persistent observation, triangulation, peer debriefing, and negative case analysis as techniques. Each of the participants was interviewed for 90 or more minutes, which provided the researcher enough time to ask a series of approximately 40 questions. Additional follow-up questions were woven in throughout the interviews. After each interview, the audio-recording was transcribed by GMR Transcription, Inc. and a cursory analysis of topics, ideas, arguments, and experiences were categorized. Upon the completion of each additional interview, the information was reviewed again for similarities and variations, which allowed for persistent observation from start-to-finish. Of particular importance was the intentional search for "negative instances relating to developing insights and adjusting the latter continuously” which complemented persistent observation nicely (Lincoln \& Guba, 1994, p. 653). In addition to the interview, field notes were taken during each interview and throughout the analysis of the data. Furthermore, memos were used as a tool to describe in detail the researcher's intentions, expectations, and reactions. These notes, memos, and detailed transcriptions provided for triangulation of data. Triangulation of data uses multiple sources of data to cross-check the data collected (Merriam, 2009). Flick (2004b) describes the triangulation of data as “combining data drawn from different sources and at different times, in different places or from different people” (p. 178).

It is important to reiterate that all human behavior is time and context bound, so the data used for triangulation was from a fixed point in time and should not be used to 
generalize a population or finding. Florio-Ruane (1991) argues that published descriptions are static and frozen in the ethnographic present. Although important techniques when conducting qualitative research, peer debriefing and member checks were not utilized in this study. However, if I was unclear with any answer provided, the answer was read back to the participant for confirmation or clarification.

With respect to authenticity, evidence was obtained by collecting documents prior to the interviews, audio-taping each interview, transcribing the entire interview, taking field notes during the interview, and developing memos throughout the analysis. Collecting documents prior to, during, and after each interview provided background to "help explain the attitudes and behavior of those in the group under scrutiny, as well as to verify particular details that participants have supplied” (Shenton, 2004, p. 66). The context and setting of each interview was described in detail and added to the field notes for further analysis as needed. The types of questions asked were purposefully created to elicit descriptive answers from participants. This level of detail was critical in analyzing the degree of fit between and across the data.

The final two criteria to measure the rigor of a qualitative study are dependability and confirmability (Lincoln \& Guba, 1994). The establishment of an audit trail is recommended. According to Merriam (2009), an audit trail “describes in detail how data were collected, how categories were derived, and how decisions were made throughout the inquiry” (p. 223). A series of memos were used throughout the collection and analysis of the data. The memos were used to record reflections, issues, emerging ideas, and questions regarding both the process of collecting and analyzing the data. 


\section{Summary}

To provide an understanding of the extent to which divisions of student affairs were involved in fundraising practices, the perspectives of the senior student affairs officer and the senior advancement officer were of central importance. This study included two interviews from seven 4-year public institutions across four states in the Midwest. The purpose of this study was to interview the senior student affairs officer and the senior advancement officer to better understand who was involved in fundraising efforts and to what extent, how participation had evolved over time, and the effects of involvement by staff on traditional responsibilities and organizational structures. Each participant was recruited by e-mail, and the interview took place in a comfortable and convenient location of the participant's choosing. A semi-structured interview format was used to provide a forum for participants to express in their own words their thoughts, opinions, and experiences. Each interview was audio-taped with the permission of the participant.

The process for data analysis was iterative. Each interview was transcribed and loosely coded before the next to identify emerging or divergent themes. Open, axial, and selective coding were used as analysis techniques. Additionally, the use of field notes, memos, and documents were used throughout the analysis stage in order to consolidate, reduce, and interpret meaning. Each document was analyzed using a framework, providing a systematic method for examination.

Steps were taken to minimize ethical concerns including researcher training and preparation, applicable disclosures of role and subsequent biases of the researcher, specific purposes of the study, safeguards in place for privacy, confidentiality, and harm, 
and purposeful framing of interview questions. Intentional techniques were also used to increase the trustworthiness and authenticity of the research design which included the use of Lincoln and Guba’s (1994) four criteria as a framework. Techniques included in this study were prolonged engagement, triangulation, and negative case analysis.

Furthermore, attention was given to transferability, dependability, and confirmability through evidence from multiple sources and the establishment of an audit trail using memos. 


\section{CHAPTER IV}

\section{STUDY RESULTS}

\section{Introduction}

Through the perspectives of senior student affairs and senior advancement officers, the purpose of this study was to examine the extent to which divisions of student affairs were involved in fundraising activities at seven 4-year public universities across four Midwestern states. More specifically, the study’s research questions were developed to better understand whether the participants believed divisions should play a role in fundraising at college and universities, to what extent they currently play a role, and what impact that involvement had on the division's traditional responsibilities and structure. Data were collected using a semi-structured interview protocol. The research design provided a forum for each of the participants to express in their own words their thoughts, opinions, and experiences in a comfortable and confidential environment. Seven of the interviews were conducted in-person, six were conducted face-to-face with the use of assistive technology (e.g., Skype, ooVoo, and Movi), and one interview was conducted via phone conference. Each individual interview was audio recorded with permission and a transcript was generated. Each transcript was coded to systematically organize the data around the phenomenon in question. In addition to interviews, documents and artifacts were collected from each of the participating institutions. The documents and artifacts were used as evidence for and indications of current processes and structures. A 
consistent framework was used to analyze the information. Furthermore, the use of field notes and memoranda were generated alongside the document and artifact review.

This chapter will provide a profile of each of the seven institutions represented by the participants. Included in each profile will be a short summary describing the university, division of institutional advancement, and division of student affairs. The retention, graduation, and alumni giving rates cited were obtained from the 2012 U.S. News and World Report on College Rankings. Following participant profiles are the study's results organized by research question.

\section{Participant Profiles}

To protect the confidentiality of the institution and those interviewed, pseudonymous were used for university and participant names. Furthermore, facts and figures about the institutions included were slightly altered to safeguard privacy.

\section{Sycamore State University}

Sycamore State University opened its doors in 1919 to meet the state's need for more teachers. It is a state-assisted residential university in a midsize Midwestern city. With more than 30 residence halls and 2 apartment complexes, approximately 7,500 students live in on-campus housing (42\%). Sycamore State has grown to include 180 bachelor, associate, and preprofessional degree programs across eight academic colleges, with 122 master's, doctoral, and specialist programs. It is home to more than 21,000 students who move throughout 100 buildings spanning more than 1,100 acres. Sycamore State University has a 6 -year graduation rate of $57 \%$ and a $79 \%$ retention rate from firstto second-year. The university's leadership includes a president who is in his ninth year serving the university, the board of the trustees, and the president's cabinet, which 
consists of seven vice presidents and the director of intercollegiate athletics. For the purposes of this study, it is important to note that both the vice president for institutional advancement and student affairs report directly to the president and serve as members of the cabinet.

With more than 30 years’ experience in fundraising, the vice president for university advancement, Samuel Lynch, has led the division for nearly 3 years. With nearly 160,000 alumni, university advancement seeks support to help provide Sycamore State University students with a distinctive education, challenging programs, and lifechanging opportunities that prepare them to succeed and make a difference in communities across the nation and around the world. With a traditional model for advancement, departments within the division include the alumni association and associated alumni relations programs and services, development, advancement services, and management of the alumni center. Sycamore State has an average alumni giving rate of $12 \%$.

Since 2005, Camilla Foster has served as Sycamore State University’s vice president for student affairs and dean of students. She leads a staff devoted to helping students embrace their educational opportunities through student-centered programs and services. These programs and services create a positive campus environment where students can thrive. The organization encompasses the office of student life (community services, Greek life, student organizations, leadership development, student legal services, social media team, student government association, and summer programs), multicultural center, disability concerns, student center and programs, housing and residential life, counseling and health services, public safety, student rights and community standards, career center, and deputy coordination of Title IX. 


\section{University of Mulberry}

Established in 1909 as an institution specializing in teacher training and education, the University of Mulberry started as a Normal school. Self-described as an in-town residential campus in a park-like setting, more than 20,000 students are enrolled in more than 200 undergraduate majors and programs across seven academic colleges.

Additionally, 2,600 students are enrolled in 87 doctoral, master's, specialist, and certificate programs. With 15 residence halls and 30 houses, 6,400 students reside in oncampus housing (44\%). With a commitment to prepare Mulberry students with an education and skills for lifelong learning that give them a competitive edge in the workplace, the University is led by a president in his third year, a board of trustees, and the president's cabinet. The cabinet includes five vice presidents (finance and administration, student affairs, advancement, executive vice president and provost and research and creative activity) in addition to other senior officers. For the purposes of this study, it is important to note that both the vice president for institutional advancement and student affairs report directly to the president and serve as members of the cabinet. The institution has a $74 \%$ retention rate from first- to second-year and a 6-year graduation rate of $58 \%$.

The division of institutional advancement's framework is designed to foster alumni success, champion a culture of philanthropy, and help to achieve Mulberry’s vision of becoming a premier learning community. Led by Nolan Callahan, who is in his first year at the University of Mulberry, the division currently includes alumni affairs, advancement services, annual giving, corporate and foundation relations, donor relations and stewardship, development, gift processing, planned giving, foundation, and 
management of the alumni center. Although in his first year at the University of Mulberry, Nolan is a seasoned vice president, having served two other institutions as vice president for advancement. The average alumni giving rate at Mulberry is $7 \%$.

A veteran student affairs administrator, Patricia Olsen, has served the University for more than 35 years. Serving as the senior student affairs officer since 2006, Patricia leads a staff committed to supporting and challenging students through a variety of new experiences designed to enhance connections between classroom learning and out-of-theclassroom opportunities. Departments within the division include campus activities, center for leadership, counseling center, dean of students office, disability services, multicultural affairs, new student orientation, recreation and wellness, residence life, student health service, student legal services, student media, and TRIO Programs.

\section{Poplar State University}

The main campus of Poplar State University spans more than 1,300 acres, enrolling more than 24,000 students in more than 200 areas of study, including 81 undergraduate degrees and 31 graduate degrees. Chartered by the state’s legislature, Poplar State University was established in 1959 and is one of the largest 4-year public universities in its state. In addition to the main campus, Poplar State also has two branch campuses and offers classes at two regional locations. With more than 5,800 beds on campus, 83\% of first-year students live on campus. The University recorded an 83\% retention rate from first-to-second year in 2012 and ranks in the top five in the state for their 6-year graduation rate of 62\%. The University’s president started her appointment in 2006 and leads Poplar State in collaboration with the board of trustees and the officers of the university, including the vice presidents for inclusion and equity, finance and 
administration, academic and student affairs, development, university relations, and the executive associate to the president (secretary, board of trustees), and university counsel. As indicated here, the vice president for development reports directly to the president, but the senior student affairs officer does not, the SSAO reports to the vice president for academic and student affairs.

Appointed vice president for university advancement in 2012, Gillian Snyder, served as assistant vice president for development at Poplar State for 12 years. Poplar State University prides itself on being one of the most efficient public universities in the state, which is made possible by efficient cost containment and growth in private giving. With more than 85,000 alumni and $84 \%$ of recent graduates working in the state, Poplar State receives the least amount of per student and per degree funding from the state. With the goal of showcasing how an investment in the University impacts students, the region, and the state, the division includes a host of units, including campaigns and special giving, development, foundation giving, scholarships and fellowships, planned giving, community giving, development services, annual giving, alumni relations, and the foundation. The alumni giving rate for Poplar State University is 6\%.

Connecting students with opportunities to be enlightened, engaged, responsible lifelong learners, and productive global citizens is the mission of the division of student affairs and is led by vice president for student affairs, Tom Farraday. Tom's tenure as the senior student affairs officer is nearing 30 years. Departments included in the division are campus health, campus recreation, career center, children’s center, dean of students office, housing and residence life, LGBT resource center, office of multicultural affairs, office of student life, university counseling center, and the women's center. 


\section{Birch University}

Birch University is considered the flagship university of its state and was founded in 1821. The university includes branch campuses throughout the state, but for the purposes of this study, only the main campus was included. In an effort to provide an ideal college experience, the staff and faculty nurture students with an exceptional support network and breadth of programs. With 2,000 acres of campus, the university describes its community as one that benefits from the urban qualities of a large city and the relaxed pace of a small town. Just over 42,000 students enroll in more than 330 degree programs for undergraduates and more than 190 master's, doctoral, and professional degrees. With more than 10 residence halls, all first-year students are required to live on campus, and a total of $38 \%$ of all students live in college-owned, operated, or affiliated housing. Birch University boasts an 89\% retention rate from first- to second-year and a 75\% 6-year graduation rate. The campus leader is the executive vice president under the supervision of the chancellor of the university system, which also has one board of trustees for all Birch campuses. There are six vice presidents on the main campus (diversity and inclusion, enrollment management, faculty and academic affairs, research, strategic initiatives, undergraduate education) and the dean of students who serves as the senior student affairs officer.

With one Foundation for the University System, support for maximizing support for Birch University includes providing fundraising services for campuses and units across the university. The University has close to 600,000 living alumni, of which nearly onehalf reside in the state. Each of the branch campuses has a development office. The main campus hired Levi Vasser in 2011 to serve as its vice president for development. As 
vice president for development, he reports to the President and CEO of the Foundation. Levi partners with deans and development officers to further the Foundation's mission of increasing private support for the university and helps foster collaboration with centralized advancement and fundraising programs on the main campus. A significant part of his role at the Foundation is to plan and implement the flagship’s upcoming capital campaign. The average alumni giving rate is $15 \%$ (the highest percentage of the institutions profiled).

With a mission of preparing students to succeed as productive citizens and leaders in a global society, the division of student affairs includes 11 departments: dean of students office, a career development center, disability services, LGBT student services, the health center, the office of alternative screening and intervention services, office of student ethics, student life and learning, student advocates, student legal services, veteran support services. With a seasoned leader at the helm, Jack Bainbridge, has spent his 35year career in higher education in a variety of positions in student affairs and general administration. As the senior student affairs officer, he is responsible for a division that actively provides student support services, removes barriers for students, and enriches students’ educational experiences.

\section{University of Alder}

Chartered in 1803, the University of Alder holds as its central purpose the intellectual and personal development of its students. In addition to the University of Alder's main campus, it also serves students through its multiple branch campuses. With a total enrollment of more 37,000 students, the main campus enrolls over 27,000 students, of which $79 \%$ are residents of the state. For the purposes of this study, only the 
main campus was included, which includes an $81 \%$ first- to second-year retention rate and a 6-year graduation rate of 64\%. Students have 282 undergraduate majors to choose from and more than 188 master's and 58 doctoral programs. U of A is led by the board of trustees and the president who has served in that capacity since 2004. Reporting to the president are the executive vice president and provost; vice presidents for finance and administration, student affairs, advancement; general counsel; director of intercollegiate athletics; executive director of communication and marketing; and director of government relations. As indicated here, both the vice president for institutional advancement and student affairs report directly to the president and serve as members of the cabinet.

The university strives to provide the nation’s best transformative learning experience and the Foundation is a proud partner of securing private giving to support the mission of Alder. With nearly 198,000 living alumni, Kevin Ryder serves as vice president for institutional advancement. Kevin, who has served in this role since 2011, has had a long history of serving in development roles in higher education and other nonprofit foundations. He is responsible for leading the university's capital campaigns and all aspects of institutional advancement. Units within the division include constituency development (gift officers), constituent relations for health affairs, corporate/foundation relations and international relations, gift planning and principal gifts, scholarships and special projects, alumni relations, advancement services (annual giving, donor relations, prospect research and management), advancement communication and marketing, and advancement operations. Alumni of the university give back at a rate of $7 \%$.

With a mission to prepare students to be responsible and contributing members of a diverse, global society by providing learning-centered environments, meaningful out- 
of-classroom opportunities, and professional support services, the division of student affairs is led by vice president Nolan Williams. Nolan has served in this role since 2012 and oversees eight departments, including the campus involvement center, campus recreation, career and leadership development center, community standards, counseling and psychological services, event services, office of the dean of students, and residential housing. Nolan is not new to Alder. Prior to becoming the senior student affairs officer, he served as the associate vice president and dean of students for 4 years.

\section{University of Osage}

University of Osage was the youngest of the institutions profiled. Opening its doors in 1956 as a second location of a much larger university founded in 1870, it met the increasing need to serve a population that did not have access to a convenientlylocated 4-year public university. For the purposes of this study, this institution was selected over the main campus because of the composition of departments within the division of student affairs. A self-described metropolitan University, Osage's campus is situated on more than 2600 acres. As an institution, they believe that education is more than classroom learning. Campus activities present students with an ever-changing spectrum of cultural, social, service, and recreational experiences designed to complement the academic program. With nearly 14,000 students, 3500 live on campus (30\%). Students can choose from 177 areas of undergraduate study and graduate degree programs are offered in 39 fields. The university boasts a 71\% first-to second-year retention rate and a 6 -year graduation rate of $52 \%$. The president of the campus has a vice president for each of the following divisions: academic affairs, administration, student affairs, and institutional advancement. In addition to the vice chancellors, 
organizational leadership includes general counsel, institutional compliance, budget, regional economic development, and athletics.

The division of institutional advancement supports the university's status as a premier metropolitan university and the Foundation is responsible for university-wide fundraising priorities. With more than 25 years' experience in higher education advancement, Phil Schroeder, joined the University of Osage in 2008. His areas of supervision include: university advancement and foundation operations, financial affairs and information systems, planned giving, alumni affairs, annual giving, university marketing and communications, prospect research, and major gifts. Although a young campus, $\mathrm{U}$ of $\mathrm{O}$ has more than 90,000 alumni who give back to the university at a rate of $5 \%$ (the lowest percentage of the institutions profiled).

A long-time advocate for students, Richard Wheaton joined Osage as vice president for student affairs in 1995. Staff members in the division are dedicated to supporting and challenging students to achieve their full potential. Through comprehensive co-curricular opportunities and access to services that enhance learning and achievement, their mission is realized through the division's centers for excellence in campus recreation, international programs, counseling services, disability support services, early childhood services, health services, leadership, university union, and university housing.

\section{Hawthorn University}

Hawthorn University includes three distinct campuses. For the purposes of this study, the flagship campus, which was founded in 1868, was included. Enrollment at Hawthorn University includes more than 32,000 undergraduate students registered in 
more than 150 undergraduate programs and an additional 9,000 graduate and professional students in more than 100 disciplines. Hawthorn has a first- to second-year retention rate of $94 \%$ and $84 \%$ of students graduate within 6 years. The campus spans more than 785 acres and includes 23 residence halls, where more than 8,000 students live on campus (37\%). With a mission to transform lives and serve society by educating, creating knowledge, and putting knowledge to work on a large scale with excellence, the university’s leadership includes one board of trustees for the system, a president in his fourth year, and a central administration of four vice presidents (academic affairs, institutional advancement, student affairs, and research), six associate vice presidents, assistant vice president for finance, campus legal counsel, executive directors of public safety and facilities and services, and the director of athletics.

With more than 400,000 alumni, institutional advancement builds lasting relationships with all constituents and generates diverse resources that facilitate Hawthorn's academic, research, economic development, and public service excellence. A veteran administrator having served at multiple universities, Carson Smith, became vice president for advancement in 2012. Areas of direct report include college/unit senior advancement officers, annual giving, foundation relations, principal gifts, recruitment and training, communications, scholarship initiatives, and public affairs. Alumni Relations is a separate 501(c)3. The institution has a $10 \%$ alumni giving rate.

Another veteran administrator, Anna Douglas joined Hawthorn as the senior student affairs officer in 2006. She served in leadership roles at three other universities before arriving at HU. The division's primary goal is to ensure that every student on campus has opportunities for personal and professional growth, with special emphasis on 
leadership, career development, health and wellness, diversity, and engagement with the larger community. Departments within the division include campus recreation, career center, counseling center, university union, leadership center, inclusion and intercultural relations, health center, minority student affairs, advancement, student conflict resolution, and university housing.

As quick reference, the institution name, year it was founded, student population size, percentage of alumni giving back, and participant names are captured in Table 1.

Table 1

Summary of Participants Profiled

\begin{tabular}{lccccc}
\hline $\begin{array}{l}\text { University } \\
\text { Name }\end{array}$ & Year & Enrollment & $\begin{array}{c}\text { Average } \\
\text { Alumni } \\
\text { Giving Rate }\end{array}$ & $\begin{array}{c}\text { Senior } \\
\text { Advancement } \\
\text { Officer (SAO) }\end{array}$ & $\begin{array}{c}\text { Senior Student } \\
\text { Affairs Officer } \\
\text { (SSAO) }\end{array}$ \\
\hline $\begin{array}{l}\text { Sycamore } \\
\text { State }\end{array}$ & 1919 & 21,000 & $12 \%$ & Samuel Lynch & Camilla Foster \\
$\begin{array}{l}\text { University of } \\
\text { Mulberry }\end{array}$ & 1909 & 23,000 & $7 \%$ & Nolan Callahan & Patricia Olsen \\
$\begin{array}{l}\text { Poplar State } \\
\text { University }\end{array}$ & 1959 & 24,000 & $6 \%$ & Gillian Snyder & Tom Farraday \\
$\begin{array}{l}\text { Birch } \\
\text { University }\end{array}$ & 1821 & 42,000 & $15 \%$ & Levi Vassar & Bainbridge \\
$\begin{array}{l}\text { University of } \\
\text { Alder }\end{array}$ & 1803 & 27,000 & $7 \%$ & Kevin Ryder & Williams \\
$\begin{array}{l}\text { University of } \\
\text { Osage }\end{array}$ & 1956 & 14,000 & $5 \%$ & Phil Schroeder & Wheaton \\
$\begin{array}{l}\text { Hawthorne } \\
\text { University }\end{array}$ & 1868 & 40,000 & $10 \%$ & Carson Smith & Anna Douglas \\
\hline
\end{tabular}




\section{Research Issue}

It is important to conduct ongoing research to examine the role divisions of student affairs play in fundraising activities because it provides practitioners insight into how organizations like student affairs can position themselves for sustainable change. Increased competition, growing expectations, and dwindling resources cause institutional leadership to consider collaborative strategies college-wide to increase private giving to the university. Using an interpretivist paradigm, the results of this study provided a greater understanding of the type of fundraising activities divisions of student affairs were participating in, how they had evolved, their impact on traditional responsibilities, and strategies for the future.

In an effort to explore perceptions, senior student affairs and senior advancement officers were specifically asked about their roles, division participation, organizational structure, methods for balancing relationships, communication strategies, barriers and opportunities, and implications for the future. Detailed information about participant experiences was gained through a semi-structured interview protocol and the analysis of documents provided by the participants and acquired by the researcher in person and on institutional websites. The following results of this study are organized by the themes that emerged and organized by research question. The senior officers interviewed hold the title of vice president; therefore, the two terms will be used interchangeably throughout the results.

\section{Research Question 1}

What role, if any, do senior advancement officers and senior student affairs officers believe divisions of student affairs can/should play in fundraising? 
Before learning about the extent to which divisions of student affairs were involved in fundraising initiatives on their campuses, participants were asked specifically about whether or not they should be involved at colleges and universities. Both senior officers of advancement and students affairs at each of the institutions interviewed believed strongly that there was a role for divisions to play in ongoing development initiatives. As to the role they should play, there was more agreement between senior student affairs officers and senior advancement officers than disagreement, specifically around the themes of (a) building a culture early, (b) family connections, (c) shaping the undergraduate experience, and (d) affinity group affiliation and alumni giving.

Building a culture early. When responding to the "should they be involved" question, both sets of vice presidents recognized and understood the role of student affairs on their campuses. Responses indicated that staff in divisions of student affairs can and should play a large role in advancing development efforts in three distinct ways. The first role for division staff was in building strong relationships with current students through the programs they develop and the services they provide. It was stated that staff members in divisions of student affairs hold unique positions because they have access to students on a daily and consistent basis. This level of contact could assist greatly in building a culture of philanthropy among students which participants believed divisions of student affairs could help develop. For example, SSAO Tom Farraday at Poplar State University commented,

[One role is clearly] being part of educating students about the lifelong relationship that they can have with their alma mater and helping to instill a sense of pride in a place ... helping them understand the importance of giving back, both in time and treasure, to help an institution continue to get better. 
Building a student culture of philanthropy required engaging students early; participants argued that it started as early as orientation. Vice President for University Advancement at Sycamore State, Samuel Lynch, pointed out that the culture of philanthropy "needs to be shared with prospective students and parents with every contact they have with the institution." As illustration, he shared the significance of the individual their welcome center was named after and why sharing that story with students and parents was powerful. It was also the first place students and parents visited when they arrived to campus. Another finding of this study focused on the role student organizations play in fundraising. Many, if not most, organizations on campus become involved in fundraising activities, but rarely do they consider the university a constituency for investment. It was discussed that there were myriad opportunities to both educate students about philanthropy and to also build loyalty to the institution through development initiatives with student organizations.

Family connections. Supplemental to student contact, responses also pointed to the important role student affairs staff members play in building relationships with parents and family members. In addition to providing assistance, information, and support, the division provided opportunities for parents and family members to engage in the life of their student and in the life of the university. Therefore, building a culture of philanthropy among parents and family members was the second recommended role for divisions to play by senior officers for advancement throughout the interviews. The documents revealed the significant role staff in student affairs play in the parent or family member's relationship with the institution. For example, it is not uncommon for parents and family members to receive information online and in hand about how to support their 
student (e.g., brochures, newsletters, Facebook pages, videos, calendars, and websites devoted to parents), ways to be involved and engaged in the university (e.g., parent and family orientations, associations, advisory councils, and celebration weekends), and ways to support the university financially. These types of communications provided divisions of student affairs with the opportunity to build a culture of philanthropy with parents and family members making it easier to ask them to invest in the programs and services their students were participating in. Developing a habit of giving while their student was enrolled was an important first step in cultivating them for future giving once their student graduates. SSAO Anna Douglas, Hawthorn University, observed that staff in student affairs were the natural partners to engage in fundraising with parents and family members because of their ongoing relationship with them.

"The experience.” The third role brought up by both advancement and student affairs officers was the importance of creating and delivering the "[insert mascot or school name] experience.” When talking with alumni, participants remarked that individuals reflected on what they considered to be the full college experience. Creating this experience was owed in large part to the work of staff in the division of student affairs. According to participants, the "[insert mascot or school name] experience” started at orientation and continued through graduation. Each student's experience was unique depending on what they chose to become engaged in and how they spent their time. For the institutions selected for this study, each had a residential requirement of $25 \%$ to $49 \%$ of degree-seeking undergraduates living on campus. This alone provided a traditional college format for introducing and supporting a unique "[insert mascot or school name] experience;” one that goes beyond the classroom. Carson Smith, vice 
president for institutional advancement, at Hawthorne University added, "My bias is that the extracurricular out-of-class opportunities are probably as important to most students' development in formative years as anything they will get in class, particularly in an undergraduate environment.” Carson’s own undergraduate experience as a student leader influenced his feelings on the role of the co-curriculum and its potential impact on alumni giving. It is well researched that the activities, programs, and services available, and the people who deliver them increase a student's satisfaction, confidence, and success at the university (Astin, 1985, 1999; Chickering \& Reisser, 1993; Kuh, 1993, 1995; Kuh et al., 2006; Pascarella \& Terenzini, 1991, 2005; Tinto, 1988, 1993). All of which lead to students persisting at the institution. SAO Nolan Callahan, University of Mulberry, explained that there was a need for student affairs staff to keep on doing what they were doing, "We can talk about prospect lists and cultivation and all this stuff, but the reality is if there is student success here, then after here, we have a chance of raising big money.” Noah's argument points out that divisions of student affairs are already highly involved in development work, but little connection is sometimes made to the influence of their contributions to money raised.

Affinity group affiliation and alumni giving. Two additional areas of congruence between the vice presidents interviewed were the opportunities to leverage affinity group affiliation and increasing alumni participation. It was agreed upon that divisions of student affairs should be involved in fundraising because of a shift in affiliation among students. Once upon a time, students were linked by class year. Similar to high school, students would come to college as the "class of___ " and persist through with their peers until graduation, even presenting the university with a class gift at commencement. 
Students today find affinity in myriad ways, such as student organization affiliation, club sport participation, alternative break experiences, support groups, or conference attendance. Each additional affiliation provides the university with more giving options to present to alumni.

With the evolution of the donor-centric model, development officers were looking for additional ways to engage alumni in addition to their major/academic college. Not all students had a strong association to their degree program. The vice president for student affairs at Hawthorn University, Anna Douglas, added that “our traditional way of thinking about linking alumni is through their academic areas, but that doesn't always resonate with everyone.” Additionally, the University of Alder’s SSAO, Nolan Williams, noted that when he called on alumni from the university, "99 out of 100 times, something they bring up is something that happened outside the classroom.” It is within that reflection that Nolan reintroduced student affairs to them and what role student affairs played in that alum's experience. These alumni reflections occurred regardless of knowing that Nolan was the vice president for student affairs. This example was not unique at the University of Alder; many participants alluded either directly or peripherally to how to leverage better the growing affinity groups on campuses.

Each campus profiled has on average between a 5\% and 15\% alumni giving rate. The opportunity to increase alumni participation was significant at each of the institutions interviewed. Birch University’s vice president for advancement, Levi Vassar, underscored the significance: "Some $90 \%$ of our 600,000 alums are sitting on the sidelines." Each advancement leader interviewed discussed strategies to increase overall giving to the university. Partnering with divisions of student affairs was one strategy being considered. 
Senior student affairs officers voiced their concerns about the financial climate, specifically budget cuts and decreases in state appropriations. It was agreed upon that whether or not to be involved in future fundraising efforts would not be optional for divisions of student affairs. According to participants, it was realistic to assume that nearly everyone at colleges and universities would need to play a role in the future. Jack Bainbridge, senior student affairs officer at Birch University, stated that he did not know of any new money that would flow to the division given the current fiscal picture. He talked about the importance of exploring grants, contracts, fundraising, and reallocation as part of preparing for the future. In order to meet student needs and provide the appropriate structure to support student success, divisions would need to discover alternative sources of funding to remain sustainable.

As explained, there was a shared belief between both sets of vice presidents that divisions of student affairs should be involved on some level in advancing fundraising efforts at colleges and universities. The exposure student affairs staff has to students and parents on a consistent basis, along with providing exceptional programs and services, makes them well-positioned to build strong relationships, affinity, and loyalty to the institution. These contributions make involving divisions of student affairs at 4-year public institutions increasingly more important.

\section{Research Question 2}

To what extent is the division of student affairs involved in fundraising activities at the institution?

With respect to the first research question, it was clear that all participants in this study believed strongly that divisions of student affairs can and should play a role in fund- 
raising at colleges and universities. To gain a greater understanding of what role they were playing, participants were asked a series of specific questions, some directed at the role the vice president played and others specific to the role of the division. The majority of SSAOs played a minimal role in university fundraising efforts and the majority of divisions were in the infancy stage of involvement as reported by both pairs of vice presidents. With respect to the role as vice president, the following themes emerged: (a) fundraising priorities, (b) supervision of fundraising, (c) cultivation of donors, and (d) culture of philanthropy.

The role as vice president. Senior student affairs officers were asked specifically to describe their role in the development efforts of the university. As indicated by the summary of responses in Table 2, the majority of vice presidents did not play an active role in university-wide fundraising initiatives.

Five of the seven vice presidents were not hired with fundraising as a position responsibility. However, four of those five vice presidents were hired 18 or more years ago. Of the two who had an expectation to play a role, one believed it was because of the division's long history with the management of scholarships and the other was a result of a highly engaged former vice president.

With the exception of one institution, there did not appear to be resistance on the part of the president for the vice president for student affairs and his or her division to be involved in development efforts. This is an important finding because prior research indicated that the president's philosophy of executive involvement in fundraising was an important factor for inclusion (Shay, 1993). Furthermore, a senior student affairs officer's ability to link divisional fundraising goals to the university’s strategic plan 
would more likely be invited to participate in university fundraising efforts. From a division leadership perspective, the senior student affairs officer often played a more direct role in development initiatives, such as setting the vision and priorities for fundraising efforts, involving staff in decision-making, seeking buy-in from departments, supervising staff with responsibility for fundraising, and cultivation, stewardship, and solicitation activities. Student affairs participants were asked specifically about their role in these activities.

\section{Table 2}

Summary of Responses Regarding the Role Senior Student Affairs Officers Play in University Development Efforts

"It's probably not what I think it should be. We have a President who is a relentless fundraiser, and it is all focused on academic affairs. So I think the role that I play as vice president for student affairs is very minimal.”

"I would say that I have limited involvement right now. Our division does some fund-raising, not a great deal, although we are looking at ways to get a bit more involved in that."

"I don’t have any particular university role, other than I am asked sometimes to show up at events.”

"As a VP, the answer is yes, but the role is not well defined at all. However, we're heading into a campaign, a university-wide campaign, so I think it will significantly increase.”

"Well, I am definitely trying to fundraise for student affairs initiatives. But I feel strongly that as an officer of the university, as a vice president, I believe personally that we are interdependent so I think it’s great if student affairs can uncover alumni who may not be giving.”

"To work closely with the [vice president for advancement], which is responsible for the fundraising and development and campaigns for the university. I provide leadership for the division of student affairs in support of campaigns and fundraising efforts.”

“I would describe my role as active. I'm part of the university's foundation board, which is kind of our fundraising board. As a vice president, I'm in all the social events with them. I'm engaged with stewardship events and alumni events, a lot of that on a very regular basis.” 
Fundraising priorities. Although the SSAO sets the direction for development efforts in his or her division, results showed three approaches to establishing fundraising priorities. The first approach included the vice president involving division leadership in creating fundraising priorities such as direct reports to the SSAO, department heads, and the director of development (if applicable).

In addition to department heads, vice presidents talked about the importance of encouraging involvement at various levels. Participants pointed out that the second approach leveraged much needed buy-in by staff and more importantly, their involvement. The third approach included a development committee comprised of a range of positions within the division. SSAO Patricia Olsen, University of Mulberry, admitted that she did not want just senior leaders around the table,

I wanted some mid-management people and I wanted a couple of students on there ... we have a small committee and they meet monthly with our director of development. I present to them what I see as the emerging priorities.

Increasing professional development for staff surfaced during this line of questioning. It was noted that in order to play a role, at any level, training in the area of development would benefit staff greatly. For example, if staff in student affairs are asked to participate in the development of fundraising priorities, they will need to understand patterns of giving by alumni at the institution, the fundraising cycle, and institutional priorities and outcomes for development campus-wide. This will enable them to make informed decisions about what priorities would resonate with prospective donors and situate the divisional priorities within the university’s fundraising goals. 
Supervision of fundraising staff. Based on the results of this study, senior student affairs officers were marginally involved in the direct supervision of staff with responsibilities for fundraising. In only a couple of instances did a member of division administration have written position responsibilities in this area and it was often at the request of the administrator to be involved. Only two SSAOs housed and supervised the director of development, both of which were at institutions where the development model was decentralized. All others were centrally located in institutional advancement and dual reported to advancement (solid reporting line) and student affairs (dotted reporting line). This type of structure was described as positive, as it provided someone representing the interests of student affairs at the "development table.” These directors shared information about student affairs with their development peers and provided important information from advancement to student affairs.

In addition to the role the director of development played, one vice president, Patricia Olson (Mulberry) stated that a development responsibility was not explicitly written in staff position descriptions, but verbally, all of her direct reports knew that development was part of their responsibilities. More specifically, she said, "it falls under one of those 'other duties as assigned."' The senior student affairs officer at Poplar State, Tom Farraday, considered development an expectation of staff and asked staff members to comment on this responsibility in their self-evaluation during annual performance reviews. It is important to note that all but one of the vice presidents interviewed indicated that responsibility for fundraising efforts would become more structured and more widespread throughout the organization in the near future. 
Cultivation of donors. Regardless of how developed fundraising efforts were in the divisions of student affairs profiled, the majority of senior student affairs officers played an important role in the cultivation and stewardship of donors, and in some cases the solicitation of gifts. Each vice president's approach was unique given the structure and characteristics of the division's development program. With the assistance of the director of development at the University of Alder, Nolan Williams got involved once the director had identified people at a certain giving level. If the individual resided locally or regionally, the vice president visited him or her for lunch or dinner. Moreover, if a donor was coming to campus, he set time aside to spend face-to-face quality time with him or her. He, along with other vice presidents interviewed, talked about the importance of correspondence from the senior level. Every gift, big or small, mattered in these divisions and acknowledging an investment with a card, letter, or phone call went a long way. Participants also discussed participation at events as an essential cultivation tool. Respondents stated that they attend parent events and alumni functions.

One vice president for student affairs, Anna Douglas (Hawthorn), spoke specifically about her role in communicating with staff about what the division was doing to cultivate and steward donors. She stated, "My role is to get them on board and to get them all supportive and make them all feel like they know what's going on.” Another vice president for student affairs, Patricia Olsen, cultivated a board of supporters. Each division at the University of Mulberry was expected to manage a board of supporters comprised of university alumni. The board for student affairs included 20 alumni and met three times per year. Their role was to cultivate new donors and "friendraise" for the division. The division’s board recently endowed a scholarship on campus. 
Culture of philanthropy. Creating a culture of philanthropy within the division was discussed as an important part of the senior student affairs and advancement officer's role. The results of this study showed that there was room for improvement. Richard Wheaton, vice president for student affairs at the University of Osage, described it less as creating a culture and more of creating recognition for the value of fundraising. Furthermore, he stated that this was reflected in his own division by the participation of staff who gave to the university. Other vice presidents reported that philanthropy was being talked about more, which was a fairly new phenomenon. SSAO Nolan Williams, University of Alder, had made more of an effort to meet with departments to talk about stewardship and discuss how to better connect current students with alumni. According to participants, developing a culture of philanthropy included encouraging staff to think about how to embed development efforts into existing programs and outreach. For example, SAO Gillian Snyder, Poplar State, developed storyboards about major donors to be displayed in high traffic areas such as the student union or residence halls. Attention was also paid to the importance of guest speakers, training, and professional development as opportunities to create a foundation of understanding among staff which could lead to a more engaged and involved division in development initiatives.

The role of the division. Institutions selected for this study included divisions of student affairs with similar characteristics, but each was engaged in development efforts at various stages. Regardless of stage, all but one had decided to become more involved and grow their fundraising efforts. The one vice president's division who was at best minimally involved saw the value, but was not sure the president or the fundraising structure would embrace the idea of growing the division's efforts. The majority of SSAOs 
consider their involvement in fundraising in the infancy stage, but evolving. Surprisingly, this included divisions that have been actively fundraising for more than 10 years and, in some cases, more than 20 years. The impetus to become involved ranged from a single project or initiative to telefund calling. The most significant evolution was moving from annual giving to what had become or will become major gift solicitation. This transition required a stronger infrastructure and staff time and commitment to develop. Table 3 shows a sample of responses from senior student affairs and advancement officers describing the role of student affairs in development efforts. When describing the role of divisions of student affairs, participants discussed their involvement, effectiveness, and specific role in fundraising efforts. In each of the areas, both vice presidents agreed there were opportunities for growth and room for improvement.

Based on the responses, it was clear that both sets of senior officers considered student affairs involvement as limited in scope. Even though a few examples of projects were discussed, senior advancement officers considered the current level of participation as minimal. There was a strong sense on the part of both sets of vice presidents that more could be done, either in planning for, developing new, or growing current efforts. Senior advancement officers reported that senior student affairs officers need to continue to develop strategies to move beyond where they are now, which included creating a solid infrastructure. For example, SAO Kevin Ryder, University of Alder, commented that although he appreciated the hiring of another director of development, student affairs may not have been ready for a full-time major gift officer. He was glad they got the ball rolling, but with no program, no database, and no prospect list, it was difficult for the director of development not to spend the majority of his or her time initially developing it. 
Table 3

How Would You Describe the Role of the Division of Student Affairs in Development Efforts at the University?

\begin{tabular}{|c|c|c|}
\hline & Senior Student Affairs Officers & Senior Advancement Officers \\
\hline \multirow[t]{8}{*}{ Involvement } & Minimally involved (Sycamore) & It's unfortunately very limited; there are a lot \\
\hline & Involvement usually includes a very & of opportunities (Sycamore) \\
\hline & $\begin{array}{l}\text { specific initiative, not a divisional } \\
\text { expectation. Infancy, but getting } \\
\text { closer to toddler (Mulberry) }\end{array}$ & $\begin{array}{l}\text { So right now, we need a lot of work bringing } \\
\text { things together here that is kind of silent in a } \\
\text { lot of ways (Mulberry) }\end{array}$ \\
\hline & Infancy, but evolving (Hawthorn) & \\
\hline & $\begin{array}{l}\text { It's very decentralized; no one said } \\
\text { we need to be doing development. In } \\
\text { order to do what we want to do, we } \\
\text { need to increase participation (Birch) }\end{array}$ & $\begin{array}{l}\text { Biggest change has been moving from an } \\
\text { annual giving program to major gift } \\
\text { solicitation, but still trying to figure out who } \\
\text { those prospects are in Student Affairs } \\
\text { (Hawthorn) }\end{array}$ \\
\hline & $\begin{array}{l}\text { Project/program-based fundraising; } \\
\text { not considering hiring a director of } \\
\text { development at this time; not sure } \\
\text { ROI is worth it (Osage) }\end{array}$ & $\begin{array}{l}\text { Doing all the right things, but still in the } \\
\text { infancy stage (Birch) }\end{array}$ \\
\hline & $\begin{array}{l}\text { I would say that we have limited } \\
\text { involvement right now. Our division } \\
\text { does some fundraising, not a great }\end{array}$ & $\begin{array}{l}\text { Involved in the annual giving cycle-two } \\
\text { mailings and calls to parents through the } \\
\text { telefund (Osage) }\end{array}$ \\
\hline & $\begin{array}{l}\text { deal although we are looking at ways } \\
\text { to get a bit more involved in that. } \\
\text { We're at the beginning stages of } \\
\text { crafting what [fundraising] might look } \\
\text { like (Poplar) }\end{array}$ & $\begin{array}{l}\text { Involved in building a culture of student } \\
\text { philanthropy, specifically one recent program } \\
\text { (Poplar) }\end{array}$ \\
\hline \multirow[t]{3}{*}{ Effectiveness } & $\begin{array}{l}\text { There is room for improvement - the } \\
\text { division could do a better job in stu- }\end{array}$ & $\begin{array}{l}\text { Has a full-time director, but not sure they were } \\
\text { ready for that; need for infrastructure (Alder) }\end{array}$ \\
\hline & $\begin{array}{l}\text { dent affairs showcasing the value of } \\
\text { campus life; part of that is communi- } \\
\text { cation, helping others understand it } \\
\text { (Alder) }\end{array}$ & $\begin{array}{l}\text { Need to develop a strategy to a major gift and } \\
\text { annual approach rather than do it ad hoc } \\
\text { (Birch) }\end{array}$ \\
\hline & $\begin{array}{l}\text { Doing above average, but unsure } \\
\text { about hiring a director of development } \\
\text { (Osage) }\end{array}$ & \\
\hline \multirow[t]{6}{*}{ Role } & $\begin{array}{l}\text { Efforts are related to our own work, } \\
\text { little connection to the university's } \\
\text { priorities (Birch) }\end{array}$ & $\begin{array}{l}\text { Student affairs can uniquely contribute to fund- } \\
\text { raising efforts with currently involved students } \\
\text { and with alumni who have had experiences in } \\
\text { student life (Birch) }\end{array}$ \\
\hline & (Mulberry) & $\begin{array}{l}\text { Responsible for prospecting and developing } \\
\text { strategies for solicitation—-student affairs staff }\end{array}$ \\
\hline & Nurturing current and prospective & are the eyes and ears on the ground (Mulberry) \\
\hline & \multirow{3}{*}{$\begin{array}{l}\text { Actively involving alumni (and } \\
\text { donors) with current students (Alder) }\end{array}$} & Assist in capturing parent and family informa- \\
\hline & & tion and a parent program for giving (Alder) \\
\hline & & $\begin{array}{l}\text { Build awareness and marshal support for } \\
\text { programs (Hawthorn) }\end{array}$ \\
\hline
\end{tabular}


Ryder added that as a result,

We've taken a step back with the staffing piece of this, we're still staffing professionally, it's still the same person, but we've added some additional responsibilities. There just wasn't enough return on investment yet to justify a fulltime fundraiser dedicated specifically to student affairs.

There appeared to be support by senior advancement officers for divisions of student affairs to remain involved and to expand their efforts, but to first consider what was needed to get off the ground or to move to the next level.

Perhaps most germane to the role divisions of student affairs were playing in fundraising initiatives was in the ways they strengthened development efforts of the university. Both SSAOs and SAOs responded similarly when asked about the unique contributions of staff in the division of student affairs. For example, SSAO Camilla Foster stated,

When you think about the way students build affinity for the institution, it may be through people, but it may also be through experiences. Those experiences that are offered through student affairs are really critical to students finding the campus to be engaging and is really where they develop a love for the institution.

Camilla's counterpart at the University of Alder, Noah Williams, substantiates this sentiment by adding, “There’s a real recognition that [student affairs] brings a lot to the table, and the campus experience brings a lot to the table for the general happiness of our graduates and donors.” One area of particular strength was alumni affinity with the groups, organizations, and programs students participated in under the direction of student affairs. Anna Douglas, SSAO at Hawthorn, recommends that "[student affairs] reach alumni who don't really connect with some of the traditional ways that we try to connect with alumni.” She went on to say that divisions of student affairs have a huge role and responsibility because alumni feel passionate about the institution and “it's typically 
because of their out-of-class experiences.” These affinities also provided alumni with a broader menu of options to choose from when giving back to the university. This was important given the desire to increase alumni participation in philanthropy at all seven institutions. SAO Samuel Lynch reinforced the need to not only increase participation each year, but to also motivate donors to give annually. He shared the following, "The bucket has a hole in it. People don't give every year. We lose three to four thousand donors every year." It is important for donors to be passionate about something at the university enough to give consistently.

Another unique contribution by student affairs staff was their access and ability to build a culture of student philanthropy. Since a growing concern was inconsistency of alumni giving, it was discussed that building that culture of consistency starts with students. Similarly, student affairs could, if not already, build that habit of giving with another important constituency, parents and family members. As indicated, in addition to creating conditions that develop and educate students, student affairs staff play an active role in assisting and supporting parents and family members. Through their work, vice president for advancement at the University of Alder, Kevin Ryder, stated that staff can engage students and parents early on and help convey important philanthropic messages.

Even though senior student affairs officers played a limited role in fundraising as a vice president for the university, they were more actively engaged in leading development initiatives for their division. Although each division was at a different stage in their fundraising efforts, the majority felt they were evolving. Any change within an organization can impact how resources are used, time is spent, and even how it is designed, which is why understanding the effects of this growth is important. 


\section{Research Question 3}

How do senior student affairs and advancement officers describe the impact of student affairs fundraising on traditional responsibilities and/or organizational structures?

When introducing a new area of responsibility, such as development, to an organization, the ways in which staff members conduct their work changes in order to adapt. This requires a shift in how divisions operate organizationally and in their day-today operations. When discussing the impact that involvement in development has had on the organization, four themes emerged: (a) expanding responsibility, (b) relationshipbuilding in new directions, (c) education and professional development, and (d) measuring success in development.

Expanding responsibility. For some institutions, the hiring of a director of development had an impact on the organizational structure of both divisions. Of the seven institutions profiled, four had a director of development assigned to fundraise for the division of student affairs. Of the four, three dual-reported to both divisions and were housed centrally in institutional advancement (Mulberry, Alder, and Hawthorn). The fourth was hired, supervised, and housed in the division of student affairs, which was common given the decentralized development model on campus (Birch). Of the three universities without a director of development assigned, one had access to a director of development for projects if needed (Poplar), one would like to hire a director in the near future (Sycamore), and the other is not entirely sure the return on investment was worth it and preferred to keep things as they were (Osage).

Regardless of whether a director of development was on staff, the majority of senior student affairs officers indicated that including development initiatives created the 
need for a cultural shift in the organization. This shift occurred when dominant views and behaviors of the organization evolved. For example, the kinds of conversations that were taking place included discussions about fundraising goals, priorities, responsibilities, and expectations. Building or maintaining an infrastructure for philanthropy required increasing expectations on an already busy staff. Patricia Olsen, vice president for student affairs at the University of Mulberry, lamented, "We're not going to get additional staff for this and when I look back, even 15 years ago, we're asking so much more of our staff and, if anything, we've decreased staff.” Therefore, staff members were being asked to re-prioritize what they do to include new responsibilities like development tasks. Only two senior student affairs officers mentioned that there had been no impact on their organizations. As a matter of consequence (or not), neither division had directors of development and were not actively fundraising. However, Camilla Foster, senior student affairs officer at Sycamore State, did allude to the fact that no impact could also be seen as negative for not having started to consider moving in that direction.

The organizational shift also included how divisional goals were prioritized, or reprioritized. A variety of artifacts were analyzed for this study including division publications; university, division, and department websites; campaign materials; fundraising brochures and handouts; strategic planning documents; and annual reports. Interestingly, the documents and artifacts available gave no indication that fundraising was a top priority for divisions of student affairs. Divisional goals and initiatives were highly concentrated in areas that support the core mission of the division. For example, one of the goals of the division of student affairs at Poplar State was to develop and sustain a rich, diverse learning and living environment in which students thrived. A 
priority for student affairs at the University of Alder included assisting students in developing responsible global perspectives on diversity, multiculturalism, ethics, civility, sustainability, and wellness. Staff members in student affairs at Sycamore State were working diligently to develop innovative experiential programs that supported student academic success, wellness, and personal growth. These illustrations were missionfocused and provided staff a clear understanding of their role on campus. But, for divisions to achieve their missions and advance their goals, priorities would need to be expanded to include fundraising in order to maintain and grow. On the surface, it did not appear to be a priority, but strategy statements such as "explore and expand new revenue generation opportunities in student affairs" and "maximize our effectiveness through responsible stewardship of resources, support innovation, and creativity in problemsolving” showed the importance of seeking alternative funding sources to support the mission and goals of each division. The documents collected did not indicate that all divisions profiled had a similar statement, but fundraising was discussed by participants as a way to strengthen programs and services.

Relationship-building in new directions. As divisions of student affairs increased their involvement in development efforts, another area of impact included the degree to which staff within departments developed relationships and collaborated with each other. Therefore, a sequence of questions was asked to gain understanding about the relationship between the senior officers of the two divisions, department interaction, and what makes for an ideal working relationship between student affairs and advancement. 
When asked how they would characterize their relationship with the senior advancement officer, the majority of SSAOs described their relationship as very good, open, and accessible. The reasons cited for the quality of the relationship included the frequency with which they saw each other, collaboration on one or more key project(s) (sometimes the only project they collaborated on), and making one another a priority. However, on a campus where student affairs had little involvement in fundraising efforts, including no director of development, Camilla Foster from Sycamore State commented that she works more closely with the other vice presidents than the vice president for advancement. On another campus where the involvement was similarly low, the two senior officers had recently started collaborating on a mutually beneficial program that started with students and had expanded to include alumni. The success of that one initiative strengthened the relationship and opened the door to discuss future collaborations.

Senior advancement officers were also asked to characterize their relationship with their student affairs counterpart. Two vice presidents simply acknowledged that they had a good or great working relationship. Kevin Ryder, University of Alder, responded that the relationship continues to evolve, "We get along well. He understands the fundraising piece of this and wants to engage.” Newly appointed to his role, Nolan Callahan, University of Mulberry, stated that he felt a responsibility to help bring in the right person to serve as the new director of development for student affairs. Due to the decentralized model of development at Birch University, the vice president for advancement characterized his relationship as cordial and comfortable with the vice president for student affairs. Levi Vassar added that when the division of student affairs decided to hire a full-time fundraiser, they met several times to structure the position appropriately. Even 
though the relationship was growing, Levi did assert that he felt a little closer with the academic deans than the vice president for student affairs.

Two vice presidents spoke specifically about having a responsibility to develop a relationship with their peers. One spoke about providing education, learning opportunities, and expertise, recognizing that the SSAO could provide him with the same in return. Carson Smith, Hawthorn University, remarked,

I respect the fact that she's the subject matter expert when it comes to student affairs programming and then I, or the associate vice president, would like to be alongside of her as the subject matter expert when it comes to building the advancement program.

With the exception of the provost in a couple of instances, other university vice presidents did not have responsibility to develop divisional fundraising programs, which provided sufficient opportunity for SSAOs and SAOs to build a mutually beneficial relationship that could support both divisions’ fundraising goals for the future.

Beyond the senior officer relationship, participants were asked about the collaboration shared between departments within their divisions. The responses indicated a much stronger relationship between departments in student affairs and alumni relations. Most of the collaboration included opportunities to engage alumni in the "life" of the university, both institution-wide and within affinity groups. Only one SSAO, Jill Carr (Mulberry), spoke to the value of having a marketing and communication liaison assigned to the division. As a result, student success stories and high impact programs and services were written about consistently and showcased in campus publications. This did not mean that stories were not being showcased in the same way at other institutions, but it was not discussed as an area of collaboration. 
One SSAO described the relationship with advancement as “clunky,” but that it was getting better, especially on the development side of things. This was in large part due to a change in the organizational chart. After 7 years of supervising the student affairs director of development, it was decided that the position would join the central development office. This transition strengthened the collaboration between divisions. Only one SSAO, Anna Douglas from Hawthorn University, stated that the relationship her division had with advancement was very similar to the relationship advancement shared with the colleges. However, it should be noted that Hawthorn, like Birch, had a decentralized development model, whereby directors were housed in the units they fundraise for.

Both SSAOs and SAOs pointed to the relationship between the division and annual giving as a strong collaboration. On campuses where the telefund workers made calls on the division's behalf, the relationship between the departments was more robust. For a few divisions of student affairs, this was the only fundraising for the division, and the majority of calls were made to parents of current students. However, many references were made about opportunities to grow the relationship beyond telefund appeals.

Finally, absent from the dialogue was any mention of the collection or management of data about student or alumni involvement, of which student affairs could be a valued partner. However, it was briefly mentioned when asked about what characteristics make for an ideal relationship between divisions. Additionally, neither senior officer of advancement nor student affairs discussed strategy building or executing. It appeared that collaborative efforts were episodic, without any over-arching goals or outcomes.

With the goal of moving from cooperation to intentional collaboration, a welldefined relationship was necessary. Participants were asked to share what characteristics 
they felt made for an ideal relationship between divisions. Table 4 provides a summary of the responses.

\section{Table 4}

\section{Characteristics for an Ideal Relationship Between Student Affairs and Institutional Advancement}

\begin{tabular}{|c|c|c|}
\hline & Senior Student Affairs Officers & Senior Advancement Officers \\
\hline \multirow[t]{3}{*}{ Communication } & $\begin{array}{l}\text { Regular Communication } \\
\text { (Mulberry) }\end{array}$ & $\begin{array}{l}\text { Clear and consistent communication } \\
\text { (Sycamore) }\end{array}$ \\
\hline & $\begin{array}{l}\text { Communication, } \\
\text { understanding, and active } \\
\text { involvement (Alder) }\end{array}$ & $\begin{array}{l}\text { Open, collaborative, and a willingness to } \\
\text { share (Alder) }\end{array}$ \\
\hline & $\begin{array}{l}\text { Willingness to talk freely about } \\
\text { potential ideas and opportunities } \\
\text { (Poplar) }\end{array}$ & $\begin{array}{l}\text { Free flowing of information and } \\
\text { eliminating barriers (Sycamore) }\end{array}$ \\
\hline \multirow[t]{9}{*}{ Reciprocity } & $\begin{array}{l}\text { Relying on another person's } \\
\text { expertise to grow (Mulberry) }\end{array}$ & $\begin{array}{l}\text { More integration between divisions; help } \\
\text { others see the holistic side of all this and } \\
\text { how it interrelates (Mulberry) }\end{array}$ \\
\hline & $\begin{array}{l}\text { Mutual respect and a willingness to } \\
\text { collaborate (Poplar) }\end{array}$ & $\begin{array}{l}\text { Understanding more fully the full picture of } \\
\text { what each other does and how we can better } \\
\text { support one another (Poplar) }\end{array}$ \\
\hline & $\begin{array}{l}\text { Mutually reinforcing relationships } \\
\text { and a common understanding of } \\
\text { what each other is trying to do } \\
\text { (Birch) }\end{array}$ & $\begin{array}{l}\text { Becoming less siloed (referred to it as } \\
\text { "many islands in one big ocean”) and being } \\
\text { intentional about connecting and collabor- } \\
\text { ating more across the campus (Birch) }\end{array}$ \\
\hline & $\begin{array}{l}\text { Continuing to collaborate on } \\
\text { projects of mutual interest (Osage) }\end{array}$ & $\begin{array}{l}\text { Respectful and appreciative of the work that } \\
\text { they have to do (Osage) }\end{array}$ \\
\hline & $\begin{array}{l}\text { It would be helpful if we had a } \\
\text { liaison position (Sycamore) }\end{array}$ & $\begin{array}{l}\text { Building trust and collaborating. It is also } \\
\text { important to have a clear vision for what you }\end{array}$ \\
\hline & $\begin{array}{l}\text { Trust - "trust that we're going to be } \\
\text { willing to speak for the whole }\end{array}$ & $\begin{array}{l}\text { want to accomplish and how you can } \\
\text { support each other (Sycamore) }\end{array}$ \\
\hline & $\begin{array}{l}\text { university, as opposed to just student } \\
\text { affairs” and confidence in division } \\
\text { staff (Hawthorn) }\end{array}$ & $\begin{array}{l}\text { Not having an "agenda"-“advancement’s } \\
\text { agenda is the campus agenda" (Sycamore) }\end{array}$ \\
\hline & $\begin{array}{l}\text { Understanding each other and what } \\
\text { each division is trying to do (Alder) }\end{array}$ & $\begin{array}{l}\text { Respect that staff members in each division } \\
\text { are the subject matter experts (Hawthorn) }\end{array}$ \\
\hline & & $\begin{array}{l}\text { Willingness to share data that we have not } \\
\text { historically had and that exists (Alder) }\end{array}$ \\
\hline
\end{tabular}


An echo could have been heard when communication was brought up as a characteristic to strengthen or improve the relationship between divisions. Moreover, the consistency with which the two communicated was emphasized. Both sets of vice presidents discussed similar distinguishing features as it related to the notion of reciprocity. They discussed how both divisions could better support the other, which included mutual respect, trust, confidence, and appreciation. Furthermore, both sets of senior officers stated that each division had subject matter expertise that would prove useful in achieving shared goals and outcomes.

Moving from short-term, episodic relationships to a more pervasive partnership required mutual understanding of the role of each division, including expectations and outcomes. This involved providing professional development and opportunities for crosstraining and information sharing.

Education and training. Results of this study shed light on an area for improvement. Participants discussed a strong need to better educate each division about the role of the other. When developing a coordinated approach with a focus on shared goals, it became increasingly important to consistently communicate and intentionally create opportunities to educate or train on content areas. When asked if SSAOs believe that advancement staff understood the role of student affairs on campus, the majority believed that at least some did, but not all. And of those that did, understanding was on a surface level. SSAO Camilla Foster, Sycamore State, mentioned that there was no formal orientation to other units. Staff members sometimes shared the big picture about what they do, but missing from the discussion was why that mattered and the impact on the student experience, student satisfaction, and student retention. Furthermore, SSAO Anna Douglas 
at Hawthorn reflected,

I think [institutional advancement] understands the service that we provide- the housing, counseling, health service. They don't understand the learning environment. I'm not sure they understand the impact of the holistic experience on the alumni's memory of this place.

There was also a difference between staff comfort and skill set when it came to participating in fundraising efforts. Most SSAOs responded that student affairs staff members were not very comfortable and unaccustomed to asking for money. This was not to say that some staff were; in fact, most if not all of the SSAOs could point to a few members of their staff that were very comfortable and successful at it. Camilla Foster, Sycamore State University, stated that most staff could talk “confidently and competently about their project or the program that we want to raise money for.” However, she pointed out that "finesse" was needed in the asking process and staff members were not appropriately trained. Tom Farraday, Poplar State, added that the "vast majority probably haven't thought much about it and if asked would be a bit nervous about it.” He added that a good number of his staff would be very comfortable and also very good, but training would be value-added moving forward. The idea of asking for money was something most student affairs staff didn’t embrace easily. One vice president labeled some staff as purists, purporting that staff claim they just want to serve students without expecting anything in return. She had heard staff members say that their focus should be on serving students and developing and transforming lives and not on selling themselves.

Most divisions of student affairs did not offer professional development in the area of development across departments, but all SSAOs mentioned the need to do more in the near future. Two vice presidents recently pulled together committees. One of which 
had begun talking about establishing fundraising priorities and what might be appropriate training for staff to learn to support their efforts. The other committee was described as a division-wide development committee. Interestingly, most of the interested staff members were young professionals, who as the vice president put it, were "thinking long term and strategically about their careers.” Another concern brought up by participants was the lack of preparation at the graduate level. In describing the Master's degree program in College Student Personnel, Tom Farraday, Poplar State, added, "More and more institutions, public and private, are going to be cultivating effective fundraising programs ... and we do not address the issue of fundraising and development very well.” The lack of proper preparation at the graduate level was a concern voiced by the majority of SSAOs.

Finally, results also indicated that university advancement sometimes offered professional development for stakeholders, but it did not appear to be strategic or consistent. Some SAOs responded that student affairs staff were involved in the training they provided, but those attending were either the director of development or the senior student affairs officer. For divisions of advancement that hosted leadership training, the vice president for student affairs was invited to participate, but few other staff members were included. It was difficult to discern if information gained by the director of development or SSAO was then carried forward and shared with division staff. The vice president for university advancement at Birch University claimed responsibility for providing professional development. He stated, "I think it is our job to put them in a position that they can best contribute to the development process." Some participants did indicate that there was more awareness and training provided campus-wide when gearing 
up for capital campaigns, but little consistently when outside of a campaign or campaign planning. In addition to providing training and professional development for staff, participants discussed the need to determine how to measure the effectiveness of the division’s development goals and outcomes.

Measuring success in development. Divisions of student affairs were accustomed to showing evidence of program effectiveness and satisfaction. It was not uncommon for staff to be expected to develop and measure intended outcomes for programs and services. The ability to connect and translate assessment data for the purposes of improving the student experience was an important tool for divisions of student affairs to demonstrate their contributions to the university’s strategic initiatives, goals, and ultimately student persistence.

Measuring the success of fundraising and development efforts was no different, but for many divisions this was a new area of assessment. As senior officers developed their fundraising initiatives, the return on investment in both time and money was an important consideration. Although every participant stated that the amount of money raised was one indicator of success, they also recognized other indicators as equally significant. Kevin Ryder, SAO at University of Alder, stated that "Not every school, college, or administrative unit is created equally.” Therefore, measures and expectations were differentiated depending on the history of the program. The five metrics Kevin used were money raised (both in hand and planned gifts), number of personal visits, total number of contacts, how many solicitations and closes, and how many new major gift prospects were identified and qualified. SAO Samuel Lynch, Sycamore State, agreed that the number of significant contacts made was important, but so was knowing whether staff 
appropriately educated alumni and donors about what they were attempting to do at Sycamore State. Increasing the number of alumni involved and engaging alumni at a higher level showed evidence of whether or not they were achieving their goals. Many of the SSAOs interviewed reported that they needed to manage their expectations and determine year to year what indicators would provide confirmation that their efforts were growing. Examples provided by participants included a stronger focus on the number of prospects, number of gifts of any amount, and the quality of relationships as important. SSAO Nolan Williams, University of Alder, expressed,

I'm very tempted to just look at the numbers. But, I get the bigger picture. I understand that some of what we're doing is building for the future and so I have patience for investing time and resources and setting things up that will help someone who is in my seat years from now.

Additionally, SSAO Jack Bainbridge, Birch University, articulated the importance of the percentage of effort that should be devoted to building databases and identifying new prospects. This should be considered when assessing how efforts are growing because it directly impacts future giving.

Finally, it was discussed by participants that success could also be measured internally with the growth in staff development and participation. One vice president in particular claimed that in terms of success, she looked at whether student affairs units felt more a part of fundraising, felt a responsibility to be engaged, and whether or not they realized the benefits from being involved. 


\section{Summary}

A qualitative study conducted with 14 vice presidents at seven 4-year public universities across four states in the Midwest provided practitioners with a deeper understanding of the type of fundraising activities they and their divisions were involved in, how these efforts were evolving, and their impact on traditional responsibilities and organizational structures. Multiple themes emerged. The first set of themes to surface was in response to the role senior officers and divisions play in fundraising, which included emerging prospects, developing a culture of philanthropy, and shaping the undergraduate experience. When examining the impact of involvement on traditional responsibilities and organizational structures, the results exposed information about expanding responsibilities, developing relationships in new directions (including current students, parents, and alumni), the need for consistent and appropriate professional development, and developing appropriate measures to assess effectiveness. The implications of these emergent themes will be discussed in Chapter $\mathrm{V}$ along with recommendations for future research. 


\section{CHAPTER V \\ DISCUSSION, IMPLICATIONS, AND RECOMMENDATIONS}

\section{Introduction}

In this final chapter, seven essential parts of this study will be discussed, some of which are summaries from previous chapters and two new sections. The chapter will start with a broad overview of the study. Following the overview, the significance of the study will be re-emphasized, demonstrating its relevance. A summary will then be shared, including who was selected and why they were profiled. Alongside the participants will be a description of the research design and methodology used to conduct the study. Next, a highlight of the research findings will be included and, finally, implications and strategies emerging from the conclusions will be shared together with recommendations for future research.

\section{Overview of the Study}

Against the backdrop of decreasing state support for higher education, fundraising consistently emerges as an income-generating strategy for public colleges and universities. Non-academic units such as divisions of student affairs are either considering, beginning new, or strengthening their development efforts. As more divisions become involved, it becomes important to learn from colleagues in the profession who are engaging in development activities. A limited amount of research has examined the role of fundraising in student affairs (Arminio et al., 2010; Gold et al., 1993; Gordon et al., 
1993; Kroll, 1991; Miller, 2010, Rovig, 2008; Schoenecke, 2005; Terrell \& Gold, 1993).

The results of this study provide insight into how seven institutions are currently engaged, including the challenges they face, plans for the future, and advice to consider.

\section{Participants}

The participants for this study included a pair of senior student affairs officers and senior advancement officers at seven 4-year public universities across four Midwestern states. The study focused on institutions that were of similar type, size, region, and mission, and Carnegie classifications were used to develop and narrow the sample. The classification used included institutions with fall enrollment showing full-time equivalent of at least 10,000 degree-seeking students at bachelor's degree granting institutions. Furthermore, $25 \%$ to $49 \%$ of degree-seeking undergraduates live on campus in institutionally-owned, -controlled, or -affiliated housing and at least 50\% attend full time. The sample of institutions was narrowed using criteria about the composition (arrangement of departments) of the division of student affairs at each institution in order to include divisions that were similar in type, size, and mission. Participants were recruited via two recruitment letters, one from a senior student affairs officer, not included in the study, to inform his counterparts about the significance of the study and its subsequent results (see Appendix A). The second recruitment letter in the form of an email was sent from me (see Appendix B).

\section{Research Design and Methodology}

The study emphasized an interpretivist approach, providing an opportunity to make sense of the human experience through the participants' responses with the goal of understanding the phenomenon more fully and develop shared meaning. All 
participants were interviewed using a semi-structured interview format. Seven of the interviews took place face-to-face in a place selected by the participant. An additional six interviews were conducted face-to-face using assistive technology such as Skype, ooVoo, and MOVI. Only one interview was conducted by phone at the request of the participant. Patton’s $(1990,2003)$ question typology was used as a framework for developing the interview guide for the study. In addition to interviews, documents and artifacts were collected in preparation for the interviews. Additional documents were collected during or directly following the interviews if needed. Documents were used to more fully understand the profile of the organizations (e.g., mission, vision, goals, strategic plan, and statistics) and the individuals (e.g., position announcements, responsibilities, and goals), as well as to provide evidence in support (or not) of statements made by participants, on websites, or in publications. The information gained from the documents provided detailed information about the universities, the divisions of student affairs, and the divisions of institutional advancement.

Data analysis for this study was iterative and included an individual interview with each participant. The interviews were audio-recorded with permission from the participant and transcribed by GMR Transcription Services, Inc. Each transcription was reviewed in full for accuracy. Each transcript was then coded using three types of coding — open, axial, and selective — to systematically organize the data around the phenomenon in question (Charmaz \& Belgrave, 2012; Strauss \& Corbin, 1998). The analysis stage also took into account field notes and memoranda as part of the coding process (Charmaz \& Belgrave, 2012). Each document and artifact collected was analyzed individually and collectively. 
Finally, steps were taken to minimize the ethical concerns, including researcher training and preparation, applicable disclosures of the role and subsequent biases of the researcher, specific purposes of the study, safeguards in place for privacy, confidentiality, and harm, and purposeful framing of interview questions. Intentional techniques were used to increase the trustworthiness and authenticity of the research design, including prolonged engagement, triangulation, and negative case analysis. Attention was also given to transferability, dependability, and confirmability through the use of narrative descriptions from multiple sources and the establishment of an audit trail.

\section{Summary of Findings}

Chapter IV provided a detailed account of the results; however, the following represents a summary of the study's findings organized by each of the three research questions. The fourth research question, regarding implications for the future, will be discussed next, with attention paid to both the limitations of the study and recommendations for continued study on this topic.

\section{Research Question 1}

What role, if any, do senior advancement officers and senior student affairs officers believe divisions of student affairs can/should play in fundraising?

The results of this study indicated that all participants believe that divisions of student affairs should be involved in fundraising at colleges and universities. Three distinct ways to be involved were identified and shared between SSAOs and SAOs. The first role for staff was in building strong relationships with current students through the provision of programs and services. Through these interactions, opportunities to build a robust culture of philanthropy were encouraged. This finding reinforced the study 
published by Hendrix-Kral (1995) in which she described the role of student affairs staff in fundraising as both unique and advantageous to university efforts. Similarly, Miller (2010) stated that staff in student affairs form bonds with current students early and continue to nurture those relationships. Leveraging these strong connections is further supported by Rissmeyer (2010) who claimed it was a valuable proponent of cultivation.

It was noted that creating this value for philanthropy started as early as orientation and should be a consistent message throughout a student's college experience. The second role for division staff to play was with parents and family members in creating opportunities to engage them in development efforts. According to participants, parents and family members did not think of public universities as non-profits, and staff members in the division have the ability to showcase the value of private giving (time and treasure) to the overall student experience.

Creating this unique and meaningful student experience was the third way divisions made an indelible difference. The majority of respondents discussed the importance of the "[insert mascot or school name] experience on their college campuses. These experiences were often talked about by alumni when reflecting on their years at the university and increased the potential for alumni investment. Specifically, Patouillet (2000) urged universities to place more emphasis on “developing a greater sense of institutional loyalty among the students while they are attending the university” (p. 88). This finding also sustained the results of Pumerantz (2004) who found that institutions with active and ongoing efforts to engage students while on campus did so intentionally and this led to greater giving by alumni. 
Finally, there was congruence between senior officers on leveraging affinity group affiliation and increasing the percentage and consistency of alumni giving. A finding that supported the research results of both Harrison et al. (1995) and Baldwin (2008). Harrison et al. (1995) found that students who participated in fraternities and sororities positively affected giving to the institution. Similarly, Baldwin (2008) discovered that becoming involved in Greek-letter organizations and being active in co-curricular activities (e.g., student government association, intramural sports, and band) increased participants willingness to invest in the university as alumni.

With the evolution of the donor centric model, advancement officers were looking for additional ways to engage alumni in addition to his or her major/academic college. The affinity groups organized and supported by divisions of student affairs were brought up by participants as another strong way to influence an alumnus’ continued relationship and loyalty to the institution. Brittingham and Pezzullo (1990) also stated nearly 25 years ago that "determining who is emotionally connected to the institution and why is one of the strongest predictors of alumni giving” (p. 35).

\section{Research Question 2}

To what extent is the division of student affairs involved in fundraising activities at the institution (senior student affairs officers and division staff)? How has participation in development efforts evolved?

Each division profiled in this study was at a different stage of fundraising at their respective university. The majority of SSAOs, however, did not perceive themselves as playing an active role as vice president in university-wide fundraising initiatives. Two SSAOs were hired with an expectation to play a role as a vice president, although neither vice president had a traditional portfolio of prospects and/or donors to manage. At the 
division level, SSAOs played a more direct role in leading development initiatives. Examples provided by participants included setting the vision, developing the priorities in partnership with staff, involving staff and seeking buy-in, managing staff with responsibility for fundraising, and traditional efforts such as cultivation, stewardship, and the solicitation of donors. Senior student affairs officers discussed three approaches to establishing fundraising priorities. All three approaches included staff involvement from the division. The majority included senior leadership and department directors, but there was also importance placed on involving more staff members at all levels of the organization and students. Involving more staff and students leveraged buy-in and participation in development efforts, which was not currently the culture in most divisions. Research results from Rovig (2008) and Crowe (2011) also supported the need for senior student affairs officers to actively involve other student affairs staff in development and fundraising efforts for the division.

The findings of this study also showed that senior student affairs officers were marginally responsible for supervising staff that had responsibility for fundraising. The most common model for housing and supervising directors of development was within institutional advancement. There were instances where the director of development was located and supervised in the division of student affairs, but both were on campuses where the development model was decentralized. Although position descriptions for staff in student affairs did not explicitly state a responsibility for fundraising, two SSAOs were developing an expectation of staff to participate or already evaluating staff members as part of the performance appraisal process. Participation did not necessarily mean engaging in solicitation, but in development efforts that either developed the internal 
infrastructure or growing their involvement in activities.

Finally, SSAOs were intimately involved with the cultivation and stewardship of donors. Examples were shared about how they participate, including attendance at events, outreach to prospects, connecting alumni to campus engagement activities, and correspondence. Time spent on these activities by the SSAO continued to increase as efforts became more defined. In addition to alumni engagement, participation with students and parents was expected to increase if the division was tasked with developing the culture of philanthropy with these two constituencies.

As for the role divisions of student affairs were playing, a summary of responses was provided in Chapter IV (see Table 3). For the most part, divisions were actively involved in telefund programs, primarily focused on parents as the constituency. They were slowly becoming involved in developing a culture of student philanthropy, but at the present time, most of them were project-based. Although the structure for affinity groups was strong at most institutions, respondents described the importance of developing a more consistent message to students about the role of philanthropy in their college experiences. Results also pointed to the need to strengthen the relationship with students once they become alumni. Creating a strategy to both engage and involve alumni after they graduate was cited as an important tactical step moving efforts forward. Finally, divisions continued to work on how to showcase the value of their programs and services as opportunities for investment. This finding reinforces the research of Morgan \& Policello (2010) and Rissmeyer (2010) who stated that the value placed on student affairs programs and services by alumni is often high and there is an increased interest to give back to activities and organizations that made a difference in their lives. 
With tuition and fees high, some SSAOs talked about the necessity to point out to students and parents what is not covered or provided at a lower cost because of the generosity of donors. There was a perception by students and parents that the amount they pay for college covers all that they receive. This was not the case and demonstrates the need for increasing private support to the institution and being more open about the division's fundraising needs. Fundraising priorities in divisions of student affairs need to be compelling, and these stories need to be articulated in ways that others understand and get excited about.

\section{Research Question 3}

How do senior student affairs and advancement officers describe the impact of student affairs fundraising on traditional responsibilities and/or organizational structures?

Shifts in organizational operations are to be expected when introducing or growing a new area of responsibility, both in staff and tasks. The magnitude of the impact depended on how deeply divisions were involved in fundraising. According to the results of this study, the effects on the organization included four themes: (a) expanding responsibility, (b) relationship-building in new directions, (c) education and professional development, and (d) measuring success in fundraising. For four of the institutions profiled, one significant impact was hiring an additional staff member with responsibility for major gift solicitation. Two others were currently considering hiring a director of development, and only one SSAO mentioned that they were not considering expanding their staff to include a 100\% full-time equivalent appointment in the near future. 
In addition to creating a culture of philanthropy among students and parents, SSAOs also discussed the need for a similar culture to be created among staff in the division. Staff members were not accustomed to thinking about what they do as an opportunity for investment. This was recognized by participants as both a positive and a negative. On one side, internal and external audiences become more aware that the programs, services, and relationships do not have term limits, but instead are transformational. As indicated by Schoenecke (2005), the culture surrounding fundraising within student affairs can impact development efforts and ultimately shapes fundraising practices. On the flip side, some staff would prefer to just do their jobs without any expectation of something in return. Including fundraising as a priority in the division also affected how some staff members spent their time. According to senior student affairs officers interviewed by Shay (1993), this was considered a drawback to participation because it required staff to spend less time on other core responsibilities to make room for additional fundraising priorities. The SSAOs in this study stated that they were attempting to do more with fewer staff and less money. Increasing private giving to the division impacted the bottom line, but required more human resources.

SSAOs also reported that another impact was on developing and strengthening relationships with students, parents, alumni, and university advancement staff. The relationships between the SSAO and SAO was considered positive by both sets of vice presidents. However, the majority of their interactions were periodic, project-based, or in his or her role as vice president. Respondents used terms to describe the relationship as evolving and growing. Only in a couple of examples shared were there discussions taking place about the strategic direction of the division's involvement in fundraising initiatives. 
Hillman (2002) concluded a similar finding in her study where she found that there was communication and cooperation between divisions, but the actual working relationship appeared ill defined.

As for the relationship between divisions, most of the collaboration existed between student affairs units and annual giving and student affairs units and alumni relations. The partnership with alumni giving centered mostly on telefund initiatives and some letter or email solicitations. In all but one case, parents were the constituency for annual giving appeals for student affairs. One institution called on a variety of constituencies, and individuals could give to whatever they were interested in, which could include student affairs programs, services, and organizations. The cooperative efforts with alumni relations included opportunities to engage alumni in the "life" of the university, connecting them to previous experiences, providing tours of campus facilities (e.g., residence halls), and with students and student groups. The results also indicated that units in student affairs collaborated on university-wide programs, such as homecoming. Respondents also expressed that if a director of development existed in the division, there was a much stronger relationship with staff in the development unit. Similarly, Eller (2010) indicated that fundraising efforts could be more effective if vice presidents collaborated as a fundraising team. This team approach would lead to a consistent, unified message that would reduce the silos that exist across divisions and increase donor engagement. Additionally, this finding supports the research of Gordon et al. (2002) who stated that horizontal communication between divisions increases the sharing of information, establishes trust, and strengthens strategic collaborations. 
In summation, there did not appear to be any resistance on the part of either division to collaborate; there was just no acknowledgement of having developed a strategy for how to work together, including the need for overarching goals and outcomes. This was, however, discussed as essential for strengthening the relationship in the future, which would require education and training.

Results of this study highlighted the need to better educate each division about the role of the other. Participants indicated that there was surface level understanding about the role each played at the institution, but not influence. For example, units in advancement were aware of the departments and services in student affairs, but the majority of staff did not understand the theory behind why they provide programs and services in specific ways and at particular times. Similarly, development was a new competency area for staff in student affairs. There were few opportunities for them to learn about advancement. SSAOs responded that there was a difference between staff skill set and comfort. Many staff would be comfortable and are comfortable, but providing consistent professional development would increase understanding, skills, and confidence. Results from this study also showed that training should be provided for staff at varying levels of the organization and not just at the top of the pyramid.

The last area of impact on traditional responsibilities included a shift in how divisions measure success when it comes to fundraising in student affairs. For student affairs, it was a new area of assessment, which included the need to develop priorities, goals, and outcomes. Participants discussed that using current advancement metrics may negatively affect how others on campus perceive their contributions to university development efforts. The amount of money raised was one indicator of success, but it was noted 
that measures and expectations should be different depending on the history of the program in that college or unit. Other important indicators discussed by participants included the number of personal visits, total number of contacts made, number of solicitations and closes, and how many new major gift prospects were identified and qualified. Additionally, the division of student affairs was recognized as a powerful partner for increasing the number of alumni involved at any level by expanding the options for alumni giving back. Finally, it was brought up that success should also be measured internally with increases in staff development and participation in the area of development.

\section{Implications for Practice}

This study provided access to 14 vice presidents, and what was perhaps most illuminating about the results of this study was what senior student affairs and advancement officers considered challenges and implications for the future. Even though the divisions profiled were at various stages of involvement, one thing was clear: fundraising as a responsibility was not temporary. It was compared to how technology had evolved in a short amount of time and embracing fundraising as a way of doing business would not be optional in the future. Yet, divisions of student affairs have made little progress in fundraising, especially in building infrastructures to support efforts. Participants discussed that there will be a higher dependency on fundraising for everyone in public higher education and this will require divisions to dedicate resources to support it, both in time and money. Therefore, the results of this study provide deliberate action steps that should not be overlooked as divisions enter into, grow, or expand their development efforts, which include:

1. Build organizational capacity for adaptive work 
2. Brand the division of student affairs

3. Draw a solid connection between co-curricular involvement and fundraising goals

4. Increase staff competency in development

5. Strengthen partnerships with institutional advancement through cultural integration

6. Cultivate a culture of philanthropy within the division at all levels of the organization

7. Develop an infrastructure for development before raising money

8. Move from cooperation to intentional collaboration

9. Effectively communicate with constituencies

\section{Build Organizational Capacity for Adaptive Work}

A challenge for divisions of student affairs is the lack of a proper infrastructure to meet fundraising goals. Divisions of student affairs and advancement must consider how to build organizational capacity for adaptive work. Therefore, it is important for division leadership to contemplate the amount of time necessary to build the foundation of philanthropy, which can take 3 to 5 years to adequately prepare. For example, hiring a major gift officer may be premature if the proper infrastructure is not in place. This was the case for a couple of institutions profiled both in return on investment and in the retention of development staff. It was suggested to focus on annual giving before major gift solicitation. This provides the division the opportunity to begin cultivating current students, parents, and young alumni. Additionally, time must be devoted to proper planning in areas of data management, categorization of funding opportunities, identification of prospects, relationship building with colleagues across campus, and the development of a brand for current and future donors. As indicated, all the SSAOs 
interviewed, some of whom have been involved for decades, described their role as in the infancy stage but evolving.

\section{Brand the Division of Student Affairs}

The results of this study focused heavily on the division's role to develop a culture of philanthropy among current students and parents. Part of developing this culture is making sure students and parents are aware that they can invest in the programs, services, and facilities in student affairs. With so few donors at each of the universities profiled (institutions were between a 5\% to 15\% alumni participation rate), competition for donors and dollars increases, but a large pool of alumni is not participating. Therefore, building a brand for student affairs is another important element to develop and implement.

\section{Draw a Solid Connection Between Co-curricular Involvement and Fundraising Goals}

As alluded to earlier, staff in student affairs already have distinct advantages given the nature of what they do on a daily basis. They should take advantage of having a captive audience while in college. This provides them with the ability to cultivate relationships with students and parents as early as orientation. It is important for staff to help students draw a connection between their co-curricular involvement and student affairs. It is equally important to impress upon them why these experiences matter to their personal and professional development. A highly developed infrastructure provides student affairs staff the opportunity to see the part they play in the overall strategy for fundraising. Likewise, it showcases the strength of the division as a valued partner in fundraising across campus. This level of involvement starts with proper training and education about philanthropy. 


\section{Increase Staff Competency in Development}

The results of this study showed a need for more training and professional development within and across divisions. Participants found it rare when a student affairs practitioner could draw upon their education or professional experience in understanding development. This study revealed a strong need to educate staff within the division about the fundamentals of fundraising. It becomes incumbent upon the senior student affairs officer to collaborate with the senior advancement officer to determine appropriate training for staff and to deliver it consistently. From the division of student affairs perspective, this is a new competency area in which to grow.

Participants stated that training could start with having philosophical conversations with staff within the division to help them understand both what fundraising is, how it is executed, why it is important, and how it can benefit current and future students. If staff members are to be expected to be involved, development principles and practices should become part of the professional development program. Staff should feel equipped with the appropriate success tools to perform what is expected of them.

\section{Strengthen Partnerships With Institutional Advancement Through Cultural Integration}

As discovered in this study, training crosses division lines. Staff members in university advancement need to learn more about the role of the division of student affairs on campus, program and service outcomes, and their contributions to achieving university goals. Furthermore, it is recommended that they gain insight into why and in what ways the division is a valued companion in achieving development goals. The results indicated that there was surface level understanding of what divisions of student 
affairs do, but it was shallow at best. This lack of understanding prevented collaboration from occurring, creating unmet need and siloed behavior. This was even more important if a director of development was not assigned to student affairs. In addition to providing structured training, effective communication within and between divisions is a critical factor for increasing staff understanding, information sharing, and cross-training. Professional development and consistent communication provides staff with opportunities to partner and to establish trust with each other. To foster what is known as cultural integration, divisions of student affairs should partner with institutional advancement (and vice versa) to establish a sense of identity through the institution's mission and core values. This provides divisions the opportunity to analyze how it interacts with and strengthens the internal and external environment.

\section{Cultivate a Culture of Philanthropy Within the Division at All Levels of the Organization}

Another challenge facing divisions of student affairs is expanding their responsibilities with students and parents to develop a culture of philanthropy. With limited staff time available and in many cases an inability to increase staffing, SSAOs will need to determine how to include additional responsibilities to grow efforts. It is important to note that this can be embedded within the existing programs and services provided, but a concrete plan of how to do it is essential. Furthermore, student affairs staff members are accustomed to working with students, but expanding their relationship with alumni is new to them. This will require discussions about how to leverage the data collected to appropriately and meaningfully engage alumni. As previously discussed, building a solid infrastructure includes proper planning in areas of data management, 
categorization of funding opportunities, and the identification of prospects. Each of these responsibilities takes staff member time to develop and maintain. It requires participation by a multitude of staff, not just one person in the central office or the director of development. It is from this foundation, the director of development is able to successfully garner support, engagement, and investment. It was reported that this takes an inordinate amount of time to develop in the beginning stages, but if systems are developed as part of the infrastructure, maintaining them is manageable. In order to create learning environments where decision making is shared, leaders of both divisions must connect strategy and behavior to the organizational culture and focus on process, flexibility, and collaboration (Kuk et al., 2010).

\section{Develop an Infrastructure for Development Before Raising Money}

Both SSAOs and SAOs shared advice on what to consider when preparing to engage in development initiatives, such as developing an infrastructure from within the central office. The vision, priorities, and expectations should be developed division-wide and not department-by-department. It was stressed that the internal structure for development must be strong before hiring staff to fundraise. The strength of this structure includes getting buy-in from the top to participate, taking stock of what data is available (e.g., parent, student, and alumni), developing systems for identifying and collecting new data, determining capacity, and being able to justify the return on investment for a part- or full-time position. Likewise, when developing strategy, it was strongly recommended to take the long view. Divisions of student affairs should first build a culture within the division and slowly build in an expectation for staff to 
participate. It was recommended to start with senior leadership. As expectations are developed, appropriate metrics should match the level of expectation and potential.

\section{Move From Cooperation to Intentional Collaboration}

In addition to developing strategy, building relationships within and beyond the division were strongly endorsed by participants. With any new venture, engaging in conversations internally and externally becomes integral to progress. Internally, participants recommended that SSAOs engage in conversations with each of the directors about how they see their department contributing to the goals of development. Each department should have different expectations; some will be highly involved and others only on the surface. The advice regarding building relationships outside the division included:

1. develop a strong partnership and a mutual understanding between advancement/student affairs divisions,

2. develop this partnership with each of the units within the division,

3. develop trust early,

4. advocate for a student affairs representative to attend development meetings (especially if a director of development has not been hired for student affairs), and

5. build relationships with other college deans so that there is no feeling of competition.

In addition to the word collaboration, the term cooperation was brought up by several vice presidents. Another important piece of advice in this category included being open about 'your' own limitations. This included the limitations of individuals, departments, and divisions. A learning curve is to be expected when getting started, and being open and honest about these limitations will strengthen the relationship and support needed. 


\section{Effectively Communicate With Constituencies}

The final category that surfaced was effective communication, and in many ways cuts across the other categories already discussed. Both sets of vice presidents encouraged their peers to hold regular meetings with their counterparts, communicate consistently with one another, and seek out creative ways to collaborate. Also important was developing a common understanding, common purpose, and common goals about fundraising and development. This should be done early in the process and increases communication, collaboration, and follow-through between staff in divisions. As senior student affairs officers contemplate engaging in development efforts, they should take into consideration the advice provided by those interviewed in this study.

\section{Scope of the Study}

This study was focused on seven pairs of administrators. An effort was made to interview senior student affairs officers and senior advancement officers in similar environments with parallel goals. However, each college and university was unique in its mission, values, composition, tradition, and location. For that reason, one senior student affairs officer's or one senior advancement officer's experience or relationship may not be reflective of another senior officer simply because of the unique organizational structure of the institution or division. The tenure of a vice president may also have influenced participant opinions, both those with a long history with the institution and those newly on boarded. Every effort was made to include institutions with centralized rather than decentralized models of development, but it was difficult to discern the model used until the interview. Two of the institutions profiled in this study included a decentralized model for development, whereby directors of development were hired, 
supervised, and housed within the units.

Since interviews rely on self-reported data, many factors could have limited this study's findings and the validity of the research, but the perceptions of the participants were paramount. Steps were taken to maximize authenticity by asking demographic questions at the start of each interview, asking for examples, seeking clarification when needed, and providing definitions of terms that could be unfamiliar.

Even though the institutions selected for this study met a set of criteria, no two universities had the same model or structure for student affairs or advancement. Therefore, the data gathered and the results can only be applied to those individuals, divisions, and universities. However, according to Merriam (2002), "readers themselves can determine the extent to which findings from a study can be applied to their context” (pp. 28-29). This has been referred to as case-to-case transfer (Firestone, 1993; Merriam, 2002). Furthermore, detailed descriptions of the study's context were provided, which Merriam (2009) argues enables "readers to compare the 'fit' with their situations” (p. 226). Moreover, greater application can be applied as a result of the maximum variation used in this study when selecting the specific sample criteria (Merriam, 2009).

Even though I am a student affairs practitioner, the type of interviews conducted in this study aligned best with Roulston's (2007) definition of a neo-positive interview through the minimization of bias through a neutral stance, asking good questions, and generating quality data that produces valid findings. By using variation in the types of questions asked, I had no expectation of a particular result. I disclosed to all of the participants that I worked in the field of student affairs, but specifically revealed that I am not responsible for major gift fundraising for student affairs. In addition, it was made 
known that the study was for the purposes of learning about the individual's particular experience in developing, implementing, or growing a student affairs fundraising program.

This study could have been improved upon by expanding the document analysis and triangulation procedures. Additionally, only those documents provided by the participants and accessible on institutional websites were analyzed. Furthermore, one of the interviews was conducted by conference call, which made it impossible for me to observe body language and non-verbal cues. I had to rely on tone of voice and pauses extensively. It may have been difficult to pick up on the some of the subtleties that a more experienced researcher might have uncovered. Moreover, the flow of communication could have been improved with better interviewing techniques and experience.

A final concern of the study was the accuracy of reporting by the participants. It became clear that this is a new competency area for participants based on how they responded to interview prompts about professional development, training, and assessment. Therefore, with or without intent, participants may have responded to questions with prejudice. However, I made every attempt to minimize misrepresentation by using focused probes, seeking clarification, and asking follow-up questions to determine trustworthiness.

\section{Recommendations for Future Research}

As indicated throughout this study, a sound rationale for involvement is central to starting or expanding any fundraising endeavor. According to the literature, there has been an upsurge in student affairs participation in fundraising activities (Arminio et al., 2010; Gold et al., 1993; Gordon et al., 1993; Kroll, 1991; Miller, 2010; Rovig, 2008; 
Schoenecke, 2005; Schuh, 2003; Terrell \& Gold, 1993). A number of reasons were cited in the literature review and by participants, but it became clear that the reason to become involved must be more than merely financial gain for the division. It requires that senior student affairs officers clearly articulate the impact of student affairs programs and services on the quality of student life on campus. Additionally, it requires that the senior student affairs officer showcase the power of partnerships across units and the value that brings to the educational environment of a college campus. The experience students have with both the curriculum and co-curriculum lead to the alumni's satisfaction with their overall experience and how much they credit that experience to their current and future success.

Communicating this impact starts with involvement in institutional strategic planning and goal setting. There were limited studies on the effect fundraising has on increasing the prestige and value of student affairs divisions. A future study could examine how involvement and success in educational fundraising affects the prestige of the division and the value of their contributions to achieving institutional goals and outcomes.

As illuminated in this research and the research of others, the president must value the contributions of student affairs enough to include the senior student affairs officer in fundraising efforts at the institution (Hodson, 2010; Shay, 1993). This vote of confidence sends a commanding message to the leadership of institutional advancement to consider how student affairs can play a role in their efforts. Without the endorsement of the president and senior advancement officer, the data reveal an uphill climb for senior student affairs officers to effectively partner with key stakeholders. Further research is 
recommended on how to successfully engage and seek endorsement from the president and senior advancement officer in becoming a valuable partner in the development efforts of the institution.

Relationships and cross-division collaboration strengthens the work of all units involved. In this study and in most of the studies reviewed, results indicated that student affairs staff members should be viewed as natural partners in working with development officers and alumni relations staff (Jackson, 2000; Miller, 2010; Morgan \& Policello, 2010; Rissmeyer, 2010; Shay 1993). Advancing the philanthropic initiatives of the university includes, but is not limited to, proper coding of involvement information, relationship-building with student leaders, participation of students and alumni in activities and events, building a culture of student philanthropy, and capturing compelling stories of donor impact on the student experience. All of which, student affairs staff members contribute to on a daily basis. The nature of the work they do builds pride, tradition, and loyalty to the institution. Continued research on how to effectively build a culture of philanthropy with current students would be value-added as divisions begin to build solid infrastructures for fundraising implementation.

The most overwhelming revelation in the results of this study and the literature is the amount of resources and recommendations extended to divisions of student affairs. With an expanding scope of responsibilities, adding educational fundraising to the division’s schema requires a development infrastructure, appropriate staffing, reallocated resources, professional development and training, and time. Becoming involved in educational fundraising is a long-term commitment that must become part of the fabric of the division at all levels. Adequate planning is critical in determining a purposeful 
direction and the expectations for short- and long-term success are heightened.

Furthermore, measuring success will need to be established early because traditional fundraising measurements may not be compatible; therefore, researching how to properly assess program effectiveness is warranted.

Even though student affairs divisions have not historically been included in traditional fundraising efforts at colleges and universities, they have been intimately involved in the quality of the student experience since the beginning of higher education. The evolution of student affairs as a profession has led to increased responsibilities, including enrollment management, athletics, academic support programs, and now educational fundraising. A focus on graduate student preparation and/or staff professional development for future studies would prove useful.

The level of service with which practitioners are expected to deliver programs, activities, and services is unparalleled to anything the profession has experienced in the past. With higher accountability standards, senior student affairs officers must find alternative ways to balance the rising costs of college with the survival and growth of the programs and services expected. Even though the amount of research conducted on student affairs fundraising is meager and, of those conducted, the samples are either too small or limited in scope to generalize to the larger population, research questions are being posed and data continues to be collected. The current information available, including the results of this study, provide senior student affairs officers with a foundation of what is occurring and aids them in determining the right questions to ask within the context of their campus. Additional research will aid institutions in identifying how to utilize leadership, advocacy, and collaboration to support development officers as 
they balance the intra-divisional arrangements and relationships between student affairs and institutional advancement to maximize private dollars to the institution and enhance the quality of the student experience.

\section{Summary}

The results of this study provided 14 individual perspectives from senior student affairs and advancement officers about development efforts in student affairs. As divisions of student affairs embark on or expand their fundraising efforts, the results provide personal accounts of how participants describe balancing and managing their role when confronted with challenges and barriers unique to fundraising in student affairs. This dissertation provides a review of the literature surrounding increased participation in divisional fundraising efforts and offers recommendations for future research. Even though the results of this study are not generalizable across institutions or divisions, it is important to consider the experiences and perceptions of individuals tasked with leading fundraising programs. The findings of this study inform leaders on factors to consider when creating an infrastructure, building a brand, lobbying for acceptance, and balancing the duality of roles between divisions. It both confirms and reinforces other research studies by providing a first-hand account of one's experience serving in these roles. Furthermore, it identifies gaps present that produce new questions of inquiry for future contemplation. 


\section{REFERENCES}

American Association of Higher Education, American College Personnel Association, and National Association of Student Personnel Administrators. (1998). Powerful partnerships: A shared responsibility for learning. Washington, DC: author.

American College Personnel Association. (1974). A student development model for student affairs in tomorrow's higher education. Washington, DC: author.

American College Personnel Association. (1994). The student learning imperative: Implications for student affairs. Washington, DC: author.

American College Personnel Association. (1996). The student learning imperative: Implications for student affairs. Retrieved from http://www.acpa.nche.edu/sli/sli.htm

American Council on Education. (1937). Student Personnel Point of View, Series I, 1 (3), Washington, DC: Author.

American Council on Education. (1983). The student personnel point of view: A report of a conference on the philosophy and development of student personnel work in colleges and universities. In G. L. Saddlemire \& A. L. Rentz (Eds.), Student affairs-A profession's heritage: Significant articles, authors, issues and documents (American College Personnel Association Media Publication No. 25, pp. 74-87). Carbondale, IL: Southern Illinois University Press. (Original work published 1937).

Arminio, J., Clinton, L. F., \& Harpster, G. (2010). Fundraising for student affairs at comprehensive institutions. New Directions for Student Services, 130, 31-45.

Association of American Colleges and Universities. (2002). Greater expectations: A new vision for learning as a nation goes to college. Washington, DC: Author.

Association of American Colleges and Universities. (2005). Liberal education and America's promise (LEAP). Washington, DC: Author.

Association of Fund-Raising Professionals. (2010). About AFP. Retrieved from http://www.afpnet.org/about/?navItemNumber=500

Astin, A. W. (1975). Preventing students from dropping out. San Francisco, CA: JosseyBass Publishers. 
Astin, A. W. (1985). Achieving education excellence: A critical assessment of priorities and practices in higher education. San Francisco, CA: Jossey-Bass Publishers.

Astin, A. W. (1999). Student involvement: A developmental theory for higher education. Journal of College Student Development, 40, 518-529.

Baldwin, K. M. (2008). How reciprocity influences alumni giving: A qualitative study. (Doctoral dissertation). Retrieved from ProQuest Dissertations and Theses database. (UMI No. 3334601 )

Barr, M. J., \& Desler, M. K. (Ed.). (2000). The handbook of student affairs administration. San Francisco, CA: Jossey-Bass Publishers.

Baum, S., \& Ma, J. (2011). Trends in college pricing. Retrieved from http://trends.collegeboard.org/

Baxter Magolda, M. B. (1999). Defining and redefining student learning. In E. Whitt (Ed.) Student learning as student affairs work (NASPA Monograph Series no. 23, pp. 35-49). Washington, DC: National Association of Student Personnel Administrators.

Baxter Magolda, M. B., \& King, P. M. (Eds.). (2004). Learning partnerships: Theory and models of practice to educate for self-authorship. Sterling, VA: Stylus Press.

Bitsch, V. (2005). Qualitative research: A grounded theory example and evaluation criteria. Journal of Agribusiness, 23(1), 75-91.

Bowen, G. A. (2009). Document analysis as a qualitative research method. Qualitative Research Journal, 9(2), 27-40.

Bremner, R. H. (1988). American philanthropy ( $2^{\text {nd }}$ ed.). Chicago, IL: University of Chicago Press.

Brittingham, B. E., \& Pezzullo, T. R. (1990). The campus green: Fundraising in higher education. ASHE-ERIC Higher Education Report No. 1. Washington, DC: School of Education and Human Development, The George Washington University.

Brubacher, J. S., \& Rudy, W. (1976). Higher Education in transition: A history of American colleges and universities. New York, NY: Harper and Row Publishers.

Brubacher, J. S., \& Rudy, W. (1997). Higher Education in transition: A history of American colleges and universities ( $4^{\text {th }}$ ed.). New Brunswick, NJ: Transaction Publishers.

Caudle, S. L. (2004). Qualitative data analysis. In J. S. Wholey (Ed.), Handbook of practical program evaluation ( $2^{\text {nd }}$ ed., pp. 417-438). San Francisco, CA: JosseyBass Publishers. 
Certified Fund Raising Executive. (n.d.). About CFRE International. Retrieved from: http://www.cfre.org/about/.

Charmaz, K., \& Belgrave, L. L. (2012). Qualitative interviewing and grounded theory analysis. In J. F. Gubrium, J. A. Holstein, A. B. Marvasti, \& K. D. McKinney (Eds.), The SAGE handbook of interview research: The complexity of the craft ( $2^{\text {nd }}$ ed., pp. 347-365). Thousand Oaks, CA: Sage Publications.

Chickering, A. W., \& Reisser, L. (1993). Education and identity (2 ${ }^{\text {nd }}$ ed.). San Francisco, CA: Jossey-Bass Publishers.

Cohen, A. M., \& Kisker, C. B. (2010). The shaping of American higher education: Emergence and growth of the contemporary system. San Francisco, CA: JosseyBass Publishers.

Cohen, D. J., \& Crabtree, B. F. (2006). Qualitative research guidelines project. Retrieved from http://www.qualres.org/

Council for Aid to Education. (2007). Voluntary support of education. New York, NY: Author.

Council for the Advancement and Support of Education. (n.d.). About advancement. Retrieved fromhttp://www.case.org/About_CASE/About_Advancement.html

Council for the Advancement and Support of Education. (n.d.). CASE history. Retrieved from http://www.case.org/About_CASE/CASE_History.html\#pred

Council for the Advancement of Standards in Higher Education. (2002). Standards and guidelines. Washington, DC: author.

Creswell, J. W. (2008). Educational research: Planning, conducting, and evaluating quantitative and qualitative research. Upper Saddle River, N.J: Pearson/Merrill Prentice Hall.

Croteau, J. D., \& Smith, Z. A. (2012). Making the case for leadership: Profiles of chief advancement officers in higher education. Lanham, MD: Rowman \& Littlefield Publishers, Inc.

Crowe, P. A. (2011). Development and fundraising practices in divisions of student affairs at 4-year, public universities. (Doctoral dissertation). Retrieved from ProQuest Digital Dissertations and Theses database. (UMI No. 3118748)

Curti, M., \& Nash, R. (1965). Philanthropy in the shaping of American higher education. New Brunswick, NJ: Rutgers University Press. 
deMarrais, K. (2004). Qualitative interview studies: Learning through experience. In K. deMarrais, \& S. D. Lapan (Eds.), Foundations for Research: Methods of Inquiry in Education and Social Sciences (pp. 51-68). Mahwah, NJ: Lawrence Erlbaum.

Denzin, N. K., \& Lincoln, Y. S. (1994). Handbook of qualitative research. Thousand Oaks, CA: Sage Publications.

Deutsch, M. (1949a). A theory of cooperation and competition. Human Relations, 2, 129152.

Deutsch, M. (1949b). An experimental study of the effects of cooperation and competition upon group process. Human Relations, 2, 199-231.

Dungy, G. J. (2003). Organization and functions of student affairs. In S. R. Komives, D. B. Woodward, \& Associates (Eds.), Student services: A handbook for the profession ( $4^{\text {th }}$ ed., pp. 339-357). San Francisco, CA: Jossey-Bass Publishers.

Eller, D. H. (2010). College vice presidents' role in fundraising activities in the 2000s and beyond: A case in California. (Doctoral dissertation). Retrieved from ProQuest Dissertations and Theses database. (UMI No. 3406629)

Ellis, S. E. (2010). Introduction to strategic planning in student affairs: A model for process and elements of a plan. New Directions for Student Services, 132, 5-16.

Evans, G. A. (1993). Organizing the development program. In M. J. Worth (Ed.), Educational fundraising: Principles and practice (pp. 275-285). Phoenix, AZ: Oryx.

Ewell, P. T. (2008). Assessment and accountability in America today: Background and context. New Directions for Institutional Research, 2008(S1), 7-17.

Flick, U. (2004a). Design and process in qualitative research. In U. Flick, E. von Kardorff, \& I. Steinke (Eds.), A Companion to Qualitative Research (pp. 146152). Thousand Oaks, CA: Sage Publications.

Flick, U. (2004b). Triangulation in qualitative research. In U. Flick, E. von Kardorff, \& I. Steinke (Eds.), A Companion to Qualitative Research (pp. 178-183). Thousand Oaks, CA: Sage Publications.

Fried, J. (1995) Shifting paradigms in student affairs: Culture, context, teaching and learning. Lanham, MD: American College Personnel Association/University Press of America.

Fried, J. (2006). Rethinking learning. In R. P. Keeling (Ed.). Learning reconsidered 2: Implementing a campus-wide focus on the student experience (pp. 3-9). 
Washington, DC: National Association of Student Personnel Administrators (NASPA), American College Personnel Association (ACPA), Association of College and University Housing Officers-International (ACUHO-I), Association of College Unions International (ACUI), National Academic Advising Association (NACADA), National Association for Campus Activities (NACA) and National Intramural-Recreation Sports Association (NIRSA).

Fygetakis, E. C. (1993). A study of the relationship between student affairs offices and development offices in fund-raising for extracurricular activities. (Doctoral dissertation). Retrieved from ProQuest Digital Dissertations and Theses database. (UMI No. 9306056)

Fygetakis, E. C., \& Dalton, J. C. (1993). The relationship between student affairs and institutional advancement offices in educational fundraising. New Directions for Student Services, 63, 17-28.

Garvin, D. A. (1980). The economics of university behavior. New York, NY: Academic Press.

Geiger, R. L. (2005). The ten generations of American higher education. In R. O. Berdahl, P. G. Altbach, \& P. J. Gumport (Eds.), Higher education in the twenty- first century ( $2^{\text {nd }}$ ed.) (pp. 38-70). Baltimore, MD: Johns Hopkins University Press.

Gold, J. A., Golden, D. C., \& Quatroche, T. J. (1993). The challenge of chief student affairs officers: Planning for the future. New Directions for Student Services, 63, 95-111.

Gordon, S. E., Strode, C. B., \& Brady, R. M. (1993). Student affairs and educational fundraising: The first critical step. New Directions for Student Services, 63, 5-16.

Greenfield, J. M. (1994). Fund-raising fundamentals: A guide to annual giving for professionals and volunteers. New York, NY: John Wiley \& Sons, Inc.

Guido, F., Chávez, A. F., \& Lincoln, Y. (2010). Underlying paradigms in student affairs research and practice. Journal of Student Affairs Research and Practice, 47(1), 122.

Hall, P. D. (1992). Teaching and research on philanthropy, voluntarism, and nonprofit organizations: A case study of academic innovation. Teachers College Record, 93(3), 403-436.

Hamrick, F. A., Evans, N. J., \& Schuh, J. H. (2002). Foundations of student affairs practice. New York, NY: John Wiley \& Sons, Inc.

Harrison, W. B., Mitchell, S. K., \& Peterson, S. P. (1995). Alumni donations and colleges’ development expenditures: Does spending matter? American Journal of Economics and Sociology, 54(4), 397-412. 
Heifetz, R. (1994). Leadership without easy answers. Boston, MA: Belknap.

Hendrix-Kral, C. L. (1995). Capital campaigns: Implications for fund raising for student affairs divisions in public universities. (Doctoral dissertation). Retrieved from ProQuest Digital Dissertations and Theses database. (UMI No. 9622395)

Hillman, J. (2002). An investigation of the current status of fundraising activities and training within student affairs divisions in Texas colleges and universities. (Doctoral dissertation). Retrieved from ProQuest Digital Dissertations and Theses database. (UMI No. 3118748)

Hodson, J. B. (2010). Leading the way: The role of presidents and academic deans in fundraising. New Directions for Student Services, 149, 39-49.

Holliday, A. (2002). Doing and writing qualitative research. Thousand Oaks, CA: Sage Publications.

Hossler, D. (2004). Refinancing public universities: Student enrollments, incentive-based budgeting, and incremental revenue. In E. P. St. John \& M. D. Parsons (Eds.), Public funding of higher education: Changing contexts and new rationales (pp. 145-163). Baltimore, MD: Johns Hopkins University Press.

Jackson, M. L. (2000). Fund-raising and development. In M. J. Barr, M. K. Desler, \& Associates (Eds.), The handbook of student affairs administration. San Francisco, CA: Jossey-Bass Publishers.

Jessup-Anger, E. R. (2009). Implementing innovative ideas: A multisite case study of putting learning reconsidered into practice. (Doctoral dissertation). Retrieved from ProQuest Digital Dissertations and Theses database. (UMI No. 3381260).

Keeling, R. P. (Ed). (2004). Learning reconsidered: A campus-wide focus on the student experience. Washington DC: National Association of Student Personnel Administrators (NASPA) and American College Personnel Association (ACPA).

Keeling, R. P. (Ed). (2006). Learning reconsidered 2: Implementing a campus-wide focus on the student experience. Washington DC: National Association of Student Personnel Administrators (NASPA), American College Personnel Association (ACPA), Association of College and University Housing Officers-International (ACUHO-I), Association of College Unions International (ACUI), National Academic Advising Association (NACADA), National Association for Campus Activities (NACA) and National Intramural-Recreation Sports Association (NIRSA).

Kezar, A. (2007). Creating and sustaining a campus ethos encouraging student engagement. About Campus 11(6), 13-18. 
Kimmel, R. B. (1986). Fund raising in student affairs: Thrust for the future? College Student Affairs Journal. 6, 5-10.

Kroll, D. M. (1991). Role expansion in student affairs: Student affairs officers and fundraising in selected Midwestern liberal arts colleges. (Doctoral dissertation). Retrieved from ProQuest Digital Dissertations and Theses database. (UMI No. 9130503)

Kuh, G. D. (1993). In their own words: What students learn outside the classroom. American Educational Research Journal, 30(2), 277-304.

Kuh, G. D. (1995). The other curriculum: Out of class experiences associated with student learning. Journal of Higher Education, 66(2), 123-155.

Kuh, G. D. (1996). Guiding principles for creating seamless learning environments for undergraduates. Journal of College Student Development, 37, 135-148.

Kuh, G. D. (2008). High-impact educational practices: What they are, who has access to them, and why they matter. Washington, DC: Association of American Colleges and Universities.

Kuh, G. D. (2009). What student affairs professionals need to know about student engagement. Journal of College Student Development, 50(6), 683-706.

Kuh, G. D., Douglas, K. D., Lund, J. P., \& Ramin-Gyurnek, J. (1994). Student learning outside the classroom: Transcending artificial boundaries. Washington, DC: The George Washington University.

Kuh, G. D., Lyons, J., Miller, T., \& Trow, J. (1994). Reasonable expectations. Washington, DC: National Association of Student Personnel Administrators.

Kuh, G. D., Gonyea, R. M., \& Williams, J. M. (2005). What students expect from college and what they get. In T. E. Miller, B. E. Bender, J. H. \& Schuh (Eds.), Promoting reasonable expectations: Aligning student and institutional view of the college experience (pp. 34-64). San Francisco, CA: Jossey-Bass Publishers.

Kuh, G. D., Kinzie, J. A., Schuh, J. H., \& Whitt, E. J. (2005). Student success in college: Creating conditions that matter. San Francisco, CA: Jossey-Bass Publishers.

Kuh, G. D., Kinzie, J., Buckley, J. A., Bridges, B. K. \& Hayek, J. C. (2006). What matters to student success: A review of the literature. Commissioned report for the National Symposium in Postsecondary Student Success: Spearheading a Dialog on Student Success. 
Kuh, G. D., \& Schuh, J. H. (Eds.). (1991). The role and contributions of student affairs in involving colleges. Washington, DC: National Association of Student Personnel Administrators.

Kuk, L. (2009). The dynamics of organizational models within student affairs. In G. S. McClellan \& J. Stringer (Eds.), The handbook of student affairs administration ( $3^{\text {rd }}$ ed., pp. 313-332). San Francisco, CA: Jossey-Bass Publishers.

Kuk, L., Banning, J. H., \& Amey, M. J. (2010). Positioning student affairs for sustainable change. Sterling, VA: Stylus Publications Inc.

Leslie, L. L., \& Ramey, G. (1988). Donor behavior and voluntary support of higher education institutions. Journal of Higher Education, 59(2), 115-132.

Levy, J. D. (2004). The growth of fundraising: Framing the impact of research and literature on education and training. New Directions for Philanthropic Fundraising, 43, 21-30. San Francisco, CA: Jossey-Bass Publishers.

Lincoln, Y. S., \& Guba, E. G. (1985). Naturalistic inquiry. Beverly Hills, CA: Sage Publications, Inc.

Lincoln, Y. S., \& Guba, E. G. (1994). Competing paradigms in qualitative research. In N. K. Denzin \& Y. S. Lincoln (Eds.), Handbook of qualitative research (pp. 105117). Thousand Oaks, CA: Sage Publications.

Lincoln, Y. S., \& Guba, E. G. (2004). The roots of fourth generation evaluation. In M. Alkin (Ed.), Evaluation roots: Tracing theorists' views and influences. Thousand Oaks, CA: Sage Publications.

Lynn, A. N. (2008). Effect of academic content on first-year seminars on student engagement in the institutional social system. (Doctoral dissertation). Retrieved from ProQuest Digital Dissertations and Theses database. (UMI No. 3353092).

Matasar, R. A. (1998). Private publics, public privates: An essay on convergence in higher education. University of Florida Journal of Law and Public Policy, 10(1), 5-26.

Maykut, P. S., \& Moorehouse, R. (1994). Beginning qualitative research: A philosophical and practical guide. Washington, DC: Falmer Press.

McEwen, M. E. (2003). The nature and uses of theory. In S. R. Komives \& D. B. Woodard, Jr. (Eds.), Student services: A handbook for the profession $\left(4^{\text {th }}\right.$ ed., pp. 153-178). San Francisco, CA: Jossey-Bass Publishers.

Merriam, S. B. (2002). Qualitative research in practice: Examples for discussion and analysis. San Francisco, CA: Jossey-Bass Publishers. 
Merriam, S. B. (2009). Qualitative research: A guide to design and implementation. San Francisco, CA: Jossey-Bass Publishers.

Miller, T. E. (2010). The context for development work in student affairs. New Directions for Student Services, 130, 3-8.

Morgan, M. F., \& Policello, S. M. (2010). Getting started in student affairs development. New Directions for Student Services, 130, 9-18.

Moxley, L. S., \& Duke, B. W. (1986). Setting priorities for student affairs programs for budgetary purposes: A case study. NASPA Journal, 23(4), 21-28.

National Association of Student Personnel Administrators. (1987). A perspective on student affairs. Washington, DC: author.

National Association of Student Personnel Administrators \& American College Personnel Association. (1997). Principles of good practice for student affairs. Washington, DC: author.

National Center for Education Statistics. (2011). The condition of education 2011. Washington, DC: Author.

Nuss, E. M. (1996). The development of student affairs. In S. R. Komives \& D. B. Woodard (Eds.), Student services: A handbook for the profession ( $3^{\text {rd }}$ ed.). San Francisco, CA: Jossey-Bass Publishers.

Pascarella, E. T., \& Terenzini, P. T. (1991). How college affects students: Findings and insights from 20 years of research. San Francisco, CA: Jossey-Bass Publishers.

Pascarella, E.T., \& Terenzini, P.T. (2005). How college affects students: A third decade of research (Vol. 2). San Francisco, CA: Jossey-Bass Publishers.

Patouillet, L. D. (2000). Alumni association members: attitudes toward university life and giving at a public AAU institution. (Doctoral dissertation). Retrieved from ProQuest Digital Dissertations and Theses database. (UMI No. 9974464)

Patton, S. L. (1993). The roles of key individuals. In M. J. Worth (Ed.), Educational fundraising: Principles and practice (pp. 3-9). Phoenix, AZ: Oryx.

Patton, M. Q. (1990). Qualitative evaluation and research methods ( $2^{\text {nd }}$ ed.). Newbury, CA: Sage Publications.

Patton, M. Q. (2002). Qualitative evaluation and research methods ( $3^{\text {rd }}$ ed.). Newbury, CA: Sage Publications. 
Penney, S. W., \& Rose, B. B. (2001). Dollars for dreams: Student affairs staff as fundraisers. Washington, DC: National Association of Student Personnel Administrators.

Pike, G. R., \& Kuh, G. D. (2005). A typology of student engagement for American colleges and universities. Research in Higher Education, 46(2), 185-209.

Pumerantz, R. K. (2004). Alumni-in-training: Institutional factors associated with greater alumni giving at public comprehensive colleges and universities. (Doctoral dissertation). Retrieved from ProQuest Digital Dissertations and Theses database. (UMI No. 3133230)

Richards, L., \& Morse, J. M. (2007). Read me first for a user's guide to qualitative methods ( $2^{\text {nd }}$ ed.). Thousand Oaks, CA: Sage Publications.

Rissmeyer, P. A. (2010). Student affairs and alumni relations. New Directions for Student Services, 130, 19-30.

Romano, C. R., Hanish, J., Phillips, C., \& Waggoner, M. D. (2010). The new normal: Senior student affairs officers speak out about budget cutting. New Directions for Student Services, 129, 5-16.

Rovig, N. G. (2008). An examination of the relationship between development support characteristics and the amount of funds raised for student affairs divisions. (Doctoral dissertation). Retrieved from ProQuest Digital Dissertations and Theses database. (UMI No. 3351867)

Rudolph, F. (1962). The American college and university. A history. New York, NY: Vintage Books.

Schoenecke, M. (2005). A description of successful fundraising programs in student affairs divisions. (Doctoral dissertation). Retrieved from ProQuest Digital Dissertations and Theses database. (UMI No. 3174535)

Schuh, J. H. (2003). The financial environment of student affairs. New Directions for Student Services, 103, 3-16.

Schuh, J. H., \& Gansemer-Topf, A. M. (2010). The role of student affairs in student learning assessment (NILOA Occasional Paper No.7). Urbana, IL: University of Illinois and Indiana University, National Institute for Learning Outcomes Assessment.

Schuh, J. H., \& Whitt, E. J. (Eds.). (1999). Creating successful partnerships between academic and student affairs. New Directions for Student Services, 87. San Francisco, CA: Jossey-Bass Publishers. 
Schroeder, C. C. (2003). Using the lessons of research to develop partnerships. In S. R. Komives \& D. B. Woodard, Jr. (Eds.), Student services: A handbook for the profession (4 ${ }^{\text {th }}$ ed., pp. 618-636). San Francisco, CA: Jossey-Bass Publishers.

Sears, J. B. (1990). Philanthropy in the history of American higher education. New Brunswick, NJ: Transaction. (Original work published in 1922).

Shay, J. E. (1993). The president's perspective on student affairs and educational fundraising. New Directions for Student Services, 63, 17-28.

Shenton, A. K. (2004). Strategies for ensuring trustworthiness in qualitative research projects. Education for Information, 22(2), 63-75.

Sonn, A. C. (2010). Institutions' needs and donors' dreams: A case study of successful student affairs fundraising collaboration at three private research universities. (Doctoral dissertation). Retrieved from ProQuest Digital Dissertations and Theses database. (UMI No. 3387315)

Speck, B. W. (2010). The growing role of private giving in financing the modern university. New Directions for Student Services, 149, 7-25.

Strange, C. C., \& Banning, J. H. (2000). Educating by design: Creating campus learning environments that work. San Francisco, CA: Jossey-Bass Publishers.

Strauss, A. L., \& Corbin, J. M. (1998). Techniques and procedures for developing grounded theory ( $2^{\text {nd }}$ ed.). Thousand Oaks, CA: Sage Publications.

Terenzini, P. T., Pascarella, E. T., \& Blimling, G. S. (1996). Students’ out-of-class experiences and their influence on learning and cognitive development: A literature review. Journal of College Student Development, 37, 149-162.

Terrell, M. C., \& Gold, J. A. (1993). Editor's Notes. New Directions for Student Services, 63, 1-3.

Thelin, J. R. (2004). A history of American higher education. Baltimore, MD: The Johns Hopkins University Press.

Tinto, V. (1987). Leaving college. Chicago, IL: University of Chicago Press.

Tinto, V. (1988). Stages of student departure: Reflection on the longitudinal character of students leaving. Journal of Higher Education, 59(4), 438-455.

Tinto, V. (1993). Leaving college: Rethinking the causes and cures of student attrition. Chicago, IL: University of Chicago Press.

Tjosvold, D. (1986). Working together to get things done. Lexington, MA: Lexington Books. 
U. S. Department of Education Institute of Education Sciences. (2010). What are the trends in the cost of college education? Retrieved from

http://nces.ed.gov/fastfacts/display.asp?id=76

Vogt, P. W. (2006). Quantitative research methods for professionals. Upper Saddle River, NJ: Pearson Publishing.

Walton, A., \& Gasman, M. (Eds.). (2008). Philanthropy, volunteerism, \& fundraising in higher education. Boston, MA: Pearson Custom Publishing.

Weber, M. (1947). The theory of social and economic organizations. Glencoe, IL: Free Press. (Original work published in 1924).

Whitt, E. J. (Ed.). (1999). Student learning and student affairs work: Responding to our imperative. Washington, DC: National Association of Student Personnel Administrators.

Wolff, S. (2004). Analysis of documents and records. In U. Flick, E. von Kardorff, \& I. Steinke (Eds.), A companion to qualitative research (pp. 284-289). Thousand Oaks, CA: Sage Publications.

Woodward, D. B., Love, P. G., \& Komives, S. R. (2000a). Resources: Money matters. New Directions for Student Services, 92, 71-80.

Woodward, D. B., Love, P., \& Komives, S. R. (2000b). Leadership and management issues for a new century. New Directions for Student Services, 92, 81-91.

Worth, M. J. (1993). Defining institutional advancement, development, and fund raising. In M. J. Worth (Ed.), Educational fundraising: Principles and practice (pp. 3-9). Phoenix, AZ: Oryx. 


\section{APPENDIX A}

\section{INTRODUCTORY E-MAIL FROM COLLEAGUE}

Dear

I am writing this letter to introduce a colleague of mine at Illinois State University and to ask you to help her in a research project. The research will assist her in completing her Doctorate in Educational Administration and Foundations and will add immeasurably to the literature in the field of student affairs and advancement.

First, please allow me to introduce Danielle Miller-Schuster to you. Danielle and I have worked together for two years. She serves as the Assistant to the Vice-President for Student Affairs for Planning and Development. In that role, she leads our strategic planning and assessment initiatives and has had responsibility for framing our friend-raising and fund-raising program. We have just hired a new Director of Development for Student Affairs and she will assist him greatly in his work. Prior to coming to the Vice-President's Office, she worked in the Dean of Students Office here as well. She is the consummate professional and a joy to have on staff. Her intellect, knowledge of the field of student affairs and advancement, and her contagious personality contribute to her success at the University. She is respected among her peers and has won a number of campus-wide awards. She has also been stellar in the classroom having just passed her prelims.

Second, I am asking for you to help her with her research. I know we receive these requests frequently and oftentimes are asked to complete a survey which may remind us of our own research. This is a similar request but frankly will take a bit more time since she is doing a qualitative study involving a personal 60 to 90 minute interview. She would be traveling to your University and meeting with the Senior Student Affairs Administrator and the Senior Advancement Administrator. Her work will inform both professions about fund-raising for Student Affairs projects, programs, and other initiatives. You and your colleague are two of only 18 colleagues selected for this study which represents Student Affairs and Advancement at 9 institutions of similar size and complexity. If you are interested in receiving the results of her research, I am sure she would be happy to provide it to you in summary form when her work is complete.

Thanks in advance for considering this request. Please know that I would be happy to help you and any of your staff with similar requests. Danielle will follow up on this correspondence shortly. Thanks again.

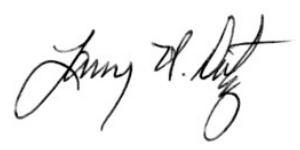

Larry H. Dietz, Ph.D.

Vice President for Student Affairs

Illinois State University 


\section{APPENDIX B}

\section{RECRUITMENT E-MAIL}

\section{Dear}

I am a doctoral graduate student under the direction of Dr. Wendy Troxel in the College of Education at Illinois State University. I am conducting a research study to examine the role of student affairs in fundraising at selected four-year public institutions in the Midwest. The study seeks to learn more about your perceptions regarding the role of student affairs in development efforts, the extent to which the division of student affairs is involved in fundraising activities at the university, how participation has evolved and impacted traditional responsibilities and/or organizational structures, and finally, implications on the future of fundraising for student affairs.

I am writing to formally ask for your participation, which will involve two stages of data collection. The first stage comprises document collection, which will include artifacts publicly available (website, publications, organizational charts, etc.) and any relevant departmental documents you feel comfortable sharing (position descriptions, committee membership lists, written policies or procedures, professional development programs, etc.). The second stage of data collection will be an individual interview with you and the University's senior advancement officer [or senior student affairs officer]. The audio-taped interview will take place in a location convenient to you. I expect the interview to last approximately 90 minutes. The questions will relate to your thoughts and experiences about your role as a Senior Student Affairs Officer [or Senior Advancement Officer] at a 4-year public college or university.

Your participation is voluntary. If you would like to be a part of this dissertation study, please respond to this e-mail. I will call you within 1-2 days to set up a convenient time for the interview.

Thank you very much for your time and potential interest in this study. I appreciate you considering this request. Your opinions will be invaluable to the success of this research study.

Sincerely,

\section{Danielle Miller-Schuster}

\section{Danielle Miller-Schuster}




\section{APPENDIX C}

\section{INFORMED CONSENT}

Dear

I am a doctoral graduate student under the direction of Dr. Wendy Troxel in the College of Education at Illinois State University. I am conducting a research study to examine the role of student affairs in fundraising at selected four-year public institutions in the Midwest. The study seeks to learn more about your perceptions regarding the role of student affairs in development efforts, the extent to which the division of student affairs is involved in fundraising activities at the university, how participation has evolved and impacted traditional responsibilities and/or organizational structures, and finally, implications on the future of fundraising for student affairs. I am requesting your participation, which will involve providing documents and artifacts you feel comfortable sharing and participating in a 90 minute interview with me at a time and place convenient to you. The interview will be audiotaped and notes will be taken with your permission.

Your participation in this study is voluntary. If you choose not to participate or to withdraw from the study at any time, there will no ramifications of any kind. The results of the research study may be published, but your name and institution will not be used. I will take all precautions to maintain your confidentiality. Pseudonyms will be used during the interview, in field notes, and in the actual research document. You may choose to not answer any questions asked of you.

Although small, the possible benefit of your participation would be to reflect upon your own experiences and to assist in identifying ways to improve fundraising in student affairs and its relationship with university advancement.

If you have questions concerning the research study, please call me at ( $\square$ ( Wendy Troxel at (309) 438-7668.

Sincerely,

Danielle Miller-Schuster

Danielle Miller-Schuster

I give consent to participate in the above study.

Signature

I give consent for my interview to be audiotaped.

\section{Date}

\section{Date}

If you have any questions about your rights as a subject/participant in this research, or if you feel you have been placed at risk, you can contact the Research Ethics \& Compliance Office at Illinois State University at (309) 438-2529. 


\section{APPENDIX D}

\section{INTERVIEW QUESTIONS}

The purpose of this study is to examine the role of fundraising in divisions of student affairs at selected 4-year public institutions in the Midwest. The study will be guided by four questions:

(1) What role, if any, do senior advancement officers and senior student affairs officers believe divisions of student affairs can/should play in fundraising?

(2) To what extent is the division of student affairs (senior student affairs officer and division staff) involved in fundraising activities at the institution? How has participation in development efforts evolved?

(3) How do senior student affairs and advancement officers describe the impact of student affairs fundraising on traditional responsibilities and/or organizational structures?

(4) What are the implications on the future of fundraising for student affairs?

\section{Introductory questions to learn about the senior officer and structure of the university and division:}

1. What is your current position title?

2. How long have you held your position?

3. How long have you been at the institution? If longer than the position currently held, ask what previous positions he or she held.

4. How would you describe the organizational structure of the university?

a. Who do you directly report to?

5. How would you describe the organizational structure of the division?

a. What departments report through your division?

6. How would you describe the role of your division at the institution?

7. Briefly describe your role and responsibilities as the senior officer in your division?

a. Who specifically reports to you as a senior officer in your division? 


\section{Specific questions about the role of the Senior Student Affairs Officer in development efforts:}

8. How would you describe your role in the development efforts of the university and your division?

9. Do you personally set the vision and priorities for fundraising efforts in your division?

a. Are others involved? If yes, who is involved and why?

10. Do you hire or supervise staff members with responsibility for fundraising?

11. What role do you play in the cultivation and stewardship of donors?

a. How are you involved in thanking donors?

b. Do your responsibilities include meeting with prospective donors?

c. In what ways do you participate in division or university events to cultivate or steward donors?

12. What role do you play in the solicitation of gifts (do you manage a portfolio)?

13. Is the role you play part of your position responsibilities?

a. If yes, when was that added to the responsibilities of this position?

b. If no, how did these responsibilities become part of your role? At whose request?

14. How comfortable are you with your level of involvement in fundraising activities?

15. Have you received any formal development/fundraising training?

a. Do you feel equipped to perform your fundraising duties? Why do you feel the way you do?

\section{Specific questions about the role of the division of student affairs in development efforts:}

16. What role do you believe divisions of student affairs should play in fundraising? What specifically has caused you to believe that?

17. How would you describe the division of student affairs role in the development efforts of your institution?

a. How has your/their involvement evolved over time?

b. What specifically caused an increase or decrease in efforts/participation?

18. Is there a director of development assigned to fundraise for student affairs?

a. To whom does the director report?

b. When was the position created?

c. What created the need to hire a fundraiser specifically for student affairs fundraising?

d. How is the position funded?

19. How would you describe the role and responsibilities of the Director of Development? 
20. What is your role with the Director of Development?

21. In what ways does the division strengthen the development efforts of the university?

a. Based on the nature of the role of student affairs at your institution, are there ways in which student affairs can (or does) uniquely contribute to these efforts?

b. How are divisional fundraising priorities identified and articulated?

c. How are those priorities perceived in the overall fundraising priorities for the institution?

d. In your opinion, how comfortable are student affairs staff members in participating in fundraising efforts?

e. Do you offer professional development in the area of development/fundraising? If yes, who is expected to participate? If no, do you plan to offer professional development in this area in the future? Why or why not?

22. What has the division done to create a culture of philanthropy among staff in the division of student affairs?

23. What impact has fundraising had on traditional responsibilities and/or organizational structures on your division?

\section{Specific questions about the relationship between student affairs and advancement:}

24. How would you characterize your relationship with the senior advancement/student affairs officer?

25. Describe your division's relationship with institutional advancement/student affairs?

a. In what ways do departments collaborate?

b. What factors prompted the increase or decrease of collaboration between divisions?

26. Describe the communication strategies used between the two divisions (formally and informally)?

27. What characteristics do you feel make for an ideal relationship between student affairs and advancement?

28. Do you believe that institutional advancement understands the role of student affairs on campus?

a. Do you believe staff in institutional advancement understand how student affairs can contribute to the goals of the division? 


\section{Additional Questions:}

29. How do you measure success in fundraising?

30. What do you believe are the most significant challenges for fundraising in student affairs?

31. What suggestions or advice would you offer to another senior officer in the beginning stages of creating a culture of philanthropy in the division of student affairs?

32. What would you say is the greatest need for student affairs to be successful in fundraising?

33. In your opinion, what is the future of student affairs fundraising?

34. What are the implications on the future of fundraising for divisions of student affairs?

35. Is there anything you would like to share about your experiences that we did not cover? 